\title{
Tender Evaluation for the Telecommunication Industry using the Analytic Network Process
}

\author{
Ali Kalanaki \\ West Virginia University
}

Follow this and additional works at: https://researchrepository.wvu.edu/etd

\section{Recommended Citation}

Kalanaki, Ali, "Tender Evaluation for the Telecommunication Industry using the Analytic Network Process" (2013). Graduate Theses, Dissertations, and Problem Reports. 284.

https://researchrepository.wvu.edu/etd/284

This Thesis is protected by copyright and/or related rights. It has been brought to you by the The Research Repository @ WVU with permission from the rights-holder(s). You are free to use this Thesis in any way that is permitted by the copyright and related rights legislation that applies to your use. For other uses you must obtain permission from the rights-holder(s) directly, unless additional rights are indicated by a Creative Commons license in the record and/ or on the work itself. This Thesis has been accepted for inclusion in WVU Graduate Theses, Dissertations, and Problem Reports collection by an authorized administrator of The Research Repository @ WVU. For more information, please contact researchrepository@mail.wvu.edu. 


\title{
Tender Evaluation for the Telecommunication Industry using the Analytic Network Process
}

\author{
Ali Kalanaki \\ Thesis submitted to the \\ College of Engineering and Mineral Resources \\ at West Virginia University \\ in partial fulfillment of the requirements \\ for the degree of \\ Master of Science \\ in \\ Industrial Engineering
}

Robert C. Creese, Ph.D., Chair

Rashpal S. Ahluwalia, Ph.D.

Feng Yang, Ph.D.

Department of Industrial and Management Systems Engineering

Morgantown, West Virginia

August, 8, 2013

Keywords: ANP, BOCR, Delphi, Tender, Telecommunication 


\title{
Abstract \\ Tender Evaluation for the Telecommunication Industry using the Analytic Network Process
}

\begin{abstract}
Ali Kalanaki
In the past few decades, tender evaluation has consistently dominated most of organizations' top strategic priorities. Additionally, the field of tender evaluation has generated a vast amount of research efforts, wherein most of these efforts center on methods enabling consideration of all affecting criteria together to make an appropriate decision. Despite the great deal of advances in the methods of tender evaluation based on technical view, there still lacks comprehensive and organizational-driven decision making tools to support organizations during the crucial task of choosing a suitable tender that best meets their business and technical needs.

Tender evaluation has a strategic role in the success of large enterprises in the telecommunication market. It is a complex, multi-person, multi-criteria process. The criteria used to evaluate a tender contain quantitative which are easy to measure and qualitative attributes which most available methods fail to deal with them. In this study, a model is developed using Analytic Network Process (ANP) in a Benefit, Opportunity, Cost, and Risk (BOCR).

The essence of this approach is decomposition of a complex problem into a hierarchy with objective at the top of the hierarchy, criteria and sub-criteria at levels and sub-levels of the hierarchy, respectively, and decision alternatives at the bottom of the hierarchy. Factors at given hierarchy level are compared in pairs to assess their relative preference with respect to each of the factors at the next upper level. These can support complex problems that would be otherwise difficult to handle. This method is capable of handling discrete criteria of both quantitative and qualitative in nature and provides complete ordering of the alternatives.
\end{abstract}


The primary feature of this methodology is its ability to simultaneously consider all types of criteria for tender evaluation in telecommunication companies. The criteria defined for the model using Delphi method from experts in the field and are general to all telecommunication tenders. The developed model is used in an empirical study on an ongoing tender in a mobile telecom service provider company to analyze the tenderers' data and evaluate and rank them. The result of this model is compared to the company's evaluation result which is obtained from traditional Texas Instruments Matrix method. The proposed model shows the ranking of the tenderers in different BOCR merits separately as local priorities to help the evaluators make a more efficient decision. A sensitivity analysis on the empirical study was conducted to show how the rankings of the tenderers are changing by changing the weights of the BOCR merits.

The research work presented here may be used by telecommunication professionals and managers to aid in making appropriate decisions on tender evaluation process and determinate strategies for reducing the risk of this process. 


\section{Acknowledgements}

It would not have been possible to write this thesis without the help and support of the kind people around me, to only some of whom it is possible to give particular mention here.

Above all, I would like to thank my wife, Mahboubeh Meimani, who provided me with love, personal support, inspiration and motivation needed to finish my studies and great patience at all times. I would like to thank my daughter, Kentia, for her great love and support. They both have given me their unequivocal support throughout, as always, for which my mere expression of thanks likewise does not suffice. I would like to thank my parents for their love, encouragement and support.

I am most grateful to Dr. Robert C. Creese, my advisor, for his outstanding guidance, patience, encouragement and advice throughout the formulation and writing of this thesis. I also want to thank my committee members, Dr. Rashpal S. Ahluwalia and Dr. Feng Yang for their kind help.

I would like to express my deepest appreciation to Dr. Thomas L. Saaty for his time, support, constructive comments and warm encouragement. I would like to thank Dr. Majid Jaridi for his precious advice and support during my studies.

Also, I like to thank the participants in my surveys, who have willingly shared their precious time during the process of my studies. 


\section{Contents}

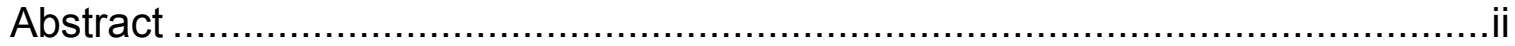

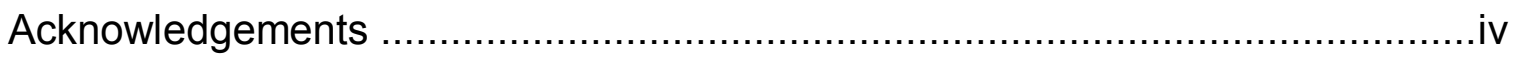

List of Tables .................................................................................................. vii

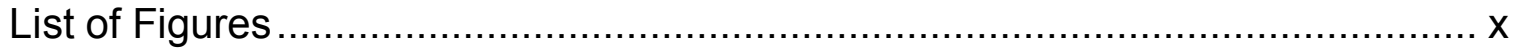

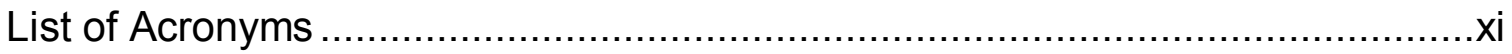

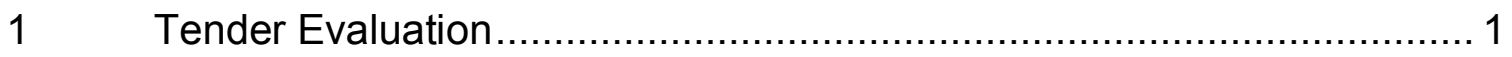

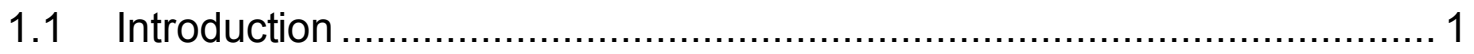

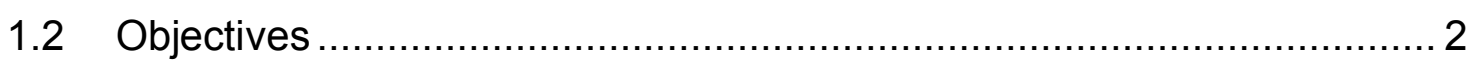

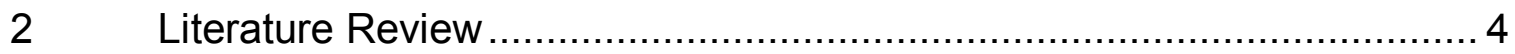

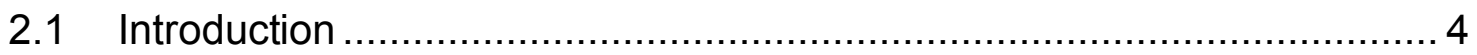

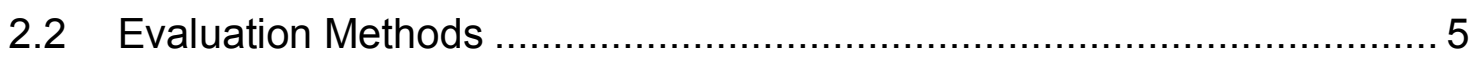

2.2.1 Categorical Method .............................................................. 5

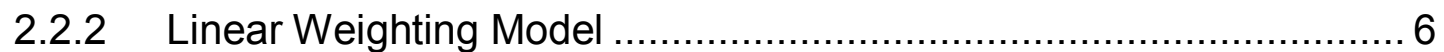

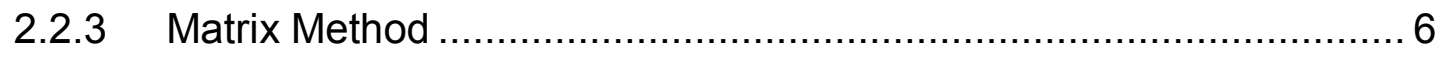

2.2.4 Mathematical Programing Methods ............................................... 7

2.2.5 Analytic Hierarchy Process (AHP) ……….............................. 8

2.2.6 Analytic Network Process (ANP) .............................................. 10

$3 \quad$ BOCR Model and ANP Applications …............................................ 13

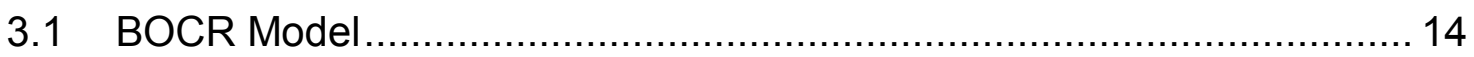

3.2 ANP in Supplier Selection and Tender Evaluation ............................. 15

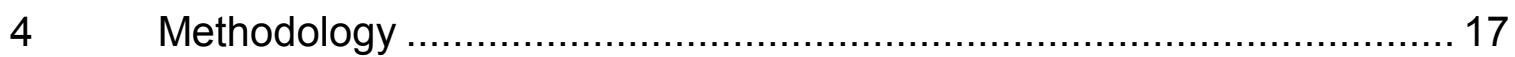

4.1 To state the decision problem clearly ............................................. 17

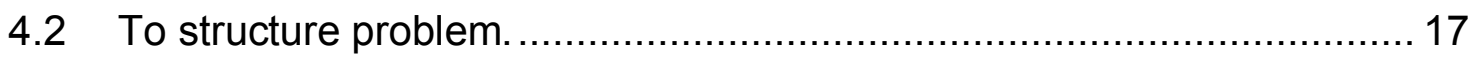

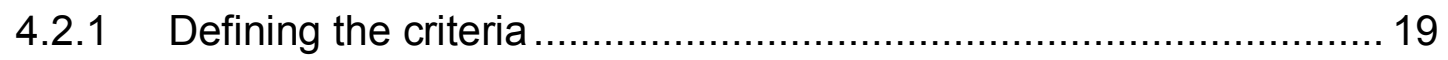

4.2.2 Criteria Classification for BOCR model ...................................... 24

4.3 Pairwise Comparisons (Designing questionnaires) …........................ 33

4.3.1 Pairwise comparison for quantitative data .................................. 35 


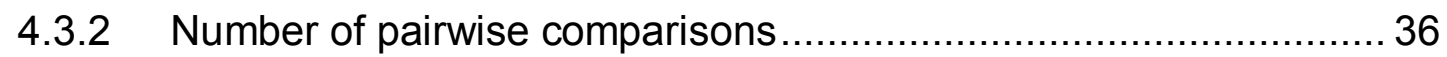

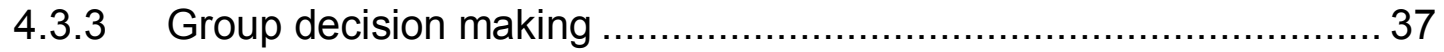

4.4 To calculate the eigenvector of each of the developed matrices. .......... 38

4.5 To measure the consistency ratio (CR) ........................................... 38

4.6 To form the super-matrix using the eigenvector of all comparison

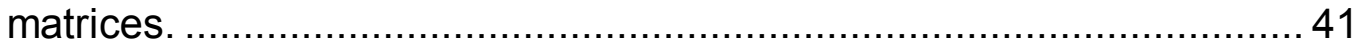

4.7 To compute the final limit super-matrix........................................ 42

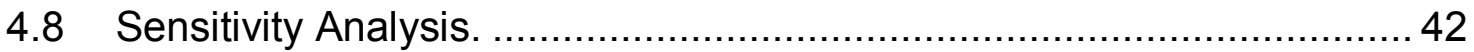

4.9 Comparing with results drawn by the company ................................ 42

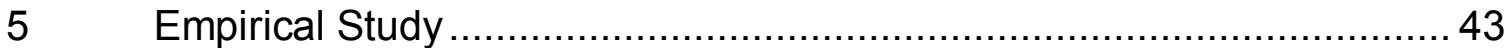

5.1 To state the decision problem clearly ................................................. 44

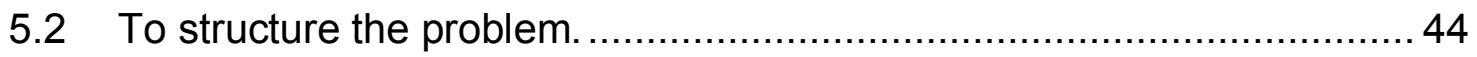

5.3 Pairwise Comparisons. ............................................................. 44

5.4 Calculating Eigenvectors …...................................................... 45

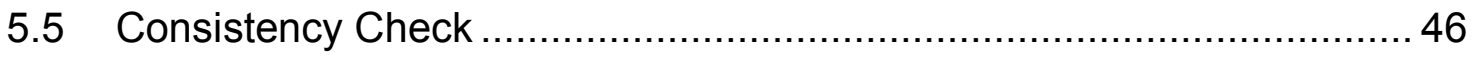

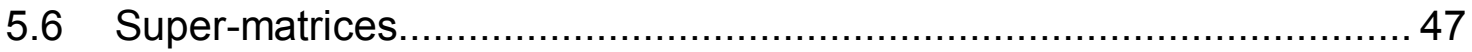

5.7 Calculating Limit Super-matrices and find the final results................... 48

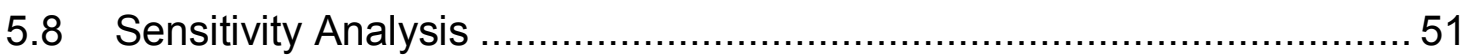

5.9 Comparing the ANP results with TI Matrix Method ............................. 54

$6 \quad$ Conclusion and Recommendations for Future Research..................... 57

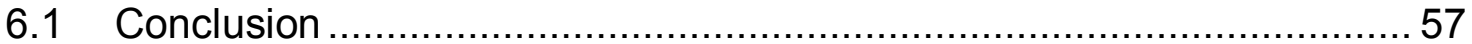

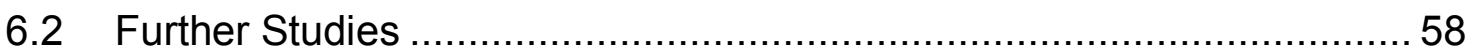

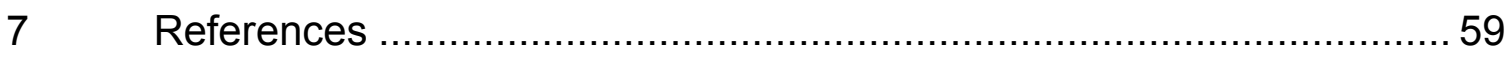

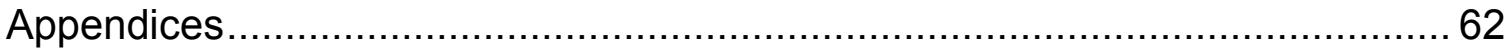

Appendix 1: The questionnaires and results of the Delphi main criteria

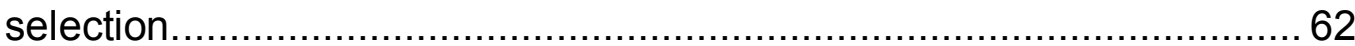

Appendix 2: The questionnaires and results of the Delphi sub-criteria selection. 67 
Appendix 3: The questionnaires and results of the Delphi criteria classification

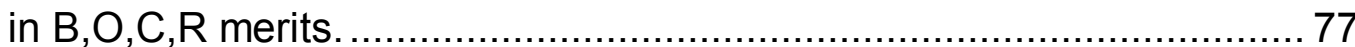

Appendix 4: Examples of pairwise comparisons, converting to matrices and

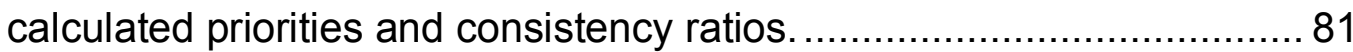

Appendix 5: Eigenvectors calculation in MATLAB examples. ........................ 83

Appendix 6: Inconsistent comparison and the revision of it............................ 85 


\section{List of Tables}

Table 2.1: Categorical Method Example, Tsai (1999)_................................... 5

Table 2.2: Example of Linear Weighting Model for 2 tenderers and 3 Criteria...... 6

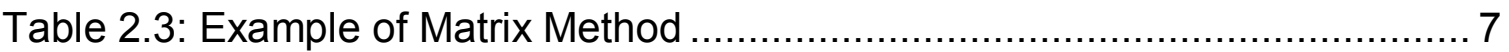

Table 2.4: Pair-Wise Comparison Scale for AHP (Saaty and Vargas (2012)) ...... 9

Table 4.1: Assigning Each Criterion to a Merit................................................ 26

Table 4.2: Benefits Criteria Categorized in 5 Clusters ..................................... 29

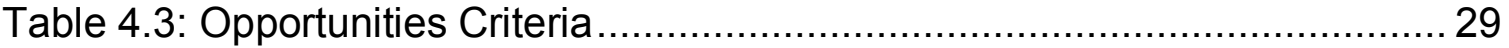

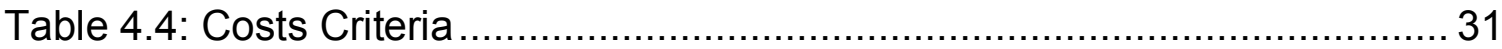

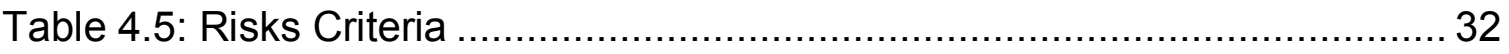

Table 4.6: Pairwise Comparison Questionnaire Sample ................................ 34

Table 4.7: The Pairwise Comparison Matrix Example for ANP.......................... 34

Table 4.8: Clustering guideline example for a pairwise comparison with regards

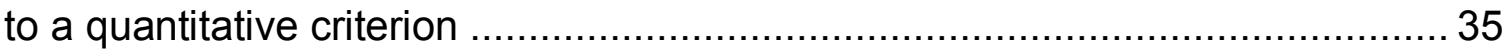

Table 4.9: Eigenvector of Merits Matrix that Shows Their Priorities................... 38

Table 4.10: Average Random Index Based on the Matrix Order (Saaty (1980)) 39

Table 5.1: Pair-wise Comparison of Alternatives with respect to "Evidence of

Previous Experience" in Risks Sub-network .................................................... 45

Table 5.2: Comparison Matrix for Alternatives with respect to "Evidence of

Previous Experience" in Risks Sub-network ................................................. 45

Table 5.3: Local Priority of the Alternatives with Respect to "Evidence of Previous

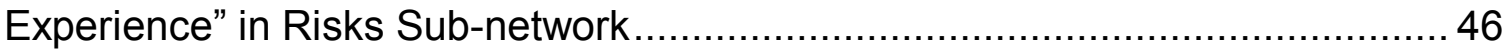

Table 5.4: Un-weighted Super-matrix for Risks sub-network ........................... 47

Table 5.5: Weighted Super-Matrix for Risks sub-network ................................. 47

Table 5.6: Limit Super-matrix for Risks Sub-network ..................................... 48

Table 5.7: Priorities of Alternatives in Risks Sub-Network ................................ 49

Table 5.8: Priorities of Alternatives in Benefits Sub-Network............................ 49

Table 5.9: Priorities of Alternatives in Opportunities Sub-Network .................... 49

Table 5.10: Priorities of Alternatives in Costs Sub-Network ............................. 49

Table 5.11: Priorities of the Alternatives using Multiplicative Formula ................ 50 
Table 5.12: Priorities of the Alternatives using Additive Formula...

Table 5.13: Normal Priorities for Alternatives and Final Rankings in Two Methods 51

Table 5.14: Evaluation Results Obtained from TI Matrix Method by the Company .

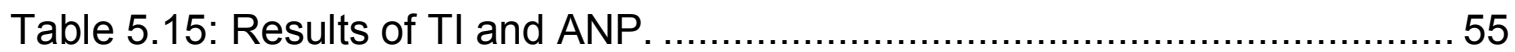




\section{List of Figures}

Figure 2.1: A General AHP Model Diagram (Saaty (1996)) …........................ 8

Figure 2.2: A General ANP Model Diagram (Saaty (2004b)) …....................... 10

Figure 4.1: A General BOCR ANP Model Diagram ....................................... 25

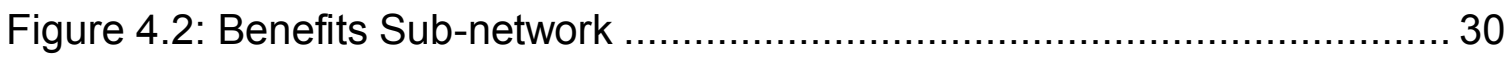

Figure 4.3: Opportunities Sub-network ..................................................... 31

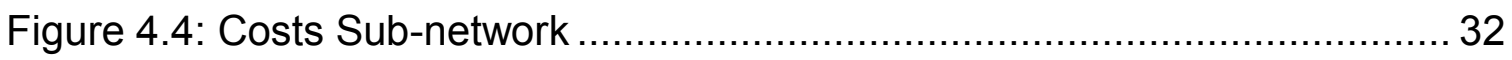

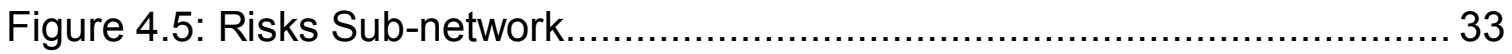

Figure 5.1: Sensitivity Analysis With Regards to Benefits.............................. 52

Figure 5.2: Sensitivity Analysis With Regards to Opportunities ........................ 52

Figure 5.3: Sensitivity Analysis With Regards to Costs .................................. 53

Figure 5.4: Sensitivity Analysis With Regards to Risks................................... 53

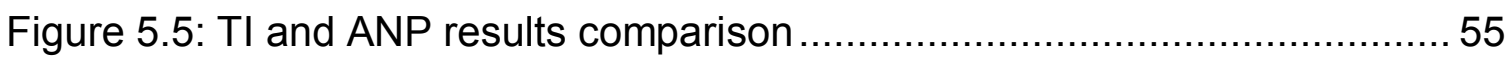




\section{List of Acronyms}

AHP: Analytic Hierarchy Process

ANP: Analytic Network Process

BOCR: Benefit, Opportunity, Cost, Risk

BSC: Balanced Score Card

CAPEX: Capital Expenditure

CDR: Call Details Record

$\mathrm{Cl}$ : Consistency Index

CR: Consistency Ratio

GSM: Global System for Mobile Communications

HSTR: High Strength Temperature Resistant

IS: Information System

MCDM: Multi-Criteria Decision Making

NTM: Non-Traditional Machining

OPEX: Operation Expenditure

RFT: Request for Tender

$\mathrm{RI}$ : Average Random Index

SWOT: Strengths, Weaknesses, Opportunities and Threats

TI: Texas Instruments

TPS: Transaction Processing System

TQM: Total Quality Management

VFM: Value for Money

VMS: Voice Messaging Service 


\section{Tender Evaluation}

\subsection{Introduction}

Large enterprises use contractors for their complex projects or procurements. Telecommunication companies use contractors for the implementation, network expansion and maintenance as well. The technology used in telecom industries is high technology and the process of selecting a contractor or supplier is extremely complicated with several different criteria and several people involved in the making of the final decision.

To identify potential contractors, companies usually conduct a tender while public sector organizations are legally obliged to select contractors through a tender process. A tender is a written offer to contract goods or services at a specified cost or rate commonly referred to as a bid. The mid-size and large businesses that outsource a service usually conduct a tender and advertise it to the public to identify potential interested contractors that claim to be able to do the project. The company needs to carefully prepare the request for tender (RFT) that outlines the company's needs. It outlines the specific requirements, criteria and instructions that are to be followed. Suppliers or contractors that are interested in signing the contract with the company will then prepare a tender and submit all the requested documents, certifications, plans, prices and schedules within a finite deadline.

The company will evaluate tenderers with regards to the defined criteria. The process of the evaluation, based on the complexity, importance and the amount of the tender, can be a simple or very complex process which can take several months to make the decision. The goal of the company is to select the tenderer that meets their needs and provides the best value for money (VFM). It simply means to select the tenderer that provides the maximum profit in short and long terms for the company.

The evaluation process consists of several quantitative and qualitative factors. Evaluation based on quantitative factors has been done traditionally. 
However, when it comes to qualitative factors, the evaluation should consider all qualitative and quantitative factors simultaneously and these qualitative criteria must be translated to quantitative factors.

Analytic Network Process (ANP) is a MCDM (Multi-Criteria Decision Making) method introduced by Dr. Thomas L. Saaty on 1996 which can be deployed in very complex models to deal with both qualitative and quantitative criteria and makes comparisons and ranks the alternatives. In this research, an Analytic Network Process BOCR (Benefit, Opportunity, Cost and Risk) model was developed for the telecom industry to evaluate tenderers and make the best decision with contractor selection. Both types of criteria, quantitative and qualitative were considered in the model. The model was tested with the data obtained from an ongoing tender for a telecom company and results were compared to the results of the telecom company which were obtained by the Texas Instruments matrix method. A sensitivity analysis was performed to check how stable are the results subject to changes in inputs.

\subsection{Objectives}

The objectives of this research are listed below:

- Evaluation of tenders specifically for a company in the telecommunication industry.

- Apply the ANP method to an ongoing complex tender to validate the model.

- Rank tenderers based on the collected data in the model.

- Compare model results with actual selection by company.

- Do the sensitivity analysis on the selected method and developed model. The planned procedure to be followed to achieve the objectives is:

- Perform a literature review of the various evaluation methods.

- Applying the selected method (ANP in this study) in a BOCR (Benefit, Opportunity, Cost, Risk) model. 
- Collecting data from an ongoing tender/bid in a mobile telecommunication company in the Middle-East.

- Validating the collected data and make necessary revisions.

- Making the appropriate model using ANP.

- Perform the calculations for the designed model.

- Compare the model rankings and company rankings and discuss the possible causes of the differences.

- Perform the sensitivity analysis of the results by changing the weight of each of Benefits, Opportunities, Costs and Risks to evaluate how they affect the rankings of the tenderers. 


\section{Literature Review}

\subsection{Introduction}

Tender evaluation is widely considered to be one of the most important responsibilities of large enterprises' business management. It can directly affect the price, quality and reliability of the products or services of the company which has huge impact on customer satisfaction and in result, company's profitability. Many businesses do not use scientific methods to evaluate their proposed contractors while the traditional methods may not be appropriate in evaluating competitive tenders that involve many criteria.

Evaluating tenders using scientific methods affects the quality and implementation of engineering projects. The existing methods which are mostly subjective, fail to compare qualitative criteria as well as quantitative criteria (Luo, Tang, and Zhao (2005)). Choosing criteria should be wisely done by enterprises for each tender separately as most of them are not common in different tenders.

Several methods have been introduced and developed in the literature to deal with tender evaluation problems, ranging from traditional methods to scientific and analytic methods. Some of them have been used with particular use in telecom industry.

de Boer, Labro, and Morlacchi (2001) categorized the supplier evaluation methods in the literature to these categories: Linear weighting methods, Total Cost of Ownership, Mathematical Programing and Statistical Methods. Evaluation methods were categorized by Thompson (1990) to: Categorical Methods, Weighted Point Methods, and Cost Base Methods including Cost-Ratio Technique. 


\subsection{Evaluation Methods}

The methods considered appropriate for tender evaluation are categorized into the following categories:

- Categorical Method

- Linear Weighting Model

- Matrix Method

- Mathematical Programing Models

- Analytic Hierarchy Process (AHP)

- Analytic Network Process (ANP)

These categories are briefly described:

\subsubsection{Categorical Method}

In this method, all the criteria are listed and then all the tenderers are evaluated for each criterion. If a tenderer is good in that criterion, a "+" sign will be assigned for that tenderer, if it doesn't have requirements, a "-" sign will be assigned and neutral is zero as illustrated in Table 2.1.

Table 2.1: Categorical Method Example, Tsai (1999)

\begin{tabular}{|l|l|l|l|l|}
\hline Tenderer & Cost & Quality & Technical support & Total \\
\hline A & Unsatisfactory (-) & Good (+) & Neutral (0) & $(0)$ \\
\hline B & Good (+) & Good (+) & Neutral (0) & $(++)$ \\
\hline C & Unsatisfactory (-) & Good (+) & Unsatisfactory (-) & $(-)$ \\
\hline
\end{tabular}

Tenderer B is the best in this example. This method is easy to implement, but the disadvantages associated with it are:

- It does not consider the relative importance of the criteria. This makes the model subjective (Hill and Nydick (1992)). 
- It relies on the experience of the evaluators.

- It is more useful in qualitative criteria.

\subsubsection{Linear Weighting Model}

Each evaluation criterion is given a weight based on its importance. The higher weight indicates the higher importance. The given score for each tenderer on each criterion is then multiplied by the criterion's weight. All weighted scores for each tenderer on all criteria are summed to obtain a total overall score for each tenderer. The tenderer with the highest overall score is the winner of the tender (Timmerman (1986) and Zenz (1981)). This method has an advantage comparing to categorical method by giving weight to criteria. However, its main disadvantage is that it is very difficult to employ it where qualitative criteria are involved (Hill and Nydick (1992)). Table 2.2 illustrates an example of linear weighting method. Although the raw score of the tenderer $A$ is higher than tenderer $B$, tenderer $B$ is the winner of the tender based on the weighted score.

Table 2.2: Example of Linear Weighting Model for 2 tenderers and 3 Criteria

\begin{tabular}{|l|l|l|l|l|l|}
\hline \multirow{2}{*}{ Criteria } & \multirow{2}{*}{ Weight } & \multicolumn{3}{|l|}{ Tenderer A } & \multicolumn{2}{l|}{ Tenderer B } \\
\cline { 3 - 6 } & & Raw Score & $\begin{array}{l}\text { Weighted } \\
\text { Score }\end{array}$ & Raw Score & $\begin{array}{l}\text { Weighted } \\
\text { Score }\end{array}$ \\
\hline Price & $20 \%$ & 80 & 16 & 30 & 6 \\
\hline Experience & $35 \%$ & 65 & 22.75 & 90 & 31.5 \\
\hline Customer support & $45 \%$ & 70 & 31.5 & 80 & 36 \\
\hline TOTAL & 100 & 215 & 70.25 & 200 & 73.5 \\
\hline
\end{tabular}

\subsubsection{Matrix Method}

This method was developed by Texas Instruments and is very similar to Linear Weighting Model, but the main criteria are broken down to sub-criteria. The specific sub-criteria can be left blank if it cannot be evaluated for a tenderer. 
The main disadvantage of this method over Linear Weighting Model is that leaving some scores blank creates inconsistency in the result (Gregory (1986)). An example of this method is illustrated in Table 2.3.

Table 2.3: Example of Matrix Method

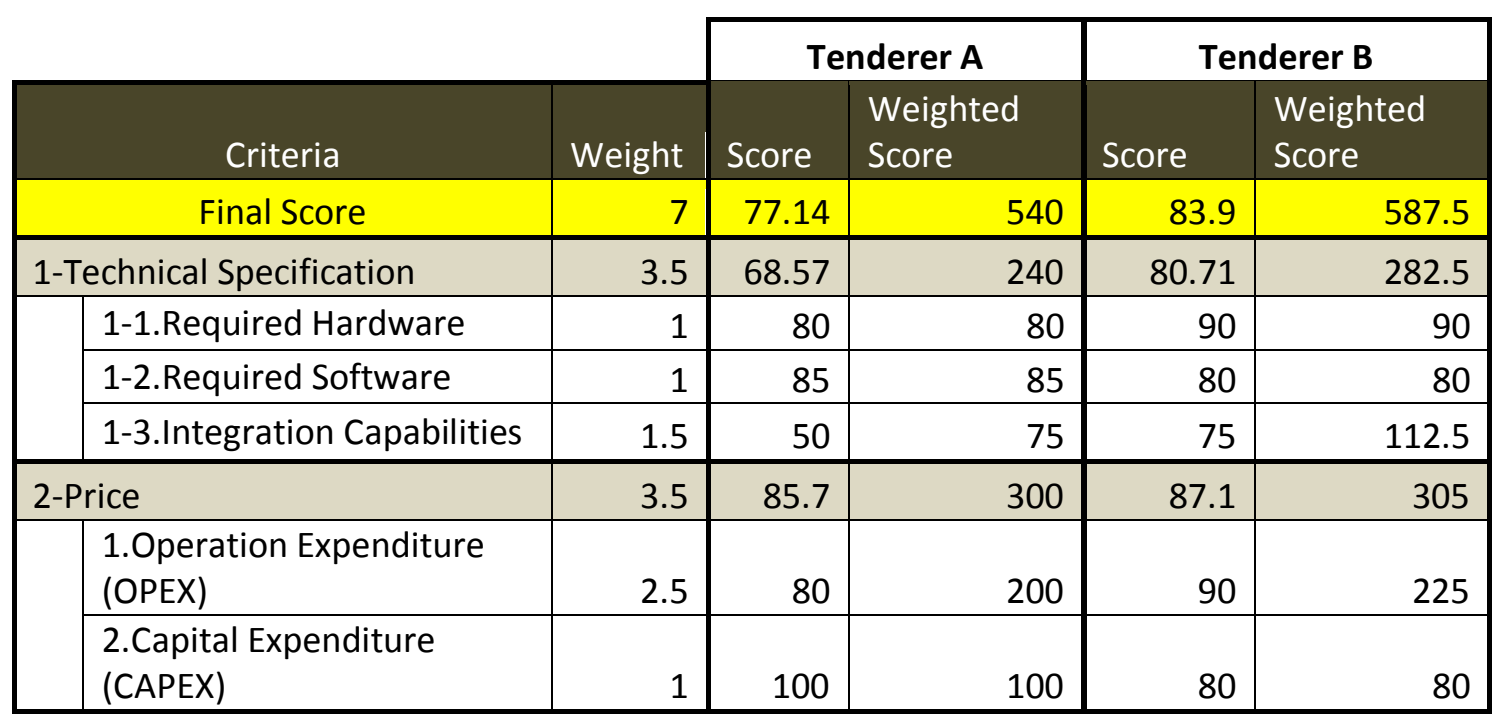

\subsubsection{Mathematical Programing Methods}

The mathematical methods that were used in the literature consisted of Linear Programming, Non-Linear Programming, Mixed Integer Programming, Goal Programming, Multiple-Objective Programming, etc. Moore and Fearon (1973) used Linear Programming method to select the best supplier based on the price. A Goal Programming model was formulated by Buffa and Jackson (1983) to select suppliers based on quality, price and delivery criteria. In a paper review study by Weber and Current (1991), the share of mathematical models employed was $14 \%$ while it was increased to $42 \%$ in a similar study done by Zhang and Lei (2004). The drawback of these models is they are limited to quantitative criteria. 


\subsubsection{Analytic Hierarchy Process (AHP)}

AHP is a method to deal with multiple criteria decision making situations involving intuitive, rational qualitative and quantitative criteria (Bhutta and Huq (2002)). AHP was developed by Thomas L. Saaty in the 1970s and has been extensively used and improved since then. It breaks down a complex decision making problem to a series of pairwise comparisons and synthesizes the results.

AHP helps decision makers to make the best decision and also gives them a rationale that it is the best decision (Saaty $(1980,1990))$. It has been applied to different problems ranging from risk analysis and prediction to supplier selection (Barbarosoglu (1997) and Benyoucef, Ding, and Xie (2003)).

AHP method can be summarized to the following seven steps (Al-Harbi (2001); Hill and Nydick (1992); Saaty (1980, 1990); Vaidya and Kumar (2006)):

1. State the exact problem.

2. Define all objectives, actors and outcomes of the problem.

3. Identify the criteria that influence the outcome.

4. Decompose the problem into a hierarchy in different levels containing: Goal, Criteria, Sub-criteria, and Alternatives.

A typical hierarchy model is shown in Figure 2.1.

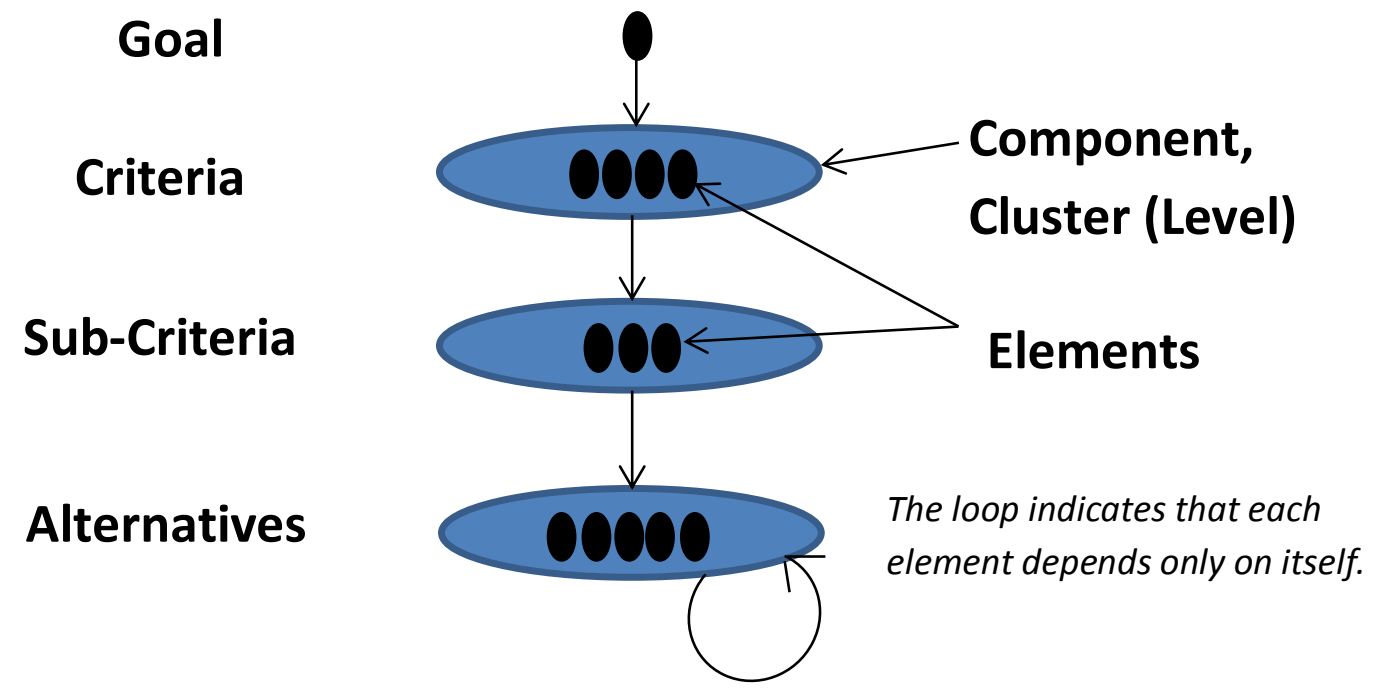

Figure 2.1: A General AHP Model Diagram (Saaty (1996)) 
5. Do the pair wise comparison between all the elements in the same level based on relative measurement scale shown in Table 2.4 .

Table 2.4: Pair-Wise Comparison Scale for AHP (Saaty and Vargas (2012))

\begin{tabular}{|c|c|c|}
\hline Importance & Intensity of Definition & Explanation \\
\hline 1 & Equal Importance & Two activities contribute equally to the objective \\
\hline 2 & Weak importance & \\
\hline 3 & Moderate importance & $\begin{array}{l}\text { Experience and judgment slightly favor one } \\
\text { activity over another }\end{array}$ \\
\hline 4 & Moderate plus importance & \\
\hline 5 & Strong importance & $\begin{array}{l}\text { Experience and judgment strongly favor one } \\
\text { activity over another }\end{array}$ \\
\hline 6 & Strong plus importance & \\
\hline 7 & $\begin{array}{l}\text { Very strong demonstrated } \\
\text { importance }\end{array}$ & $\begin{array}{l}\text { An activity is favored very strongly over another; } \\
\text { its dominance demonstrated in practice }\end{array}$ \\
\hline 8 & Very, very strong importance & \\
\hline 9 & Extreme importance & $\begin{array}{l}\text { The evidence favoring one activity over another } \\
\text { is of the highest possible order of affirmation }\end{array}$ \\
\hline
\end{tabular}

This requires $n(n-1) / 2$ comparisons in each level where $n$ is the number of elements to be compared in each level.

6. Perform calculations to find Consistency Ratio (CR).

If the $C R$ is less than 0.1 , the judgments are consistent and acceptable. If not, the comparisons should be revised by the decision maker. CR is calculated based on maximum eigenvalue and random index for each matrix.

7. If the $C R$ is satisfactory, than the decision is taken based on normalized value for each alternative.

One of the advantages of AHP is that it measures the degree of inconsistency of judgments and inconsistent measures can be identified and be judged again (Liberatore \& Nydick, 2008). A noticeable disadvantage of AHP is that it does not consider interdependencies between the criteria and the alternatives. 


\subsubsection{Analytic Network Process (ANP)}

The Analytic Network Process (ANP) was first introduced by (Saaty, 1996) as a theory of measurement in multi criteria decision making used to prioritize individual judgments as well as actual measurements normalized to a relative form (Saaty (2004a, 2004b)).

ANP is the more general form of Analytical Hierarchy Process (AHP) which considers interdependence between criteria and overcomes the limitations of AHP. It is a decision making model that lets the decision maker include all criteria, tangible or intangible in the decision process to make the best decision. An ANP network is shown in Figure 2.2.

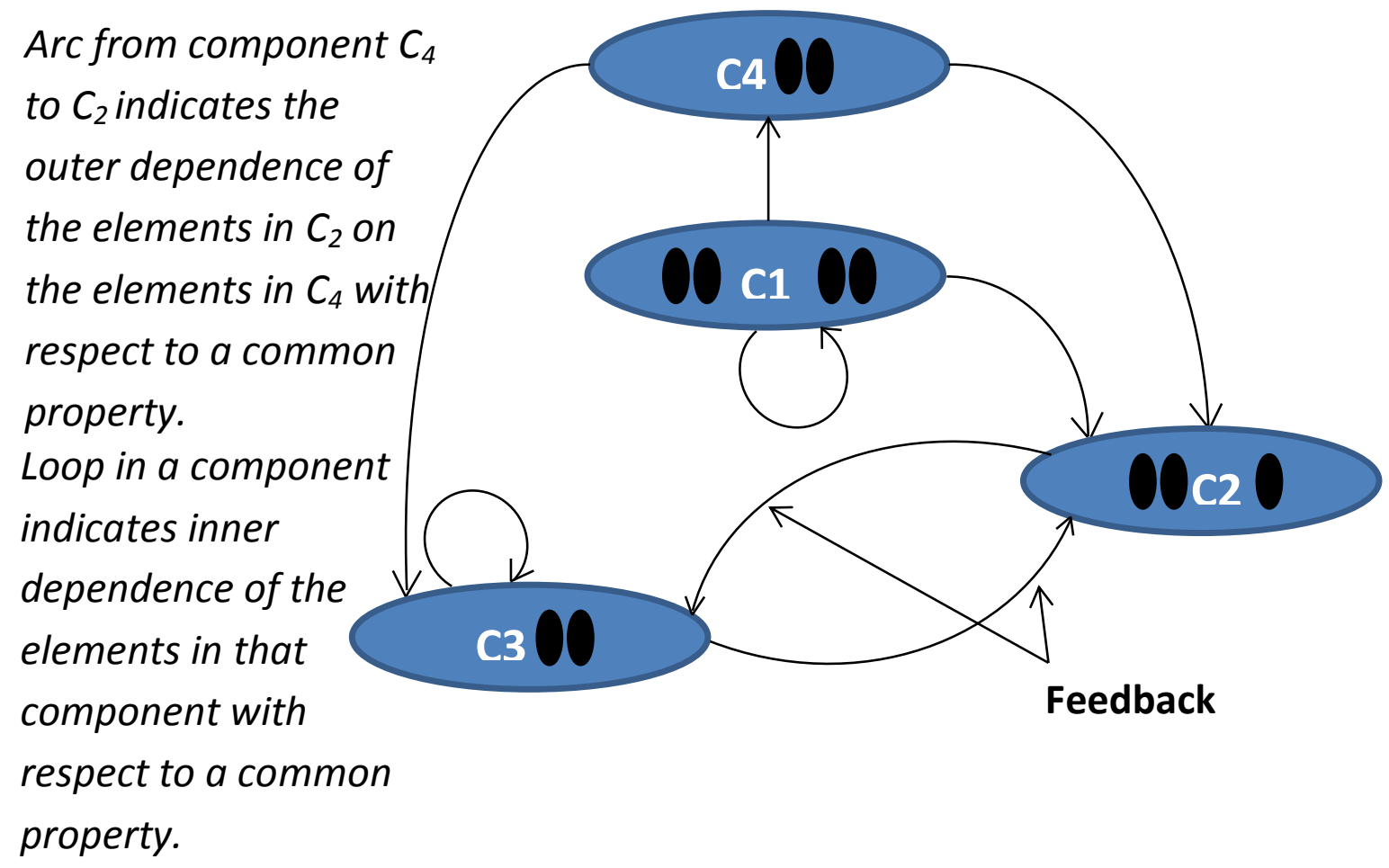

Figure 2.2: A General ANP Model Diagram (Saaty (2004b))

An advantage of ANP over several other MCDM methods is its flexibility and the fact that it considers interactions within cluster of elements (inner 
dependence) and between clusters (outer dependence) and the feedback between them.

Another advantage of the ANP is that it measures the consistency of the judgments. If the judgments are not consistent, they should be judged again to comply with desired level of consistency. A comprehensive study by Taslicali and Ercan (2006) outlines some advantages of AHP/ANP over other MCDM methods:

1- Comparing to other MCDM models, AHP/ANP are not complicated, and this makes the model transparent to the management of businesses and organizations and help them understand it better.

2- They are able to mix quantitative and qualitative factors into a decision.

3- ANPIAHP can be used with other solution approach such as goal programming.

4- They use a hierarchical structuring of the factors. The hierarchical structuring is common to the composition of almost all complex decision making problems, and is a natural problem-solving pattern to deal with complex problems.

5- In AHP/ANP, judgments are completed using a decomposition approach, which has been shown in empirical studies to reduce decision making errors.

ANP has been used in a wide variety of areas including "Risk assessment" (Ergu, Kou, Shi, and Shi (2009)), "Asset management" (Yong and Chunyan (2010)), "Logistics" (Yang, Hui, Leung, and Chen (2010)), "Tunnel Equipment Selection" (Yazdani-Chamzini and Yakhchali (2012)) and "Forecasting" (Niemira and Saaty (2004)). Bayazit and Karpak (2007) developed a framework based on ANP to "Assess the Implementation of Total Quality Management (TQM)". 
ANP and AHP are both new techniques to MCDM realm but it has been shown that ANP has advantages over AHP (Sarkis, 2005). AHP requires strict linear hierarchical relation between elements in a problem while ANP goes beyond linear relation between elements and allows interrelation between them (Tran, Knight, O'Neill, \& Smith, 2004). ANP makes a network that replaces single direction relations in a hierarchy with multidirectional dependence and feedback (Saaty (1996, 2004a, 2006)).

Although ANP has several advantages comparing to the other MCDM methods, a noticeable disadvantage of this method is that it requires filling out several questionnaires for pairwise comparisons by evaluators. It can make the process of evaluating very time consuming for the evaluators. Moreover, many mathematical calculations must be done and processing of the data is demanding. 


\section{BOCR Model and ANP Applications}

Analytic Network Process was selected for this study because it is simple to understand by the decision makers at the management level and since it measures the inconsistency of the decisions, the results of ANP are reliable in very complex Multi-Criteria, Multi-Attribute, Multi-Person decision making problems.

ANP can be adapted into broad range of applications. Since it was introduced by Saaty (1996), several studies have been done in numerous different problems using ANP or its combination with other methods to best fit into the specific problems.

ANP was used in a study by Viglas, Fitsilis, and Kameas (2011) to select Information Systems (IS). In this paper, Balanced Score Card (BSC) methodology was combined with ANP in order to assessing the selection of IT system. This method was used to select a quality management Information System for a Greek retailer as a case study.

Erdoğmuş, Aras, and Koç (2006) used ANP to find the best fuel for the residential heating in Turkey. They used a total of 13 criteria using brainstorming in a meeting with experts in energy field and ranked them using ANP. They showed that natural gas is the most appropriate fuel for Turkey and should be replaced by current dominant fuel which is coal.

In a study by Das and Chakraborty (2011), ANP was employed to select the best widely used Non-Traditional Machining (NTM) processes to make accurate shapes in high strength temperature resistant (HSTR) alloys, fiber-reinforced composites, ceramics, refractories and other difficult-to-machine alloys like titanium. The results of the study were compared to the previous researches in this area and ANP results found to be close to the other methods but they were obtained with less complexity.

ANP was used in SWOT (Strengths, Weaknesses, Opportunities and Threats) analysis and was applied to a textile firm in a study by Dağdeviren, Yüksel, and Kurt (2008). This method is capable to measure the possible 
dependencies among the strategic factors in SWOT analysis and takes them into account.

Sevkli et al. (2012) developed a fuzzy ANP based SWOT analysis for airline industry in Turkey to evaluate alternative strategies in order to determine the best one for given business setting. It provided a quantitative basis to analytically determine the ranking of the factors in SWOT analysis and was successfully implemented in airline industry.

A fuzzy ANP model was developed by Özdağoğlu (2012) to deal with facility location selection. It measures all quantitative and qualitative variables and takes them into consideration to find the best location for the facilities. It was applied in a case study to a food industry in order to find a location to establish a new facility in Istanbul, Turkey.

ANP was used for sales forecasting by Voulgaridou, Kirytopoulos, and Leopoulos (2009) in order to ease the process of the forecasting and make an applicable method that can be used in the industry for the sales forecasting purposes. In this study, 10 criteria in 3 clusters are compared to rank 3 level of High, medium and low sale as forecast for the new product sales.

Hosseini, Tavakkoli-Moghaddam, Vahdani, Mousavi, and Kia (2013) used ANP to select the best strategy to reduce risks in supply chain. The total of 13 criteria in 4 sub-networks was used in the model and it was shown that TQM is the best reactive supply chain risk management among the other methods which were Alignment, Adaptability and Agility.

\subsection{BOCR Model}

All decision problems have some favorable and unfavorable concerns that need to be considered in the decision making process. Some of these concerns are certain and some others are those that are not certain or may happen in the future. In BOCR model, certain concerns that are favorable are called "Benefits" while unfavorable certain concerns are called "Costs". The uncertain concerns of 
a problem that are positive towards the goal of the problem are called "Opportunities" and those uncertain concerns that have negative impact are called "Risks". These four control concerns are called BOCR as an abbreviation for "Benefits", "Opportunities", "Costs" and "Risks" respectively. In this model all the criteria in a decision making problem are classified and analyzed under one of these merits. On the other hand, these merits are synthesized under the goal of the problem and got a weight based on the decision makers' opinion. The final results were obtained by using BOCR weights and the results obtained by analysis of the criteria under each merit in a multiplicative or additive priority calculation formula.

Using BOCR model makes it possible to break down complex problems into very specific criteria that leads to a better clustering and analysis of the problem and the final decision would be more accurate because each of these four merits utilizes a separate structure for the decision and nothing remains out of these four merits.

Several models were developed using Analytic Network Process and BOCR. Demirtas and Üstün (2008) employed ANP and BOCR to solve the order allocation problem. In this study 14 criteria were used to shape the network and rank the suppliers in term of order allocation priority.

Azizi, Amiri, and Modarres (2005) used ANP and BOCR in a study to find the best location for a plywood plant among 6 locations. A real case study depicts the application of the model. The total of 18 criteria are used in the study to make the network and rank the alternatives.

\subsection{ANP in Supplier Selection and Tender Evaluation}

There is no Tender Evaluation study using ANP in the literature. However, there are several contractor selection models which are close to tender evaluation with some differences. 
In the contractor selection field, in a study by Cheng and Heng (2004) ANP was used as a MCDM method to select the best supplier and it was briefly compared to AHP. To describe the model in more details, it was demonstrated in an example. The criteria used in this study were taken from a study by Fong and Choi (2000) which is dedicated to construction contractor selection by AHP and then the model was modified to use in ANP model. This model can be useful in construction field. This study did not use any other models besides ANP like BOCR or Fuzzy, etc.

Eshtehardian, Ghodousi, and Bejanpour (2013) used both ANP and AHP simultaneously to develop a decision support system to select appropriate supplier for construction and civil engineering companies. They defined 18 criteria by sending questionnaires to logistics managers of construction companies. It uses 18 criteria to rank 3 suppliers as a case study. The main focus of this study is on pre-evaluation of contractors and the method did not consider BOCR model. 


\section{Methodology}

ANP is a multi-criteria decision making method which considers both quantitative (tangible) and qualitative (intangible) criteria to make the best decision. The desired result in this research is to identify the most beneficial tenderer among all competitors in a tender conducted by telecom enterprises in order to provide a specific service. The tenderers were ranked based on specific criteria and the contract will be awarded to the first tenderer in the ranking. The process consists of the following steps:

\subsection{To state the decision problem clearly.}

The first and one of the most important steps is to clearly state the problem and define the desired outcome of the analysis. The specific objective is "to evaluate and rank tenderers in a BOCR model based on their qualifications and capabilities using the ANP method for a telecommunication company seeking a contractor to outsource telecom services."

\subsection{To structure problem.}

Defining the goal starts the process of decomposition of the problem to the final level which is scenarios or alternatives. The topmost level which is the decision problem is an abstract in nature. It should be decomposed to a set of manageable and measurable criteria and levels to the last level which is scenarios or alternatives to be assessed. The criteria to be considered in the evaluation process should be defined at this stage. They should be categorized in clusters, main criteria and sub-criteria. To cope with complex decision making problem, the BOCR (Benefit, Opportunity, Cost, Risk) model was proposed to characterize each alternative with regard to a given objective. BOCR covers all the aspects of the evaluation. Since this thesis is to evaluate tenderers based on 
BOCR model, 4 different networks under each of B,O,C,R merits should be composed and all the alternatives should be evaluated on each of the Benefits, Opportunities, Costs, Risks sub-networks. Benefits and Opportunities make positive contribution towards the final decision while Costs and Risks make negative contribution. The final priority score for each tenderer will be calculated based on either multiplicative or additive formula:

Multiplicative:

$P_{i_{m}}=\frac{\left[\left(b \times B_{i}\right) \times\left(o \times O_{i}\right)\right]}{\left[\left(c \times C_{i}\right) \times\left(r \times R_{i}\right)\right]}$

Additive:

$P_{i_{a}}=\left[\left(b \times B_{i}\right)+\left(o \times O_{i}\right)\right]-\left[\left(c \times C_{i}\right)+\left(r \times R_{i}\right)\right]$

Where:

$P_{i_{m}}=$ Priority of the alternative $i$ using multiplicative method

$P_{i_{a}}=$ Priority of the alternative $i$ using additive method

$b, o, c, r=$ Calculated weights for Benefits, Opportunities, Costs and Risks merits respectively.

$B_{i}, O_{i}, C_{i}, R_{i}=$ Calculated priorities for alternative $i$ in Benefits, Opportunities, Costs, Risks sub-networks respectively.

Using additive formula may result in having negative priorities while multiplicative formula will never provide a negative result. The additive formula provides a positive result for alternatives that have more positive aspects (Benefits and Opportunities) than negative (Costs and Risks) and a negative result for alternatives that do not reach a breakeven point (Junzo Watada (2012)). There is no advantage on multiplicative over additive BOCR model or vice-versa. It all depends on the managers and decision makers of a project to decide which one to be used. 


\subsubsection{Defining the criteria}

In order to define the criteria, Delphi method was used to collect data from the experts to come up with the best possible set of criteria. The criteria were defined for telecommunication projects in general and cover all aspects of the tenders in this area. However, some project specific criteria may need to be added to this set to best describe all aspects of the project if needed. The data were collected using Delphi method and a panel of 6 experts from a GSM mobile telecommunication company in the Middle-East.

\subsubsection{Delphi method}

In the 1950's the Unites States military leaders wanted to know the future technological capabilities that might be used against them by enemy militaries. But the traditional methods failed short and the military was not satisfied with the results. So they turned into the RAND Corporation to develop a new method. The developed method by Norman Dalkey is called Delphi. It turned out to be very useful and accurate method for the military and soon they used it for forecasting enemy attacks and many other factors (Hartman, Krahn, and Skulmoski (2007))

Delphi is a method that seeks to aggregate opinions from a panel of experts and is done without bringing them together for a meeting. It is a method to anonymously collect and distill the experts' opinions about a subject through iterations of data collections and providing feedback to the experts. In many face to face meetings or discussions about a topic, one person is considered the expert and dominates the conversation and many ideas will be lost. Delphi overcomes this problem and maintains anonymity by sending questionnaires to the participants and collecting the answers and sending a collection of the answers to the participants without mentioning the name of them. So even though they all see the answers to the questions and other people's comments, they will not know who said what. It allows the participants to freely express their 
opinions knowing that their anonymity is maintained. The iterations allow participants to refine their idea by receiving feedback from others in the group from round to round.

To apply the Delphi method to this study and come up with a set of reliable criteria that covers all aspects of the tender evaluation, two sets of iteration were performed to define main criteria and sub-criteria. The first question sent out to a panel of 6 main decision makers which after 3 rounds of iterations, the answers converged to a set of main criteria and they all agreed on the final result. The expert panel were chosen from the most influential positions in the evaluation process in 6 different positions: "Product Manager", a "Product Specialist", "Director of Product Marketing", "VAS (Value Added Service) Manager", "Director of Service Delivery" and "Procurement Manager".

\subsection{First question details}

In this step a general question was asked to gain a broad understanding of the views of the experts about the criteria. The question was "What are the main criteria for the tender evaluation if you need to outsource a service for your company". The initial round's results were collected and compared to each other in order to find the common answers and provide a statistics over the common answers along with the uncommon answers and were sent to the experts for the $2^{\text {nd }}$ round. The total number of the criteria collected from the panel of experts was 25 criteria.

The $2^{\text {nd }}$ round was to give an idea about the others' views and let the experts revise their original answers if needed along with their comments on the others' ideas or a justification about their own answers. The collected answers were analyzed again to find out the common ideas and providing the statistics for the next round. After the second round, the 25 criteria were reduced to 11 criteria

The $3^{\text {rd }}$ round was conducted for the tender evaluation process and the criteria which had a frequency of less than 2 were removed and the results were sent to the experts(6) for the verification. This resulted in the criteria being 
reduced from 11 to 8 items. The detailed questions and answers along with the statistics are attached to the Appendix 1.

\subsection{Second question details}

Another Delphi iterations were run to find out the details about the previous question. The question in this stage was: "Please split each of the following criteria into more specific criteria in order to make the evaluation possible and more accurate." With the comment: Please provide as details as necessary for the following main criteria." along with a list of the criteria defined in the previous step.

The $1^{\text {st }}$ round of collecting the data was to get as many relative details as possible for both general main criteria and the project specific main criteria. This round of data collection was like a brainstorming and all the possible criteria were collected and listed with their frequencies for the $2^{\text {nd }}$ round. In this round, 92 criteria were defined as sub-criteria.

For the next iteration, all the answers were sent back to the experts along with statistics about the common answers and also pointing out the uncommon answers. The experts were asked to revise their first answers if needed and also make comments about others' answers or defend their own answers if they need. After the $2^{\text {nd }}$ round, some criteria were changed and some comments were added by the experts in order to justify their idea or change the others' idea for the $3^{\text {rd }}$ round. The criteria were reduced to 63 at this round.

In the third iteration, statistics and answers were provided from the $2^{\text {nd }}$ iteration to the experts and they were allowed to revise their answers again. After the $3^{\text {rd }}$ round, the criteria with the frequency of less than 2 were removed resulting in having 37 sub-criteria and the results were sent to the experts for the final verification. The questionnaires and answers with statistics and comments are attached to the Appendix 2 


\subsubsection{Delphi criteria selection results}

In the analysis to drive a selection of tender evaluation criteria, a set of 8 main criteria were chosen that are both basic to all models of tender evaluation and meet the goals of all tenders within the telecommunication industry. One of these sets of the criteria was defined as project specific and need to be defined for every project separately. They are categorized under "Required Project Specific Functionalities" title. These factors are some of the most important to decision makers. Some other criteria have been identified which can be considered as sub-criteria of the 8 main criteria. The main criteria are:
a) General Requirements
b) Required Project Specific Functionalities
c) Customer/User Interfaces
d) Privacy Management
e) Billing and Charging
f) Extra Features
g) Technical Specifications
h) Price

There are 37 identified sub-criteria as follows:

a) Sub-criteria of "General Requirements":

1. Company Profile

2. Project Management Capabilities

3. Implementation Support (on-site)

4. After Launch Support

5. Implementation Time/ Minimum Time to Market

6. Flexibility and Agileness in Customization

7. Evidences of Previous Experiences

8. On-site Developments 
b) Sub-criteria of "Required Functionalities":

These sub-criteria exist in all tender evaluations but they vary based on the specific tenders. In our case (implementing Voice Message System) they are:

1. Sending Voice Message Features

2. Delivery and Notification Options

3. Voice Mailbox Types

4. IVR Access to System

5. Greeting Messages

6. Access Methods to Mailboxes

7. Notifications

8. Number Blocking

c) Sub-criteria of "Customer/User interfaces":

1- Multi Language Support

2- Different Calendars Support

3- Administrative/Operation Interface

4- User Interface

5- Feel and Look

d) Sub-criteria of "Privacy Management":

1. Enforcing End Users to Accept Terms and Conditions

2. Managing Privacy Courtesy Information

e) Sub-criteria of "Billing and Charging":

1. General Notice

2. Prepaid Charging

3. Postpaid Charging 
f) Sub-criteria of "Extra Features":

1. Licensing

2. Sizing

g) Sub-criteria of "Technical Specifications":

1. Required Hardware

2. Required Software

3. Integration Capabilities

4. CDR Generation and Documentation

5. Provisioning Features

6. Alarm/Performance Monitoring and Reporting

7. Training

h) Sub-criteria of "Price":

1. Operation Expenditure (OPEX)

2. Capital Expenditure (CAPEX)

\subsubsection{Criteria Classification for BOCR model}

To classify the criteria in a BOCR model, the network should be drawn in details and then, the relations between all elements of the network should be defined. A general form of BOCR network is shown in Figure 4.1. Each of "Benefits", "Opportunities", "Costs" and "Risks" merits, consists of sub-networks. All these sub networks include "Alternatives" and the comparison criteria appropriated to that merit. In order to shape the network, the decision makers defined each criterion to be a sub category of a merit as shown in Table 4.1. The process of assigning each criterion to a merit was done through another Delphi session. The question in this Delphi session was: "Please assign each of the listed criteria to one of the Benefits, Opportunities, Costs or Risks merits". The answers of the experts were collected in 3 rounds Delphi data collection. In the 
first round, all the 37 sub-criteria were listed for the panelists regardless of their main classifications that were obtained in previous Delphi surveys and they were asked to classify them in B,O,C,R merits. An analytic result was provided to them to let them see the others' opinions after the $1^{\text {st }}$ round and they were asked to revise their previous decision if necessary and provide comments on the results when needed. In the provided result, the number of votes for each criterion to be under each merit was given to the panelists along with the comments. After the $2^{\text {nd }}$ round data collection, results were changed slightly and exactly the same process was repeated for the $3^{\text {rd }}$ and the last time. After this round all the votes for each criterion and merit were counted and were normalized on each criterion to show the percentage of the belonging of them to each merit. The criteria were classified under $\mathrm{B}, \mathrm{O}, \mathrm{C}$ and $\mathrm{R}$ merits such that each criterion belongs to a merit with the highest percentage of the belonging. The details of the questionnaires and answers and analysis of the results to classify the criteria are attached in Appendix 3.

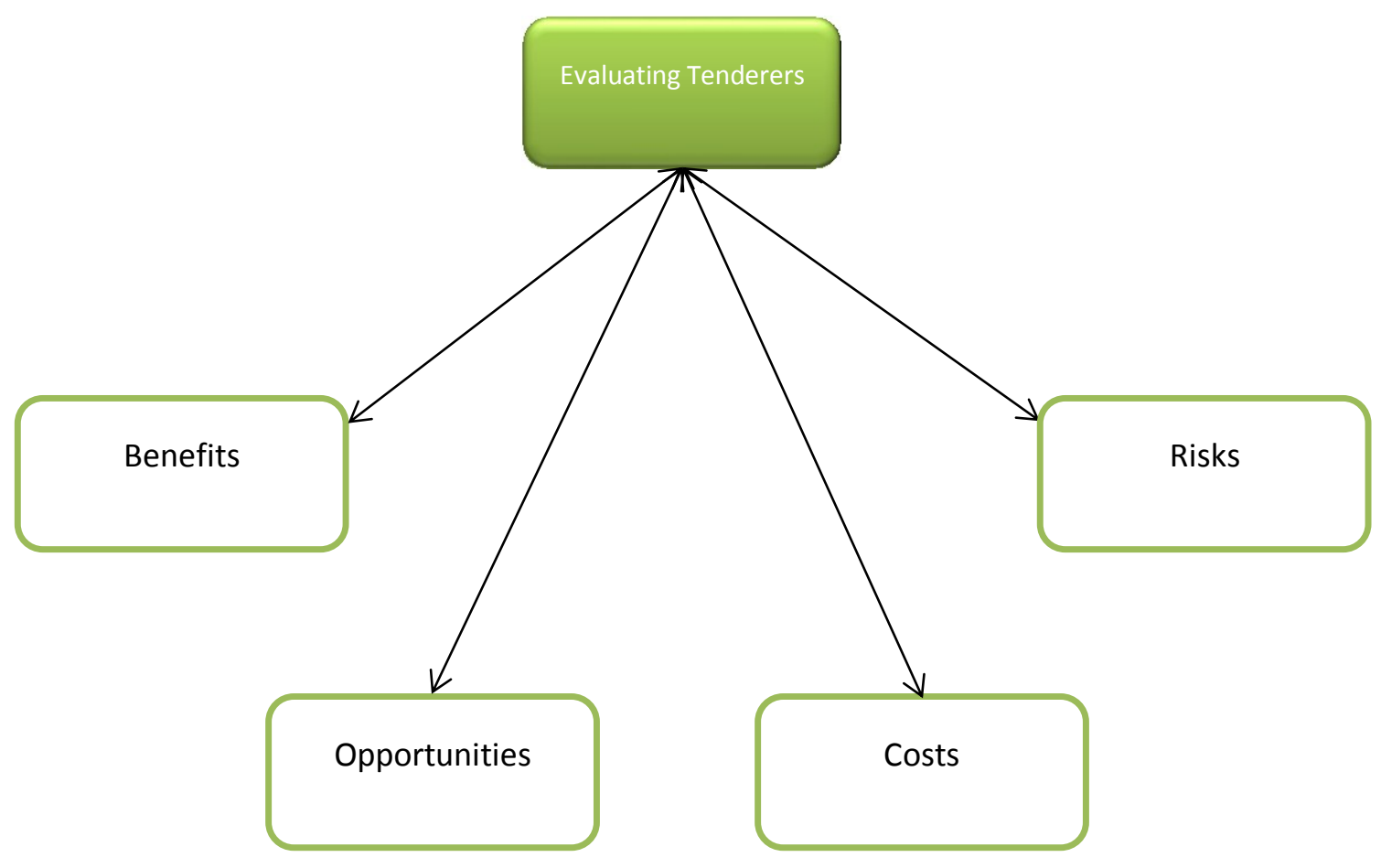

Figure 4.1: A General BOCR ANP Model Diagram 
Table 4.1: Assigning Each Criterion to a Merit

\begin{tabular}{|l|l|}
\hline \multicolumn{1}{|c|}{ Criteria } & \multicolumn{1}{|c|}{ Merits } \\
\hline a) Sub-criteria of "General Requirements": & \\
\hline 1. Company Profile & Risk \\
\hline 2. Project Management Capabilities & Risk \\
\hline 3. Implementation Support (on-site) & Benefit \\
\hline 4. After Launch Support & Benefit \\
\hline 5. Implementation Time/ Minimum Time to Market & Benefit \\
\hline 6. Flexibility and Agileness in Customization & Opportunity \\
\hline 7. Evidences of Previous Experiences & Risk \\
\hline 8. On-site Developments & Opportunity \\
\hline b) Sub-criteria of "Required Functionalities": & \\
\hline 1. Sending Voice Message Features & Benefit \\
\hline 2. Delivery and Notification Options & Benefit \\
\hline 3. Voice Mailbox Types & Benefit \\
\hline 4. IVR Access to System & Benefit \\
\hline 5. Greeting Messages & Benefit \\
\hline 6. Access Methods to Mailboxes & Benefit \\
\hline 7. Notifications & Benefit \\
\hline 8. Number Blocking & Benefit \\
\hline c) Sub-criteria of “Customer/User Interfaces": & \\
\hline 1- Multi Language Support & Opportunity \\
\hline 2- Different Calendars Support & Benefit \\
\hline 3- Administrative/Operation Interface & Benefit \\
\hline 4- User Interface & Benefit \\
\hline 5- Feel and Look & Benefit \\
\hline d) Sub-criteria of “Privacy Management": & \\
\hline 1. Enforcing End Users to Accept Terms and Conditions & Benefit \\
\hline 2. Managing Privacy Courtesy Information & Risk \\
\hline e) Sub-criteria of "Billing and Charging": & \\
\hline 1. General Notice & Benefit \\
\hline 2. Prepaid Charging & Benefit \\
\hline 3. Postpaid Charging & Benefit \\
\hline
\end{tabular}


Table 4.1: Assigning Each Criterion to a Merit (cont.)

\begin{tabular}{|l|l|}
\hline f) Sub-criteria of "Extra Features": & \\
\hline 1. Licensing & Benefit \\
\hline 2. Sizing & Opportunity \\
\hline g) Sub-criteria of “Technical Specifications": & \\
\hline 1. Required Hardware & Cost \\
\hline 2. Required Software & Cost \\
\hline 3. Integration Capabilities & Benefit \\
\hline 4. CDR Generation and Documentation & Benefit \\
\hline 5. Provisioning Features & Benefit \\
\hline 6. Alarm/Performance Monitoring and Reporting & Risk \\
\hline 7. Training & Benefit \\
\hline h) Sub-criteria of “Price": & \\
\hline 1. Operation Expenditure (OPEX) & Cost \\
\hline 2. Capital Expenditure (CAPEX) & Cost \\
\hline
\end{tabular}

All the criteria for the decision making problem, regardless of the problem, can be assigned to one of the merits by the experts (raters). If a criterion belongs to more than one merit, the criterion will be considered to be under the one that is more relevant to the criterion. For instance, if experts believe that a criterion could be under both Opportunities and Benefits merits and the degree of belonging to them is $60 \%$ Opportunities and $40 \%$ Benefits, then it will be considered under the more relevant merit which is Opportunities.

Each of the main merits $B, O, C, R$ will have a sub-network containing all related criteria and all alternatives as follows:

Benefits:

There are totally 24 criteria in this sub-network. In ANP, it is suggested not to have more than 7 criteria in a cluster because it makes the comparisons inaccurate by increasing the number of the pairwise comparisons and on the other hand, makes the calculations more difficult. In order to classify the Benefits criteria in clusters, the experts defined 5 categories and classified them in the 
clusters in a brainstorming session in the company. The clusters in a subnetwork can be compared in order to determine the weights of each of them if they are not of equal importance in the sub-network with regards to the goal. The cluster comparisons then will be converted to a cluster matrix in the same way as criteria pair-wise comparisons as described in Chapters 4.3, 4.4 and 4.5. The final priorities calculated for cluster matrix will be used to weight the un-weighted super-matrix in the process of forming the limit super-matrix. If the clusters are of the same importance, there is no need for calculating the cluster matrix and all the results will have the same weight in the super-matrices.

The criteria in this merit were categorized in 5 clusters namely: Financial, Technical, Customer Satisfaction, Marketing, and Operational. Benefits criteria based on the clusters are shown in Table 4.2. In this sub-network, the criteria are divided into 5 clusters:

- Customer Satisfaction Benefits

- Financial Benefits

- Marketing Benefits

- Operational Benefits

- Technical Benefits

There are interaction connections between all these clusters and the alternatives cluster. The Benefits sub-network is illustrated in Figure 4.2.

Opportunities:

Four criteria are classified as opportunities. They are shown in Table 4.3 and the sub-network of opportunities is depicted in Figure 4.3. 
Table 4.2: Benefits Criteria Categorized in 5 Clusters

\begin{tabular}{r|l|l|l|}
\hline & \multicolumn{1}{|c|}{ Criteria } & \multicolumn{1}{c|}{ Merits } & \multicolumn{1}{c|}{ Cluster } \\
\hline 1 & Access Methods to Mailboxes & Benefits & Customer Satisfaction \\
\hline 2 & Notifications & Benefits & Customer Satisfaction \\
\hline 3 & Number Blocking & Benefits & Customer Satisfaction \\
\hline 4 & User Interface & Benefits & Customer Satisfaction \\
\hline 5 & General Notice & Benefits & Customer Satisfaction \\
\hline 6 & Implementation time/Minimum Time to Market & Benefits & Financial \\
\hline 7 & Prepaid Charging & Benefits & Financial \\
\hline 8 & Postpaid Charging & Benefits & Financial \\
\hline 9 & Licensing & Benefits & Financial \\
\hline 10 & Greeting Messages & Benefits & Marketing \\
\hline 11 & Voice Mailbox Types an Features & Benefits & Marketing \\
\hline 12 & IVR access to System & Benefits & Marketing \\
\hline 13 & Different Calendars Support & Benefits & Marketing \\
\hline 14 & Sending Voice Message Features & Benefits & Marketing \\
\hline 15 & Delivery and Notification Options & Benefits & Operational \\
\hline 16 & Administrative/Operation interface & Benefits & Operational \\
\hline 17 & Feel and Look & Benefits & Operational \\
\hline 18 & Enforcing End Users to Accept Terms \& Conditions & Benefits & Operational \\
\hline 19 & CDR Generation and Documentation & Benefits & Operational \\
\hline 20 & Implementation Support (on-site) & Benefits & Technical \\
\hline 21 & After Launch Support & Benefits & Technical \\
\hline 22 & Integration Capabilities & Benefits & Technical \\
\hline 23 & Provisioning Features & Benefits & Technical \\
\hline 24 & Training & Benefits & Technical \\
\hline
\end{tabular}

Table 4.3: Opportunities Criteria

\begin{tabular}{|c|l|c|}
\hline & \multicolumn{1}{|c|}{ Criteria } & Merits \\
\hline 1 & Flexibility and Agileness in Customization & Opportunities \\
\hline 2 & On-site Developments & Opportunities \\
\hline 3 & Multi Language Support & Opportunities \\
\hline 4 & Sizing & Opportunities \\
\hline
\end{tabular}




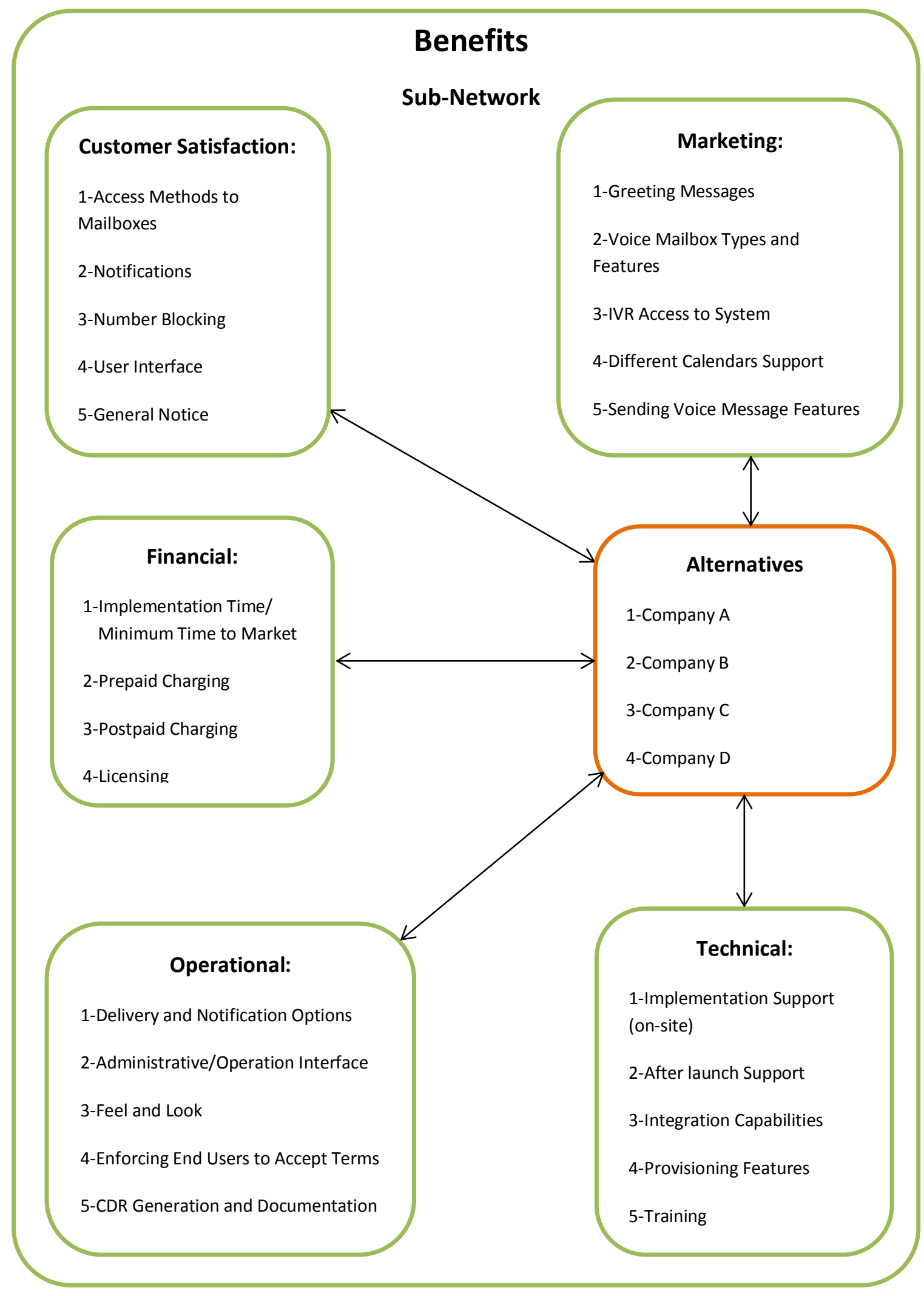

Figure 4.2: Benefits Sub-network 


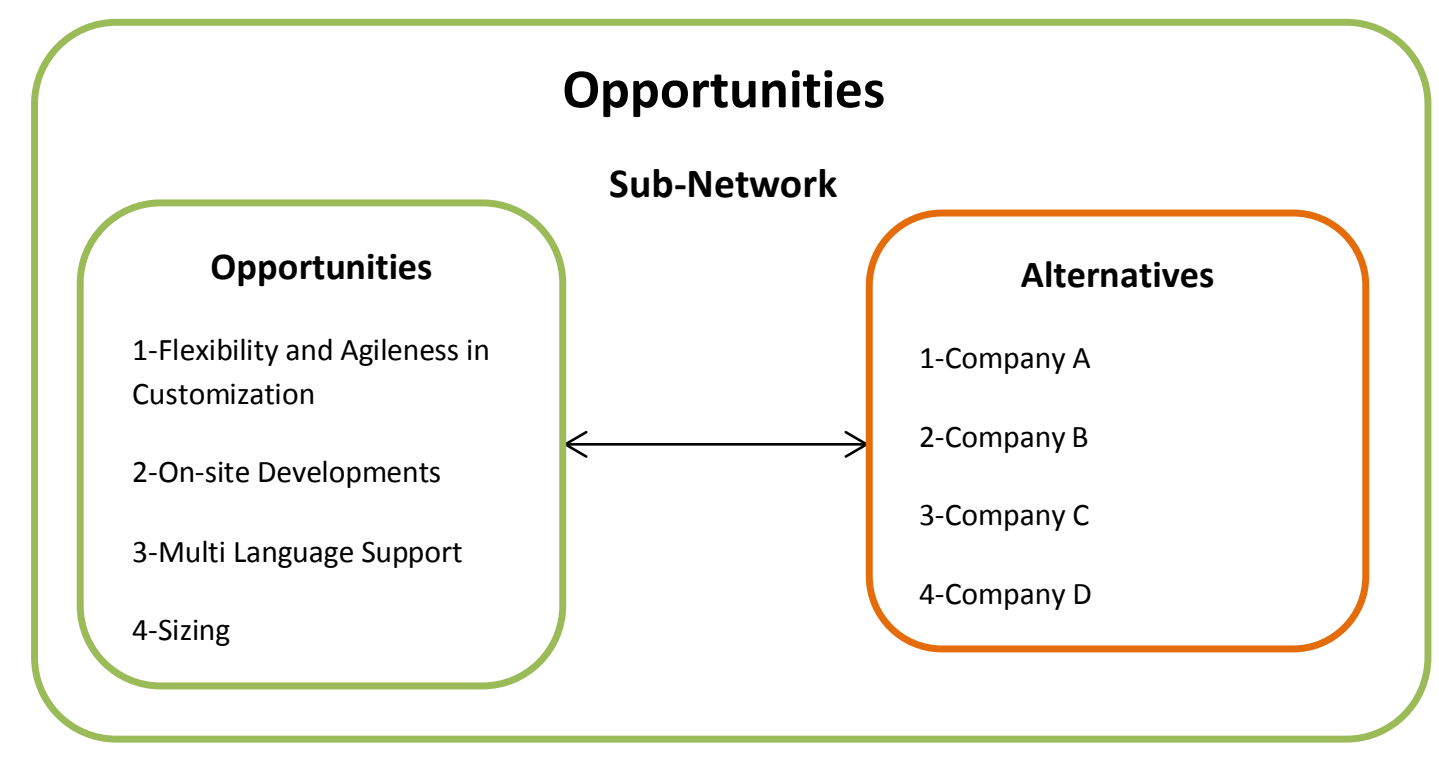

Figure 4.3: Opportunities Sub-network

\section{Costs:}

Four criteria are considered in costs sub-network. They are listed in Table 4.4 and the sub-network diagram is shown in Figure 4.4.

Risks:

There are 5 criteria in this sub-network. They are shown in Table 4.5 and the sub-network is shown in Figure 4.5.

\section{Table 4.4: Costs Criteria}

\begin{tabular}{|c|l|l|}
\hline & \multicolumn{1}{|c|}{ Criteria } & \multicolumn{1}{|c|}{ Merits } \\
\hline 1 & Required Hardware & Costs \\
\hline 2 & Required Software & Costs \\
\hline 3 & Operation Expenditure (OPEX) & Costs \\
\hline 4 & Capital Expenditure (CAPEX) & Costs \\
\hline
\end{tabular}


Table 4.5: Risks Criteria

\begin{tabular}{|c|l|l|}
\hline & \multicolumn{1}{|c|}{ Criteria } & \multicolumn{1}{c|}{ Merits } \\
\hline 1 & Company Profile & Risk \\
\hline 2 & Project Management Capabilities & Risk \\
\hline 3 & Evidences of Previous Experiences & Risk \\
\hline 4 & Managing Privacy Courtesy Information & Risk \\
\hline 5 & Alarm/Performance Monitoring and Reporting & Risk \\
\hline
\end{tabular}

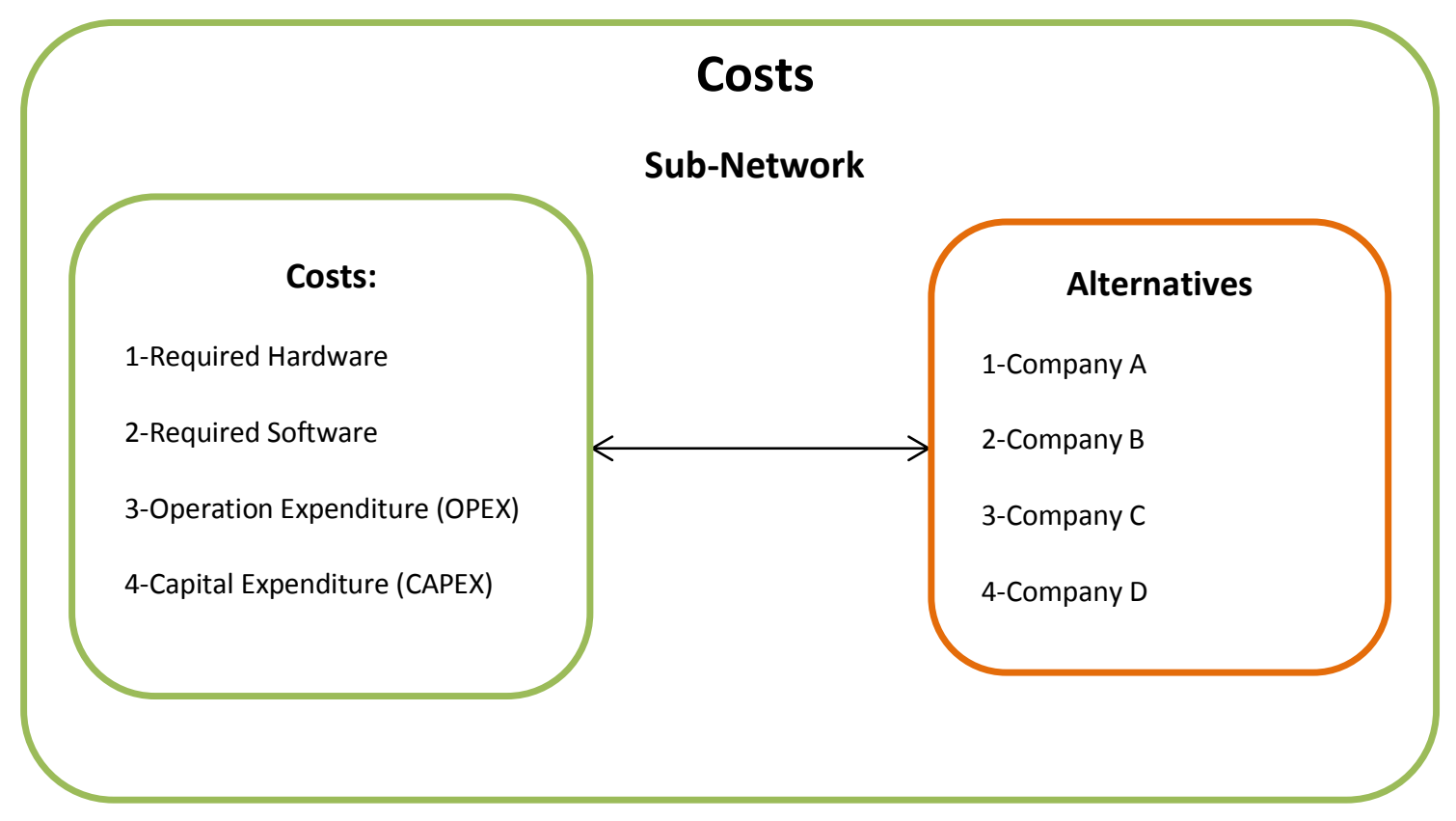

Figure 4.4: Costs Sub-network 


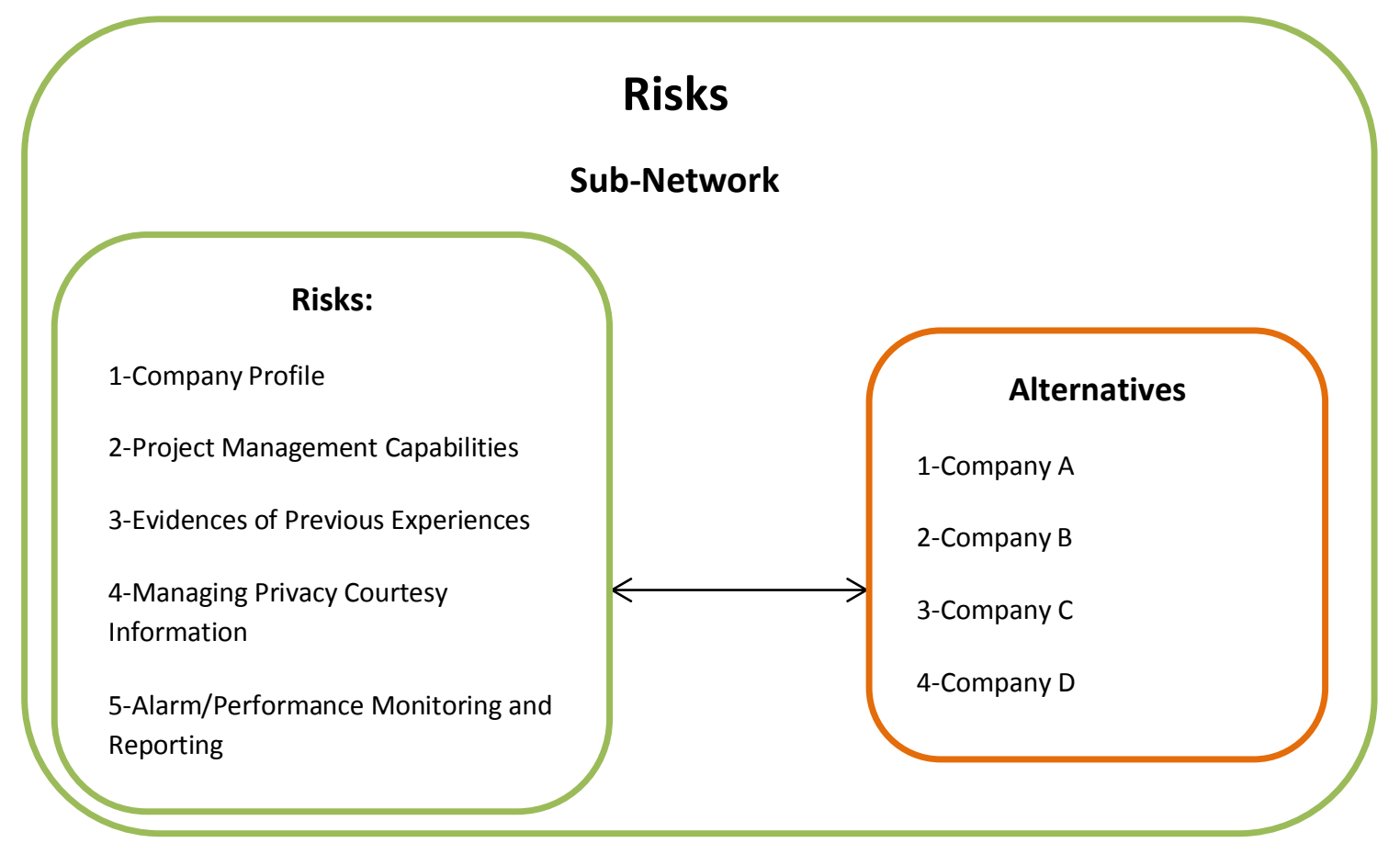

Figure 4.5: Risks Sub-network

\subsection{Pairwise Comparisons (Designing questionnaires)}

Based on the network and the relations in the network designed in the previous stage, questionnaires should be designed to ask the judges' idea about the relevant importance of 2 elements at a time with regards to a control criterion. It is common to use the 9 point priority scale introduced by Saaty (1996) to measure the relative importance between paired elements, shown in Table 2.4.

One can use a fraction of these scales to compare two elements such as 1.2 or 6.3 etc. In other words, there are weights to be assigned to an element comparing to another element in a comparison between integer scales. These comparisons are usually those which compare quantitative elements like price or weight, etc. It makes the comparison of quantitative data more accurate.

The first comparison would be to compare Benefits, Opportunities, Costs and Risks merits to find out their importance and weights in the network. These 4 
merits should be compared pairwise in order to define the weight of each which will be used in the calculations later in the model.

To do the pairwise comparison, a 4 by 4 matrix should be formed with all these merits on both columns and rows. The comparison result should fill out the matrix elements based on the 9 point scale (Saaty, 2004b). Since there are 4 criteria to be compared, the total number of 6 comparisons should be made $(\mathrm{n}(\mathrm{n}-1) / 2, \mathrm{n}=4)$. A sample pairwise questionnaire that should be filled by the raters is shown in Table 4.6.

Table 4.6: Pairwise Comparison Questionnaire Sample

\begin{tabular}{|c|c|c|c|c|c|c|c|c|c|c|c|c|c|c|c|c|c|c|}
\hline \multirow[b]{2}{*}{ Benefits } & \multicolumn{17}{|c|}{ Comparisons With Regards to Goal } & \multirow[b]{2}{*}{ Costs } \\
\hline & 9 & 8 & 7 & 6 & 5 & 4 & 3 & 2 & 1 & 2 & 3 & 4 & 5 & 6 & 7 & 8 & 9 & \\
\hline Benefits & 9 & 8 & 7 & 6 & 5 & 4 & 3 & 2 & 1 & 2 & 3 & 4 & 5 & 6 & 7 & 8 & 9 & Opportunities \\
\hline Benefits & 9 & 8 & 7 & 6 & 5 & 4 & 3 & 2 & 1 & 2 & 3 & 4 & 5 & 6 & 7 & 8 & 9 & Risks \\
\hline Costs & 9 & 8 & 7 & 6 & 5 & 4 & 3 & 2 & 1 & 2 & 3 & 4 & 5 & 6 & 7 & 8 & 9 & Opportunities \\
\hline Costs & 9 & 8 & 7 & 6 & 5 & 4 & 3 & 2 & 1 & 2 & 3 & 4 & 5 & 6 & 7 & 8 & 9 & Risks \\
\hline Opportunities & 9 & 8 & 7 & 6 & 5 & 4 & 3 & 2 & 1 & 2 & 3 & 4 & 5 & 6 & 7 & 8 & 9 & Risks \\
\hline
\end{tabular}

This will be converted to a matrix form. In matrix form all the criteria to be compared are written on the left column of the matrix and also the row on the top of the matrix. The elements of the matrix are the priority of the left criteria to the top criteria. The questionnaire shown in Table 4.6 is converted to the matrix form in Table 4.7.

Table 4.7: The Pairwise Comparison Matrix Example for ANP

\begin{tabular}{|l|l|l|l|l|}
\hline Goal & Benefits & Opportunities & Costs & Risks \\
\hline Benefits & 1 & 3 & 2 & 4 \\
\hline Opportunities & $1 / 3$ & 1 & 2 & 3 \\
\hline Costs & $1 / 2$ & $1 / 2$ & 1 & 4 \\
\hline Risks & $1 / 4$ & $1 / 3$ & $1 / 4$ & 1
\end{tabular}

As an explanation, in this example the priority of Benefits over the Opportunities (as experts believe) is 3 that is "Benefits" merit is moderately more 
important than "opportunities" merit. It can be translated like "Benefits" is 3 times more important than "Opportunities" with regards to our goal (in this case, tender evaluation). These comparisons should be made for all nodes that are related to each other on the network with regards to a parent (Or control) element or cluster.

\subsubsection{Pairwise comparison for quantitative data}

In order to perform pairwise comparisons for quantitative criteria such as cost, the acceptable range of that criterion should be clustered by the experts or evaluators into 9 equal size intervals and evaluators should perform the pairwise comparison based on the difference of that criterion between 2 alternatives and compare it to the intervals. If the difference falls in the first interval, the pairwise comparison result would be 1 , meaning that both alternative are equally preferred. If the difference falls in the $2^{\text {nd }}$ interval, the result would be 2 to the favor of the more beneficial alternative and so on. As an illustration, if the acceptable capital expenditure (CAPEX) of the project for the company is between $\$ 100,000$ and $\$ 130,000$ then the guideline for the comparison will look like Table 4.8.

Table 4.8: Clustering guideline example for a pairwise comparison with regards to a quantitative criterion

\begin{tabular}{|l|r|r|r|}
\hline Cluster & \multicolumn{1}{|l|}{ Lower range } & Upper range & Rank \\
\hline C1 & $\$ 0$ & $\$ 3,333$ & 1 \\
\hline C2 & $\$ 3,334$ & $\$ 6,667$ & 2 \\
\hline C3 & $\$ 6,668$ & $\$ 10,000$ & 3 \\
\hline C4 & $\$ 10,001$ & $\$ 13,333$ & 4 \\
\hline C5 & $\$ 13,334$ & $\$ 16,667$ & 5 \\
\hline C6 & $\$ 16,668$ & $\$ 20,000$ & 6 \\
\hline C7 & $\$ 20,001$ & $\$ 23,333$ & 7 \\
\hline C8 & $\$ 23,334$ & $\$ 26,667$ & 8 \\
\hline C9 & $\$ 26,668$ & $\$ 30,000$ & 9 \\
\hline
\end{tabular}


If the tenderer A's CAPEX is $\$ 105,000$ and the tenderer B's CAPEX is $\$ 110,000$, then the difference between these 2 tenders is $\$ 5,000$ which falls in the $2^{\text {nd }}$ category. So in the pairwise comparison that compares tenderer $A$ and $B$ with regards to CAPEX, the result would be 2 in the favor of tenderer A. It means there is a weak preference for the tenderer $A$ comparing to tenderer $B$ with regards to CAPEX.

\subsubsection{Number of pairwise comparisons}

The number of comparisons for comparing categories in the network is calculated as below:

$C=$ Number of categories

$N_{c}=$ Number of category comparisons

$N_{c}=C \times(C-1) / 2$

Category comparisons for the empirical study is calculated as below:

$N_{c}=4 \times(4-1) / 2=6$ comparisons

The number of comparisons to be made for each category or sub-network is calculated as below:

$n_{1}=$ Number of the elements in cluster 1

$n_{2}=$ Number of the elements in cluster 2

$N=$ Total number of comparisons for each 2 clusters that are connected

$N=n_{1} \times \frac{\left(n_{1}-1\right)}{2} \times n_{2}+n_{2} \times \frac{\left(n_{2}-1\right)}{2} \times n_{1}$

The total number of comparisons for the network will be:

$N_{t}=$ Total number of comparisons for the network 


$$
N_{t}=N+N_{c}
$$

The number of comparisons to be made for sub-networks in the empirical study is calculated as below:

$$
\begin{aligned}
& N_{\text {Benefits }}=N_{\text {Cust.Satisf. }}+N_{\text {Financial }}+N_{\text {Marketing }}+N_{\text {Operational }}+N_{\text {Technical }}+N_{c} \\
& \quad=4 \times\left[\left[5 \times \frac{(5-1)}{2} \times 4\right]+\left[4 \times \frac{(4-1)}{2} \times 5\right]\right]+\left[\left[4 \times \frac{(4-1)}{2} \times 4\right]+\left[4 \times \frac{(4-1)}{2} \times 4\right]\right]+\left[5 \times \frac{(5-1)}{2}\right] \\
& =4 \times 70+48+10=338 \text { Comparisons } \\
& N_{\text {Opportunities }}=\left[4 \times \frac{(4-1)}{2} \times 4\right]+\left[4 \times \frac{(4-1)}{2} \times 4\right]=48 \text { Comparisons } \\
& N_{\text {Costs }}=\left[4 \times \frac{(4-1)}{2} \times 4\right]+\left[4 \times \frac{(4-1)}{2} \times 4\right]=48 \text { Comparisons } \\
& N_{\text {Risks }}=\left[5 \times \frac{(5-1)}{2} \times 4\right]+\left[4 \times \frac{(4-1)}{2} \times 5\right]=70 \text { Comparisons }
\end{aligned}
$$

So the number of comparisons for all sub-networks is:

$N=338+48+48+70=504$ Comparisons

And the total number of comparisons for the study is:

$$
N_{t}=504+6=510 \text { Comparisons }
$$

To ease the process of filling out the questionnaires and get more accurate results, questionnaires were designed in MS-Excel spreadsheets.

\subsubsection{Group decision making}

There are situations that more than one person should give his or her idea about a comparison. If there is more than one rater for a criterion, the pairwise comparison should be done by each rater separately and then the geometric 
mean of the comparisons should be calculated and be considered for that specific comparison. It has been suggested to use geometric mean is such situations for more accurate results (Saaty (2001)).

\subsection{To calculate the eigenvector of each of the developed matrices.}

This should be done to find out the priorities of the elements and then, use them in other steps of the model. The priorities of BOCR merits are calculated as a sample, by calculating the eigenvector of the correspondent matrix. The calculated eigenvector which shows priorities of these merits is shown in Table 4.9.

Table 4.9: Eigenvector of Merits Matrix that Shows Their Priorities

\begin{tabular}{|l|r|}
\hline Benefits & 0.46206187 \\
\hline Opportunities & 0.251060492 \\
\hline Costs & 0.208590852 \\
\hline Risks & 0.078286787 \\
\hline
\end{tabular}

These calculated priorities are weights for 4 merits in our example which were shown by $b, o, c, r$ in the additive and multiplicative final priority calculation formula.

\subsection{To measure the consistency ratio (CR)}

In decision making process, when different attributes or criteria are involved, there are inconsistency issues involved. Inconsistency in judgments is when a judge believes factor $A$ is better than $B$ and in another comparison believes that factor $B$ is better than $C$ and in another comparison states that $C$ is better than $A$. The $3^{\text {rd }}$ comparison is inconsistent with first two comparisons because $A$ would logically be better than two others. These judgments are inconsistent and should be revised. 
The accuracy of the final results in the tender evaluation depends on how accurate the pairwise comparisons are. Therefore for all pairwise comparison matrices, the consistency ratio should be measured before they are used in next steps to form the super-matrix and be analyzed.

In ANP, if the calculated CR was higher than an acceptable level, it is suggested to do the pairwise comparison again. 0.1 is suggested by Saaty (2004a) as the limit. Obviously the lower the CR, the more accurate the judgments.

The consistency ratio is calculated as below:

$$
C R=\frac{C I}{R I}<0.1
$$

Where :

CR: Consistency Ratio

$$
C I=\left(\lambda_{\max }-n\right) /(n-1)
$$

$C I$ : Consistency Index where $\lambda_{\max }$ is the maximum eigenvalue and $n$ is the order of the matrix

RI: Average Random Index based on the size of the matrix given in Table 4.10.

Table 4.10: Average Random Index Based on the Matrix Order (Saaty (1980))

\begin{tabular}{|l|l|l|l|l|l|l|l|l|l|l|}
$\boldsymbol{n}$ & $\mathbf{1}$ & $\mathbf{2}$ & $\mathbf{3}$ & $\mathbf{4}$ & $\mathbf{5}$ & $\mathbf{6}$ & $\mathbf{7}$ & $\mathbf{8}$ & $\mathbf{9}$ & $\mathbf{1 0}$ \\
\hline $\boldsymbol{R I}$ & 0 & 0 & 0.52 & 0.89 & 1.11 & 1.25 & 1.35 & 1.40 & 1.45 & 1.49 \\
\hline
\end{tabular}

To depict the CR calculation, the calculations for the BOCR comparisons matrix are shown below:

To show the procedure of calculating Inconsistency Ratio, the comparison matrix $A$ which is the matrix form of the merits comparison questionnaire in the previous example, is defined as: 


$$
A=\left(\begin{array}{cccc}
1 & 3 & 2 & 4 \\
1 / 3 & 1 & 2 & 3 \\
1 / 2 & 1 / 2 & 1 & 4 \\
1 / 4 & 1 / 3 & 1 / 4 & 1
\end{array}\right)
$$

Then the matrix should be normalized such that sum of each column would be 1:

$$
\text { Normalized } A=\left(\begin{array}{cccc}
0.48 & 0.62 & 0.38 & 0.33 \\
0.16 & 0.21 & 0.38 & 0.25 \\
0.24 & 0.10 & 0.19 & 0.33 \\
0.12 & 0.07 & 0.05 & 0.08
\end{array}\right)
$$

The average of the elements of each row on Normalized $A$ matrix, makes matrix $W$ :

$$
W=\left(\begin{array}{l}
0.45 \\
0.25 \\
0.22 \\
0.08
\end{array}\right)
$$

Then the matrix $A W$ which is the multiplication of $A$ times $W$ would be:

$$
A W=A \times W=\left(\begin{array}{l}
1.96 \\
1.07 \\
0.89 \\
0.33
\end{array}\right)
$$

Each element in this matrix should be divided by the correspondent element in matrix $W$ and the Average of these elements would be $\lambda_{\max }$. In this example,

$$
\lambda_{\max }=\left(\frac{1.96}{0.45}+\frac{1.07}{0.25}+\frac{0.89}{0.22}+\frac{0.33}{0.08}\right) / 4=4.2015
$$


The Consistency Index $(C I)$ is:

$$
C I=\frac{\lambda_{\max }-n}{n-1}=\frac{4.2015-4}{4-1}=0.0672
$$

The Random Index (RI) for a 4x4 matrix can be read from Table 4.10:

$$
R I=0.089
$$

And Finally, Consistency Ratio is calculated as below:

$$
C R=\frac{C I}{R I}=\frac{0.0672}{0.089}=0.07547
$$

Since the Consistency Ratio is less than 0.1 , it can be assumed that the judgments have been consistent.

These calculations should be done for every single comparison matrix and if one comparison matrix was not consistent, the rating for the whole set of inconsistent comparisons should be done again.

\subsection{To form the super-matrix using the eigenvector of all comparison matrices.}

The super matrix is a matrix that contains all the calculated eigenvectors for all the relations and matrices:

$$
W=\left(\begin{array}{cccc}
W_{11} & W_{12} & \ldots & W_{1 m} \\
W_{21} & W_{22} & \ldots & W_{2 m} \\
\ldots & \ldots & \ldots & \ldots \\
W_{m 1} & W_{m 2} & \ldots . & W_{m m}
\end{array}\right)
$$


Where: $W_{i j}$ is the calculated eigenvector for pairwise comparison matrix between cluster $\boldsymbol{i}$ elements and cluster $\boldsymbol{j}$ elements.

Then the weighted super-matrix will be calculated by normalizing all the columns of the super-matrix.

\subsection{To compute the final limit super-matrix.}

To obtain the final priorities, the weighted super-matrix should be raised to relatively high number of powers until all columns of the weighted super-matrix converge. This matrix is called limit super-matrix. The final priorities will be read from the limit super-matrix. They will be used in the additive or multiplicative priority calculation formula in order to find the final ranking for alternatives.

\subsection{Sensitivity Analysis.}

After obtaining the final results and priorities, the sensitivity analysis will be performed to find-out how much sensitive our results are to the change of the merit weights. In order to perform the sensitivity analysis, both additive and Multiplicative BOCR models will be used. This would be a what-if type of sensitivity analysis.

\subsection{Comparing with results drawn by the company.}

The final results will be compared to those obtained by the telecom company which uses Texas Instruments Matrix method to rank the tenderers. The data collected for this study are different than those in Texas Instruments method but the evaluators for both methods are the same persons. 


\section{Empirical Study}

The ANP model was applied to an industry case which was a tender to install and setup a VMS (Voice Messaging Service) value added service to a running GSM network operated by a relatively big mobile service provider telecom company.

The main purpose of this tender was to maximize revenue generation of voice communications in the company's network by providing VMS service to customers in order to increase the chance of a successful communication when a call fails and does not connect to the destination and provide benefit to the company out of the failed call attempts. The investment for the new voice message service system was forecasted to be relatively very low compared to the whole network value while the expected increase in revenue was forecasted to be around 10 percent of the yearly revenue.

The method that the company used to evaluate tenderers was Texas Instruments matrix method. The criteria for the evaluation were defined by brainstorming in an unorganized way. Each part of this matrix was completed by several people and finally, a ranking along with weights was extracted from this matrix.

In this study, the evaluation was done using ANP method by collecting data from raters using designed pairwise comparisons, following the steps described in methodology chapter. To obtain the criteria for the evaluation, Delphi method was used as described in details in the methodology. The expert panel in the Delphi method consisted of 6 persons: "Product Manager", a "Product Specialist", "Director of Product Marketing", "VAS (Value Added Service) Manager", "Director of Service Delivery" and "Procurement Manager". The empirical study was performed in the following steps: 


\subsection{To state the decision problem clearly.}

In this empirical study, it is: "To evaluate and select the tenderer for providing VMS system for the telecom company that provides the maximum value added profit with the minimum cost".

\subsection{To structure the problem.}

The problem was structured and the network was shaped completely in Methodology (Chapter 4.2) in order to illustrate the ANP method.

\subsection{Pairwise Comparisons.}

Using the structured problem and the network and relations between elements and clusters, questionnaires were designed in MS-Excel spreadsheets and forwarded to correspondent departments or persons to fill them out with their ideas about the relevant importance of two elements with regards to a control criterion and send them back. In this study the 9 point priority scale introduced by Saaty (1996) was used to measure the relative importance between paired elements. Table 5.1 shows the questionnaire sample for risks network which compares alternatives with regard to "Evidence of previous experience". In the pairwise comparisons, it is very important to state the question clearly for the participants and make sure they understand the main question in each questionnaire. For instance, the question here is "Which one of the two companies has more risk with regards to "Evidence of previous experience" and how much?". The other questionnaire samples are shown in Appendix 4. 
Table 5.1: Pair-wise Comparison of Alternatives with respect to "Evidence of Previous Experience" in Risks Sub-network

\begin{tabular}{|l|l|l|l|l|l|l|l|l|l|l|l|l|l|l|l|l|l|l|}
\hline Company A & 9 & 8 & 7 & 6 & 5 & 4 & 3 & 2 & 1 & 2 & 3 & 4 & 5 & 6 & 7 & 8 & 9 & Company B \\
\hline Company A & 9 & 8 & 7 & 6 & 5 & 4 & 3 & 2 & 1 & 2 & 3 & 4 & 5 & 6 & 7 & 8 & 9 & Company C \\
\hline Company A & 9 & 8 & 7 & 6 & 5 & 4 & 3 & 2 & 1 & 2 & 3 & 4 & 5 & 6 & 7 & 8 & 9 & Company D \\
\hline Company B & 9 & 8 & 7 & 6 & 5 & 4 & 3 & 2 & 1 & 2 & 3 & 4 & 5 & 6 & 7 & 8 & 9 & Company C \\
\hline Company B & 9 & 8 & 7 & 6 & 5 & 4 & 3 & 2 & 1 & 2 & 3 & 4 & 5 & 6 & 7 & 8 & 9 & Company D \\
\hline Company C & 9 & 8 & 7 & 6 & 5 & 4 & 3 & 2 & 1 & 2 & 3 & 4 & 5 & 6 & 7 & 8 & 9 & Company D \\
\hline
\end{tabular}

The questionnaires were answered by 16 raters and the total number of comparisons made by raters in this study was 510 comparisons as calculated in Chapter 4.2 in 69 different questionnaires. Each questionnaire was answered by a related qualifying person selected by the "Procurement Manager" of the company as the tender was going to be conducted under direct supervision of this department. The raters were asked to answer the questionnaires based on the category of the questionnaires. The questionnaires then were converted to the matrix form in order to do the calculations in next steps.

\subsection{Calculating Eigenvectors}

All the collected answers to the questionnaires were converted to the matrix form. Table 5.2 shows the converted matrix form of the questionnaire shown in Table 5.1 as an example. More examples of the matrices are shown in Appendix 4.

Table 5.2: Comparison Matrix for Alternatives with respect to "Evidence of Previous Experience" in Risks Sub-network

\begin{tabular}{lcccc}
\hline & Company A & Company B & Company C & Company D \\
\hline Company A & 1.0000 & 3.0000 & 5.0000 & 0.3333 \\
Company B & 0.3333 & 1.0000 & 4.0000 & 0.2500 \\
Company C & 0.2000 & 0.2500 & 1.0000 & 0.1667 \\
Company D & 3.0000 & 4.0000 & 6.0000 & 1.0000 \\
\hline
\end{tabular}


The eigenvectors were calculated for each matrix in order to find out the local priority of the elements and also to calculate the consistency ratio in the next step. As an example, the eigenvector of the matrix in Table $\mathbf{5 . 2}$ is shown in Table 5.3. It shows the local priorities of the alternatives with regards to "Evidence of Previous Experience" in Risks Sub-network. More eigenvector samples are attached in Appendix 4.

Table 5.3: Local Priority of the Alternatives with Respect to "Evidence of Previous Experience" in Risks Sub-network

\begin{tabular}{|l|l|}
\hline Company A & 0.2724 \\
\hline Company B & 0.1392 \\
\hline Company C & 0.0556 \\
\hline Company D & 0.5328 \\
\hline
\end{tabular}

The eigenvector calculations are illustrated in Appendix 5

\subsection{Consistency Check}

The next step in processing the data was to check the consistency ratio of the questionnaires. The inconsistent pair-wise comparisons should be evaluated again by the raters until they provide a consistent result for the comparison. The process to calculate the Consistency Ratio is given in Methodology chapter (4.5). In this study one questionnaire result had a consistency ratio of 0.13 which was greater than the maximum acceptable ratio of 0.1 suggested by Saaty (1996). So the raters were asked to revise their judgments and compare the elements again. Both inconsistent pair-wise comparison and the revised one are attached in Appendix 6. 


\subsection{Super-matrices}

In this empirical study, since the network is formed in BOCR model, there are totally 4 ANP networks to analyze. For each of Benefits, Opportunities, Costs and Risks network, an un-weighted super-matrix were formed using the calculated eigenvectors from the correspondent questionnaires. Then they were converted to Weighted Super-matrix using the cluster comparisons results (cluster matrices) and by normalizing each column of the matrix. The calculations for Risks sub-network as an example are shown below.

Table 5.4: Un-weighted Super-matrix for Risks sub-network

\begin{tabular}{|c|c|c|c|c|c|c|c|c|c|}
\hline & $\begin{array}{c}\text { Company } \\
\text { A }\end{array}$ & $\begin{array}{c}\text { Company } \\
\text { B }\end{array}$ & $\begin{array}{c}\text { Company } \\
\text { C }\end{array}$ & $\begin{array}{c}\text { Company } \\
\text { D }\end{array}$ & $\begin{array}{l}\text { Company } \\
\text { Profile }\end{array}$ & P M Cap & $\begin{array}{c}\text { Evidences } \\
\text { of ... }\end{array}$ & $\begin{array}{c}\text { Privacy } \\
\text { Info }\end{array}$ & $\begin{array}{c}\text { Alarm } \\
\text { Monitoring }\end{array}$ \\
\hline Company A & 1.0000 & 0.0000 & 0.0000 & 0.0000 & 0.0784 & 0.0448 & 0.2724 & 0.2500 & 0.3257 \\
\hline Company B & 0.0000 & 1.0000 & 0.0000 & 0.0000 & 0.0820 & 0.1597 & 0.1392 & 0.2500 & 0.1936 \\
\hline Company C & 0.0000 & 0.0000 & 1.0000 & 0.0000 & 0.4296 & 0.1845 & 0.0556 & 0.2500 & 0.1243 \\
\hline Company D & 0.0000 & 0.0000 & 0.0000 & 1.0000 & 0.4100 & 0.6110 & 0.5328 & 0.2500 & 0.3564 \\
\hline Company Profile & 0.0900 & 0.0665 & 0.5189 & 0.1273 & 1.0000 & 0.0000 & 0.0000 & 0.0000 & 0.0000 \\
\hline P M Cap & 0.0900 & 0.5295 & 0.2603 & 0.3969 & 0.0000 & 1.0000 & 0.0000 & 0.0000 & 0.0000 \\
\hline Evidences of ... & 0.5555 & 0.2255 & 0.0736 & 0.3969 & 0.0000 & 0.0000 & 1.0000 & 0.0000 & 0.0000 \\
\hline Privacy Info & 0.0937 & 0.0829 & 0.0736 & 0.0326 & 0.0000 & 0.0000 & 0.0000 & 1.0000 & 0.0000 \\
\hline Alarm Monitoring & 0.1708 & 0.0958 & 0.0736 & 0.0464 & 0.0000 & 0.0000 & 0.0000 & 0.0000 & 1.0000 \\
\hline
\end{tabular}

Table 5.5: Weighted Super-Matrix for Risks sub-network

\begin{tabular}{|c|c|c|c|c|c|c|c|c|c|}
\hline & $\begin{array}{c}\text { Company } \\
\text { A }\end{array}$ & $\begin{array}{c}\text { Company } \\
\text { B }\end{array}$ & $\begin{array}{c}\text { Company } \\
\text { C }\end{array}$ & $\begin{array}{c}\text { Company } \\
\text { D }\end{array}$ & $\begin{array}{l}\text { Company } \\
\text { Profile }\end{array}$ & P M Cap & $\begin{array}{c}\text { Evidences } \\
\text { of ... }\end{array}$ & $\begin{array}{c}\text { Privacy } \\
\text { Info }\end{array}$ & $\begin{array}{c}\text { Alarm } \\
\text { Monitoring }\end{array}$ \\
\hline Company A & 0.5000 & 0.0000 & 0.0000 & 0.0000 & 0.0392 & 0.0224 & 0.1362 & 0.1250 & 0.1629 \\
\hline Company B & 0.0000 & 0.5000 & 0.0000 & 0.0000 & 0.0410 & 0.0799 & 0.0696 & 0.1250 & 0.0968 \\
\hline Company C & 0.0000 & 0.0000 & 0.5000 & 0.0000 & 0.2148 & 0.0923 & 0.0278 & 0.1250 & 0.0622 \\
\hline Company D & 0.0000 & 0.0000 & 0.0000 & 0.5000 & 0.2050 & 0.3055 & 0.2664 & 0.1250 & 0.1782 \\
\hline Company Profile & 0.0450 & 0.0332 & 0.2595 & 0.0636 & 0.5000 & 0.0000 & 0.0000 & 0.0000 & 0.0000 \\
\hline P M Cap & 0.0450 & 0.2647 & 0.1302 & 0.1984 & 0.0000 & 0.5000 & 0.0000 & 0.0000 & 0.0000 \\
\hline Evidences of ... & 0.2778 & 0.1127 & 0.0368 & 0.1984 & 0.0000 & 0.0000 & 0.5000 & 0.0000 & 0.0000 \\
\hline Privacy Info & 0.0469 & 0.0414 & 0.0368 & 0.0163 & 0.0000 & 0.0000 & 0.0000 & 0.5000 & 0.0000 \\
\hline Alarm Monitoring & 0.0854 & 0.0479 & 0.0368 & 0.0232 & 0.0000 & 0.0000 & 0.0000 & 0.0000 & 0.5000 \\
\hline
\end{tabular}




\subsection{Calculating Limit Super-matrices and find the final results.}

In this step, each of the weighted super-matrices calculated in the previous step for each of the BOCR merits were raised to a relatively large power until all the columns of the matrices were converged and became stable. Table $\mathbf{5 . 6}$ shows the limit super-matrix for the weighted super-matrix shown in Table 5.5.

Table 5.6: Limit Super-matrix for Risks Sub-network

\begin{tabular}{|c|c|c|c|c|c|c|c|c|c|}
\hline & $\begin{array}{l}\text { Company } \\
\text { A }\end{array}$ & $\begin{array}{c}\text { Company } \\
\text { B }\end{array}$ & $\begin{array}{c}\text { Company } \\
\text { C }\end{array}$ & $\begin{array}{c}\text { Company } \\
\text { D }\end{array}$ & $\begin{array}{l}\text { Company } \\
\text { Profile }\end{array}$ & P M Cap & $\begin{array}{c}\text { Evidences } \\
\text { of ... }\end{array}$ & $\begin{array}{l}\text { Privacy } \\
\text { Info }\end{array}$ & $\begin{array}{c}\text { Alarm } \\
\text { Monitoring }\end{array}$ \\
\hline Company A & 0.0809 & 0.0809 & 0.0809 & 0.0809 & 0.0809 & 0.0809 & 0.0809 & 0.0809 & 0.0809 \\
\hline Company B & 0.0731 & 0.0731 & 0.0731 & 0.0731 & 0.0731 & 0.0731 & 0.0731 & 0.0731 & 0.0731 \\
\hline Company C & 0.0927 & 0.0927 & 0.0927 & 0.0927 & 0.0927 & 0.0927 & 0.0927 & 0.0927 & 0.0927 \\
\hline Company D & 0.2533 & 0.2533 & 0.2533 & 0.2533 & 0.2533 & 0.2533 & 0.2533 & 0.2533 & 0.2533 \\
\hline Company Profile & 0.0925 & 0.0925 & 0.0925 & 0.0925 & 0.0925 & 0.0925 & 0.0925 & 0.0925 & 0.0925 \\
\hline P M Cap & 0.1707 & 0.1707 & 0.1707 & 0.1707 & 0.1707 & 0.1707 & 0.1707 & 0.1707 & 0.1707 \\
\hline Evidences of ... & 0.1688 & 0.1688 & 0.1688 & 0.1688 & 0.1688 & 0.1688 & 0.1688 & 0.1688 & 0.1688 \\
\hline Privacy Info & 0.0287 & 0.0287 & 0.0287 & 0.0287 & 0.0287 & 0.0287 & 0.0287 & 0.0287 & 0.0287 \\
\hline Alarm Monitoring & 0.0394 & 0.0394 & 0.0394 & 0.0394 & 0.0394 & 0.0394 & 0.0394 & 0.0394 & 0.0394 \\
\hline
\end{tabular}

The ranking and priorities of the alternatives in each of Benefits, Opportunities, Costs and Risks sub-network can be read from the correspondent limit super-matrix. For instance, the priorities of the alternatives in the risks subnetwork from Table 5.6 are shown in Table 5.7 along with normalized priorities and Ideal priorities. Ideal priorities are calculated by dividing the raw priority score of each alternative to the highest raw score so that the priority of the best alternative under risks sub-network is 1 and others get their proper proportions less than 1. 
Table 5.7: Priorities of Alternatives in Risks Sub-Network

\begin{tabular}{cccc}
\hline Alternatives & Raw & Normal & Ideal \\
\hline Company A & 0.0809 & 0.1618 & 0.3193 \\
Company B & 0.0731 & 0.1463 & 0.2887 \\
Company C & 0.0927 & 0.1853 & 0.3657 \\
Company D & 0.2533 & 0.5066 & 1.0000 \\
\hline
\end{tabular}

Following the same procedure, the priorities of the alternatives in other subnetworks were calculated. These priorities were used in Multiplicative and Additive formula to calculate the final rankings.

Table 5.8: Priorities of Alternatives in Benefits Sub-Network

\begin{tabular}{lccc}
\hline Alternatives & Raw & Normal & Ideal \\
\hline Company A & 0.1256 & 0.2512 & 0.8093 \\
Company B & 0.1552 & 0.3104 & 1.0000 \\
Company C & 0.1429 & 0.2858 & 0.9208 \\
Company D & 0.0763 & 0.1526 & 0.4918 \\
\hline
\end{tabular}

Table 5.9: Priorities of Alternatives in Opportunities Sub-Network

\begin{tabular}{cccc}
\hline Alternatives & Raw & Normal & Ideal \\
\hline Company A & 0.1202 & 0.2405 & 0.7068 \\
Company B & 0.1701 & 0.3403 & 1.0000 \\
Company C & 0.1306 & 0.2612 & 0.7676 \\
Company D & 0.0790 & 0.1581 & 0.4646 \\
\hline
\end{tabular}

Table 5.10: Priorities of Alternatives in Costs Sub-Network

\begin{tabular}{cccc}
\hline Alternatives & Raw & Normal & Ideal \\
\hline Company A & 0.1606 & 0.3211 & 0.9249 \\
Company B & 0.0748 & 0.1497 & 0.4312 \\
Company C & 0.0910 & 0.1821 & 0.5245 \\
Company D & 0.1736 & 0.3472 & 1.0000 \\
\hline
\end{tabular}


To calculate the final priorities of alternatives all normal local priorities have been used with the BOCR weights that were calculated in Table 4.9. Multiplicative priorities are shown in Table 5.11 and additive priorities are shown in Table 5.12.

Table 5.11: Priorities of the Alternatives using Multiplicative Formula

\begin{tabular}{l|ccc|} 
Alternatives & Ideal & Normal & Raw \\
\hline Company A & 0.2411 & 0.1395 & 8.2605 \\
Company B & 1.0000 & 0.5786 & 34.2632 \\
Company C & 0.4587 & 0.2654 & 15.7180 \\
Company D & 0.0284 & 0.0165 & 0.9746 \\
\cline { 2 - 4 }
\end{tabular}

Table 5.12: Priorities of the Alternatives using Additive Formula

\begin{tabular}{l|ccc|} 
Alternatives & Ideal & Normal & Raw \\
\hline Company A & 0.5199 & 0.2251 & 0.0968 \\
Company B & 1.0000 & 0.4330 & 0.1862 \\
Company C & 0.7797 & 0.3376 & 0.1451 \\
Company D & -0.0100 & -0.0043 & -0.0019 \\
\cline { 2 - 4 }
\end{tabular}

All the results are shown together in Table 5.13 by the normal priorities of alternatives along with the alternatives rankings in each sub-network in parenthesis. Since Benefits and Opportunities have positive contribution towards the goal, the lower rank in these two merits indicates the better alternative while in Costs and Risks merit that have negative effect on the goal, lower rank means the worse alternative. While both additive and multiplicative formulas results reflect the same ranking of the alternatives, the additive formula shows the actual contribution of the alternatives towards the goal. In this study, from additive results it can be concluded that with the current weights of the $B, O, C, R$, Company $C$ has no overall positive contribution towards the goal while from multiplicative results, it can just be concluded that company $D$ has the lowest overall rank. 
Table 5.13: Normal Priorities for Alternatives and Final Rankings in Two Methods

\begin{tabular}{llcllcc}
\hline & Benefits & Opportunities & Costs & Risks & Multiplicative & Additive \\
\hline Company A & $0.2512(3)$ & $0.2405(3)$ & $0.3211(3)$ & $0.1618(2)$ & $0.1395(3)$ & $0.2251(3)$ \\
Company B & $0.3104(1)$ & $0.3403(1)$ & $0.1497(1)$ & $0.1463(1)$ & $0.5786(1)$ & $0.4330(1)$ \\
Company C & $0.2858(2)$ & $0.2612(2)$ & $0.1821(2)$ & $0.1853(3)$ & $0.2654(2)$ & $0.3376(2)$ \\
Company D & $0.1526(4)$ & $0.1581(4)$ & $0.3472(4)$ & $0.5066(4)$ & $0.0165(4)$ & $-0.0043(4)$ \\
\hline
\end{tabular}

\subsection{Sensitivity Analysis}

Sensitivity analysis is widely used for model assessment in order to measure the stability of the results to the change of the inputs and see if these changes will change the order of the alternatives. The sensitivity analysis was done using additive formula because in multiplicative formula, the priorities of BOCR cancel out each other.

To perform the sensitivity analysis, the weights of Benefits, Opportunities, Costs and Risks merits at the first layer of the model were changed, once at a time and the calculations were done to obtain the priority and ranking of tenderers at different levels of $B, O, C$ and $R$. The changing range is selected to be between 0 and 1 in 0.05 steps. Figure 5.2 to Figure 5.4 are the sensitivity analysis with respect to $B, O, C$ and $R$ respectively. The transition points in the graphs are calculated and marked. The transition point indicates a point at which the ranking of an alternative changes from the original value when the weights of $B, O, C$ or $R$ are changed. The original weights of $B, O, C$ and $R$ are also pointed in the graphs. 


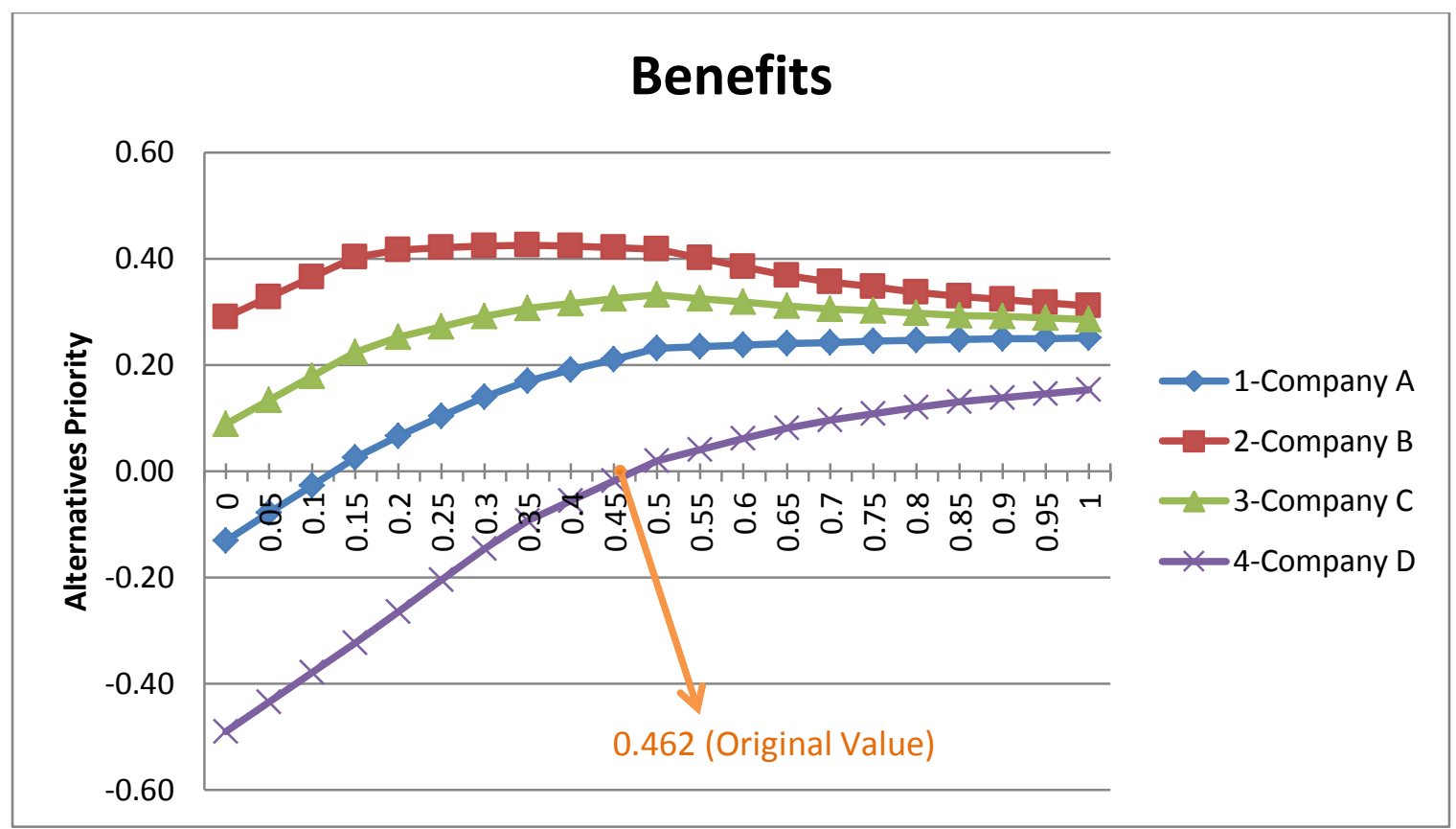

Figure 5.1: Sensitivity Analysis With Regards to Benefits

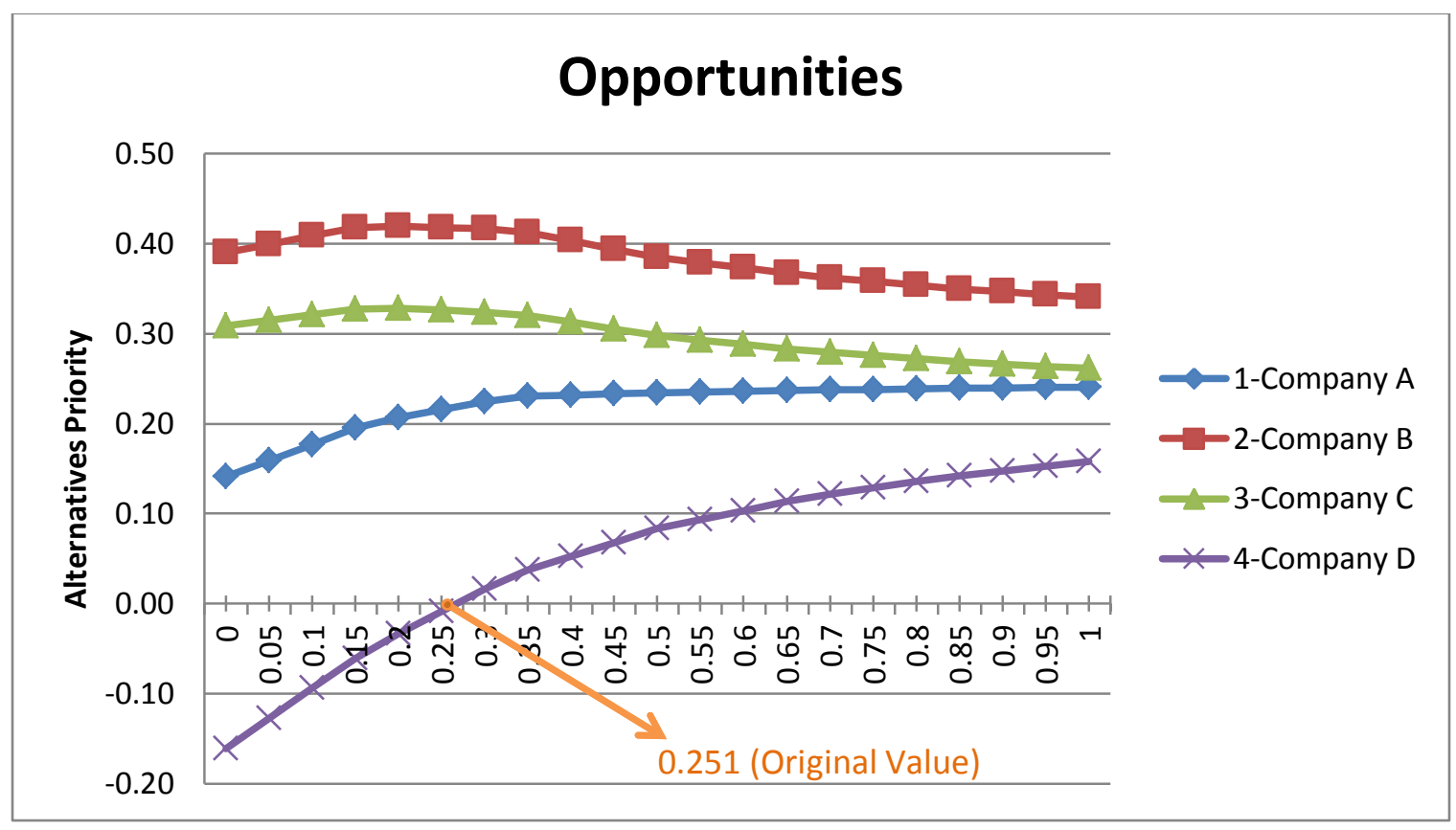

Figure 5.2: Sensitivity Analysis With Regards to Opportunities 


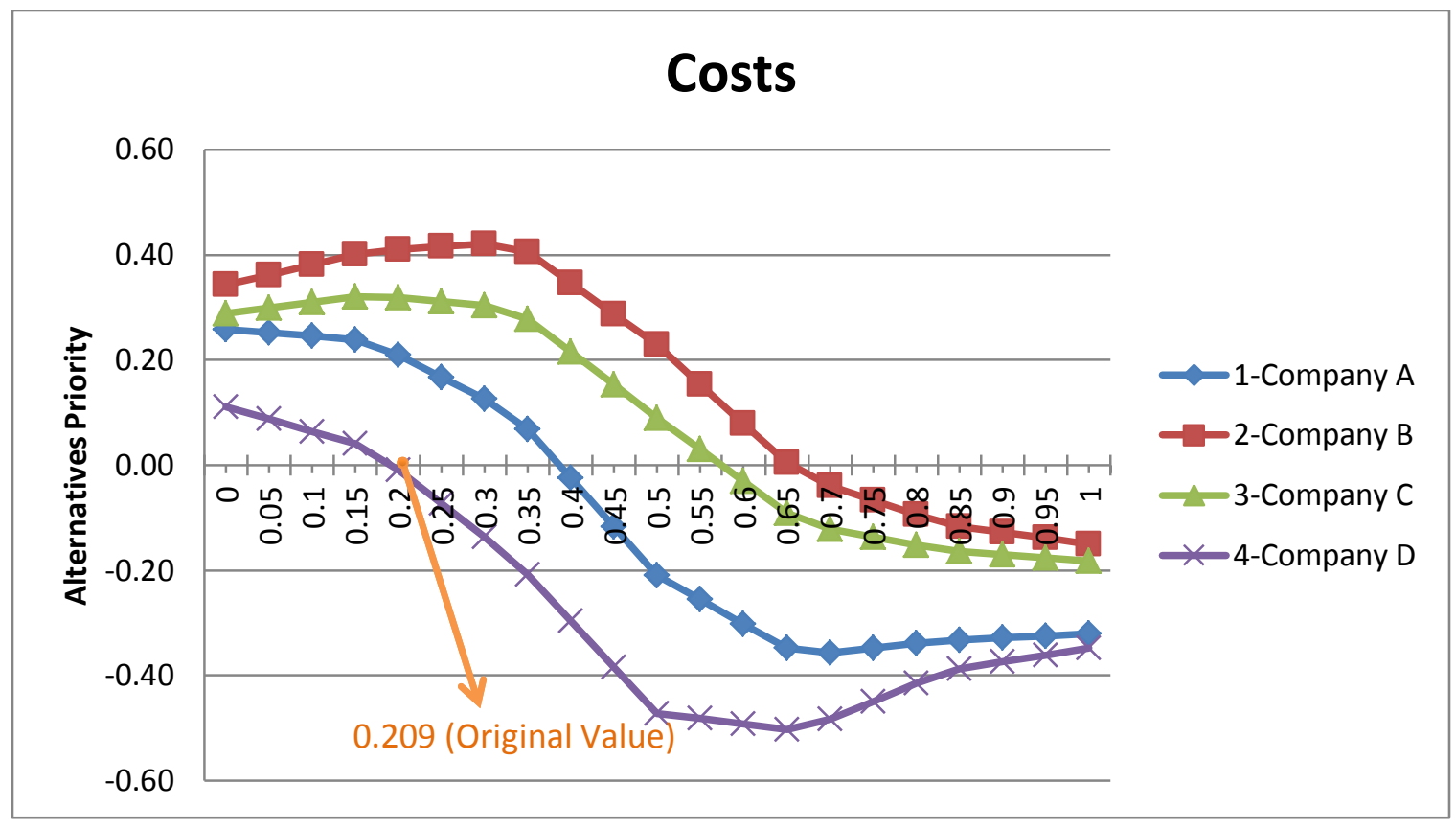

Figure 5.3: Sensitivity Analysis With Regards to Costs

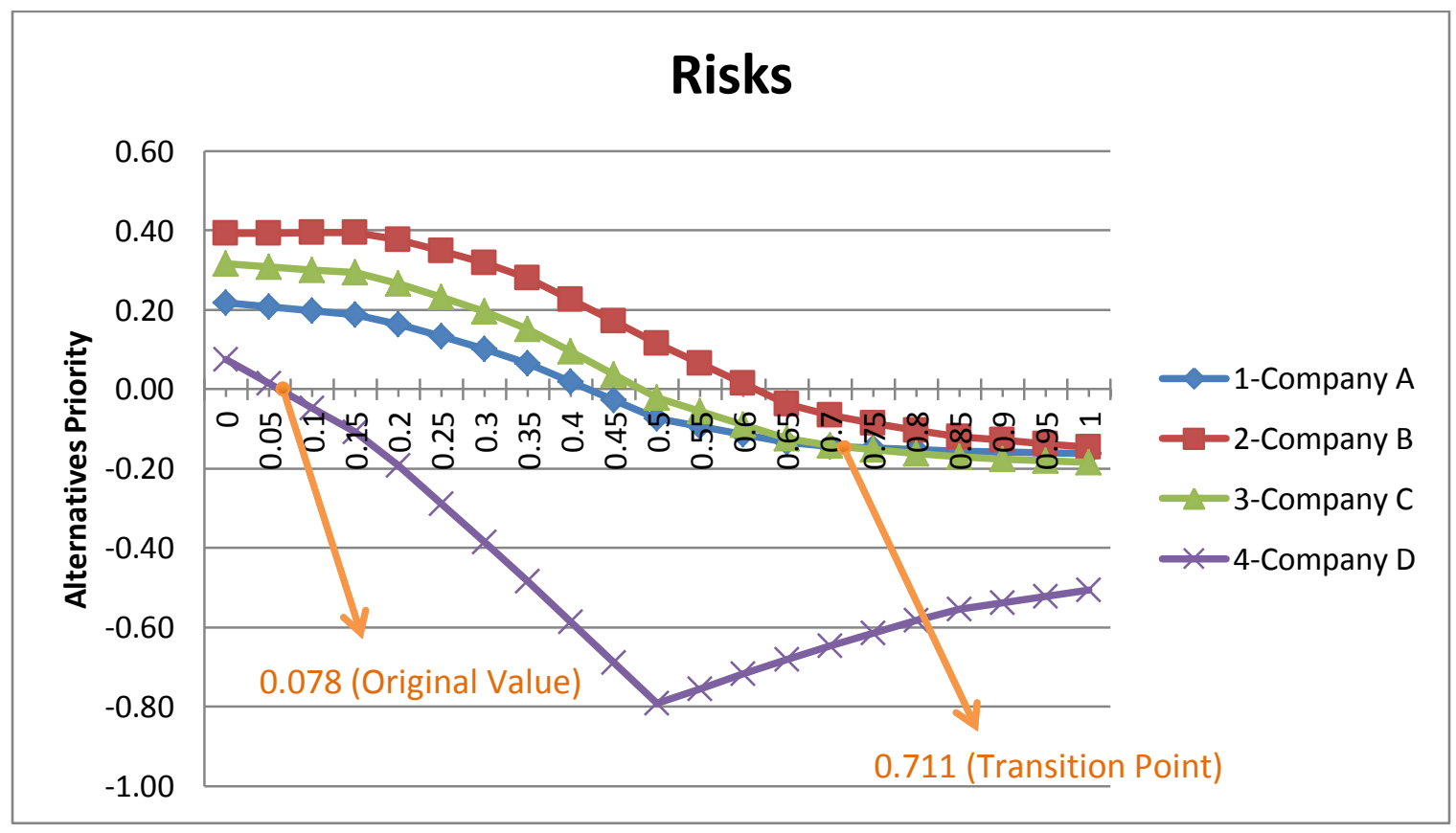

Figure 5.4: Sensitivity Analysis With Regards to Risks

From charts, it is obvious that Company $B$ is the most desirable alternative, no matter how much the priorities of $B, O, C$ and $R$ are changed. On the other 
hand, Company $D$ has the lowest rank regardless of the weight of the $B, O, C$ and $R$ merits. Company $C$ remains in the $2^{\text {nd }}$ rank and Company $A$ keeps the $3^{\text {rd }}$ rank when the priority of Benefits, Opportunities or Costs are changing. However, in Risks sensitivity analysis, the ranking of these two companies change when the Risks priority increases to 0.711 and Company $A$ becomes the $2^{\text {nd }}$ rank after this point and Company $\mathrm{C}$ becomes the $3^{\text {rd }}$ rank. This point is shown as "Transition Point" in Figure 5.4.

In Costs and Risks sensitivity graphs, when the priority of Costs or Risks are increased to $65 \%$ and more, overall priorities of alternatives became negative that means when the company puts more emphasis on Risks or Costs and less on Benefits and Opportunities, the criteria that have negative impact towards the goal will get much more weight and in result, all the companies will have negative impact on the goal.

\subsection{Comparing the ANP results with TI Matrix Method}

The results of this study show that Company $B$ is the winner of the tender following by Company $\mathrm{C}$, Company $\mathrm{A}$ and Company $\mathrm{D}$. The results that were obtained by the company's method which was Texas Instruments Matrix Method are shown in Table 5.14. This result is the same as the ANP results in ranking the tenderers but the weights are different comparing to the priorities obtained in the proposed ANP model. In order to compare the results, the TI method results were normalized and compared with multiplicative and additive ANP. They are shown in Table $\mathbf{5 . 1 5}$ and a comparative graph is shown in Figure 5.5.

It can be observed that in TI method, all the companies have close priorities while in multiplicative ANP, their weights are quite different and this difference is adjusted in additive ANP by considering the weights of B,O,C,R into account. It is observed that only in additive formula, alternatives can have a negative priority which in this empirical study Company $D$ has negative priority. 
Table 5.14: Evaluation Results Obtained from TI Matrix Method by the Company

\begin{tabular}{|c|c|c|c|}
\hline & & & Rank \\
\hline \multirow{2}{*}{ Company A } & Weighted & 2090 & \multirow{2}{*}{3} \\
\hline & Out of 20 & 15.26 & \\
\hline \multirow{2}{*}{ Company B } & Weighted & 2445 & \multirow{2}{*}{1} \\
\hline & Out of 20 & 17.85 & \\
\hline \multirow{2}{*}{ Company C } & Weighted & 2247.5 & \multirow{2}{*}{2} \\
\hline & Out of 20 & 16.41 & \\
\hline \multirow{2}{*}{ Company D } & Weighted & 1592.5 & \multirow{2}{*}{4} \\
\hline & Out of 20 & 11.62 & \\
\hline \multicolumn{2}{|c|}{ Total Weight } & 137.0 & \\
\hline
\end{tabular}

Table 5.15: Results of $\mathrm{TI}$ and ANP.

\begin{tabular}{lccc}
\hline & TI & ANP Multiplicative & ANP Additive \\
\hline Company A & 0.2496 & 0.1395 & 0.2251 \\
Company B & 0.2920 & 0.5786 & 0.4330 \\
Company C & 0.2684 & 0.2654 & 0.3376 \\
Company D & 0.1901 & 0.0165 & -0.0043 \\
\hline
\end{tabular}

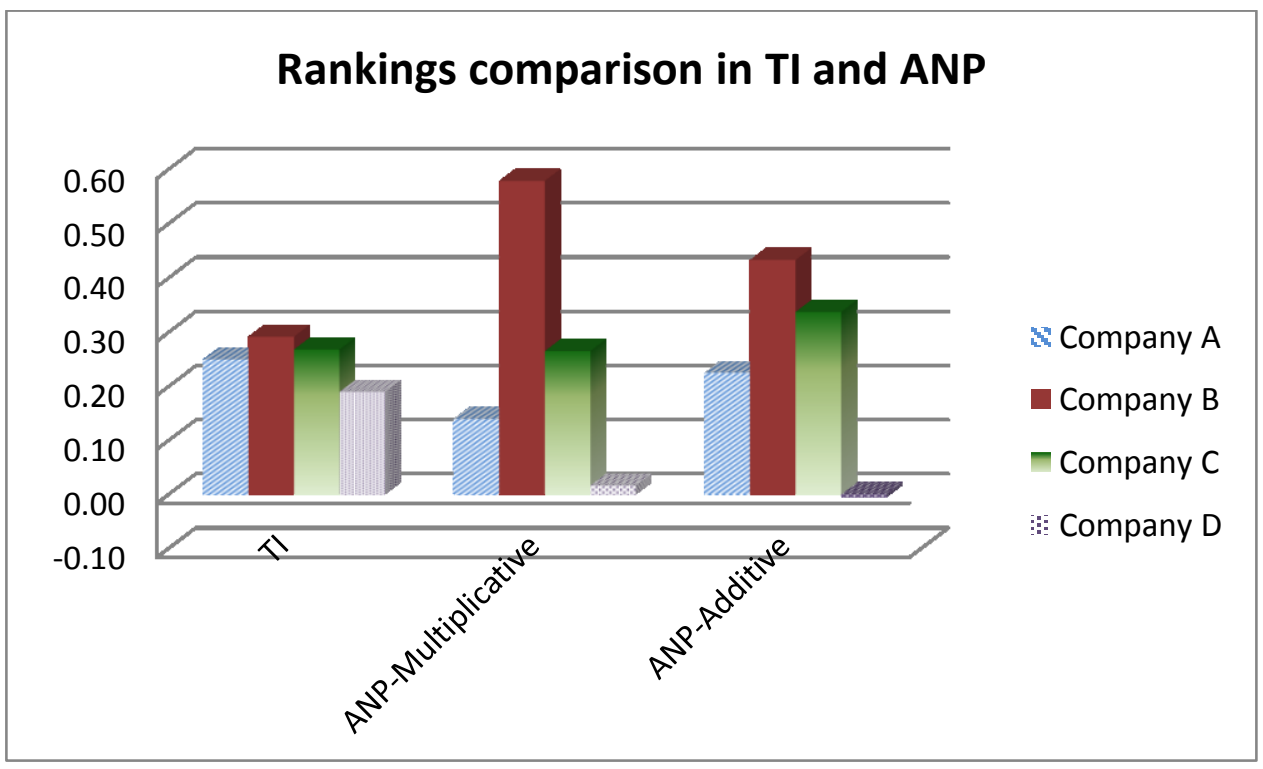

Figure 5.5: $\mathrm{TI}$ and ANP results comparison 
It shows that company $D$ will not contribute towards the goal with the given weights to the $B, O, C, R$ merits while the $\mathrm{TI}$ method does not show this fact and just ranks it as the last desirable company.

There are several reasons to describe the difference in the weights. The most important one is that in TI Matrix Method, blank scores for a criterion is allowed and this may result in inconsistent evaluation. Although in this case study, rankings are the same for both methods, they could have been different if there were several blank scores in the TI Matrix evaluation.

The weights in the $\mathrm{TI}$ Matrix Method are given to the criteria in an unorganized way while in ANP, the weights are given to the categories $(B, O, C, R)$ and also based on the comparisons, that is, a relative importance of the alternatives are considered for the evaluation. It makes the weighting more reasonable. 


\section{Conclusion and Recommendations for Future Research}

\subsection{Conclusion}

Large companies outsource several services that they need in order to run the business. The ideal contractor should be identified through conducting a tender. Tender evaluation directly influences the large enterprises performance and in result, their benefit. Therefore, it needs to be done in the best way possible. It is a complex multi-criteria multi-person process and involves several quantitative and qualitative criteria.

Defining the criteria for the evaluation purpose is a key factor to the evaluation success which is missing in most of the supplier selection studies in the literature. A model can be appropriate if the criteria of the model are selected appropriately. This study contributed to the field of tender evaluation by achieving the followings:

- A set of important criteria were defined for the tender evaluation in telecommunication industry in general and a set for the Voice Message System implementation in specific, using Delphi method and a panel of experts in this area. The set of criteria can be used in general for tender evaluation purpose in Telecommunication companies.

- A BOCR Analytic Network Process model was developed for tender evaluation in a telecommunication company.

- The data were collected from an ongoing tender in a GSM mobile service provider in the Middle-East using pairwise comparisons questionnaires.

- The results of the proposed model were compared to the TI Matrix method results and they found to be a match in ranking the alternatives to the results of the TI Matrix method that was used by the company for the evaluation purpose. However, the weights of the alternatives are different in 2 methods.

- The sensitivity analysis was performed and it was shown that the results were stable and the decision making model was robust. 


\subsection{Further Studies}

In the decision making process, there are cases that more than one decision maker is evaluating a set of criteria. In such situations, the geometric mean of the different decisions is used but there are cases that the decisions of the different persons are completely different or there are some outlier data from some of the decision makers. Dealing with such data and extracting the most appropriate result could be a challenging and interesting subject for further studies.

Another part that needs further work is the way that criteria are assigned to the merits or clusters. Some of the criteria could belong to more than one merit or cluster. A study about how to deal with such criteria would be a step forward in improving the model. 


\section{References}

1. Al-Harbi, Kamal M. Al-Subhi. (2001). Application of the AHP in project management. International Journal of Project Management, 19(1), 19-27. doi: http://dx.doi.org/10.1016/S0263-7863(99)00038-1

2. Azizi, M., Amiri, S., \& Modarres, M. (2005). Using Anp and Bocr Structure for Location Analysis of Plywood and Veneer Industry Plants, the Case of Iran. Journal of the Institute of Wood Science, 17(1), 24-33.

3. Barbarosoglu, Gulay; Yazgac, Tulin. (1997). An application of the analytic hierarchy process to the supplier selection problem. Production and Inventory Management Journal, 38(1), 1421.

4. Bayazit, Ozden, \& Karpak, Birsen. (2007). An analytical network process-based framework for successful total quality management (TQM): An assessment of Turkish manufacturing industry readiness. International Journal of Production Economics, 105(1), 79-96. doi: http://dx.doi.org/10.1016/j.ijpe.2005.12.009

5. Benyoucef, Lyès, Ding, Hongwei, \& Xie, Xiaolan. (2003). Supplier selection problem: Selection criteria and methods. INRIA LORRAINE(4726).

6. Bhutta, Khurrum S., \& Huq, Faizul. (2002). Supplier selection problem: a comparison of the total cost of ownership and analytic hierarchy process approaches. Supply Chain Management: An International Journal, 7(3), 10.

7. Buffa, Frank P., \& Jackson, W.M. (1983). A Goal Programming Model for Purchase Planning. Journal of Purchasing and Materials Management, 19(2).

8. Cheng, Eddie W. L., \& Heng, Li. (2004). Contractor selection using the analytic network process. Construction Management \& Economics, 22(10), 1021-1032. doi: 10.1080/0144619042000202852

9. Dağdeviren, Metin, Yüksel, İhsan, \& Kurt, Mustafa. (2008). A fuzzy analytic network process (ANP) model to identify faulty behavior risk (FBR) in work system. Safety Science, 46(5), 771783. doi: http://dx.doi.org/10.1016/i.ssci.2007.02.002

10. Das, Shaswata, \& Chakraborty, Shankar. (2011). Selection of non-traditional machining processes using analytic network process. Journal of Manufacturing Systems, 30(1), 41-53. doi: http://dx.doi.org/10.1016/j.jmsy.2011.03.003

11. de Boer, Luitzen, Labro, Eva, \& Morlacchi, Pierangela. (2001). A review of methods supporting supplier selection. European Journal of Purchasing \& Supply Management, 7(2), 75-89. doi: http://dx.doi.org/10.1016/S0969-7012(00)00028-9

12. Demirtas, Ezgi Aktar, \& Üstün, Özden. (2008). An integrated multiobjective decision making process for supplier selection and order allocation. Omega, 36(1), 76-90. doi: http://dx.doi.org/10.1016/j.omega.2005.11.003

13. Erdoğmuş, Şenol, Aras, Haydar, \& Koç, Eylem. (2006). Evaluation of alternative fuels for residential heating in Turkey using analytic network process (ANP) with group decisionmaking. Renewable and Sustainable Energy Reviews, 10(3), 269-279. doi: http://dx.doi.org/10.1016/i.rser.2004.09.003

14. Ergu, Daji, Kou, Gang, Shi, Yong, \& Shi, Yu. (2009). Analytic network process in risk assessment and decision analysis. Computers \& Operations Research(0). doi: http://dx.doi.org/10.1016/j.cor.2011.03.005

15. Eshtehardian, Ehsan, Ghodousi, Parviz, \& Bejanpour, Azadeh. (2013). Using ANP and AHP for the supplier selection in the construction and civil engineering companies; Case study of 
Iranian company. KSCE Journal of Civil Engineering, 17(2), 262-270. doi: 10.1007/s12205013-1141-z

16. Fong, S.P., \& Choi, S.K. (2000). Final contractor selection using the analytical hierarchy process. Construction Management \& Economics, 18(5), 11.

17. Gregory, R.E. (1986). Source Selection: A Matrix Approach. Journal of Purchasing and Material Management, 22(2), 24-29.

18. Hartman, Francis T., Krahn, Jennifer, \& Skulmoski, Gregory J. (2007). The Delphi Method for Graduate Research. Journal of Information Technology Education 6.

19. Hill, Ronald Paul, \& Nydick, Robert L. (1992). Using the analytic hierarchy process to structure the supplier selection procedure. International Journal of Purchasing and Materials Management, 28(2), 31-36.

20. Hosseini, L., Tavakkoli-Moghaddam, R., Vahdani, B., Mousavi, S. M., \& Kia, R. (2013). Using the Analytical Network Process to Select the Best Strategy for Reducing Risks in a Supply Chain. Journal of Engineering, 2013, 9. doi: http://dx.doi.org/10.1155/2013/375628

21. Junzo Watada, Toyohide Watanabe, Gloria Phillips-Wren, Robert J. Howlett, Lakhmi C. Jain. (2012). Intelligent Decision Technologies. New York Springer.

22. Liberatore, Matthew J., \& Nydick, Robert L. (2008). The analytic hierarchy process in medical and health care decision making: A literature review. European Journal of Operational Research, 189(1), 194-207. doi: http://dx.doi.org/10.1016/j.ejor.2007.05.001

23. Luo, F. Z., Tang, X. L., \& Zhao, F. T. (2005). Application of multi-objective programming in the evaluation of bids for engineering projects.

24. Moore, D.L., \& Fearon, H.E. (1973). Computer-Assisted Decision-Making in Purchasing. Journal of Purchasing and, 9(4), 21.

25. Niemira, Michael P., \& Saaty, Thomas L. (2004). An Analytic Network Process model for financial-crisis forecasting. International Journal of Forecasting, 20(4), 573-587. doi: http://dx.doi.org/10.1016/i.ijforecast.2003.09.013

26. Özdağoğlu, Aşkın. (2012). A multi-criteria decision-making methodology on the selection of facility location: fuzzy ANP. The International Journal of Advanced Manufacturing Technology, 59(5-8), 787-803.

27. Saaty, Thomas L. (1980). The analytic hierarchy process. New York: McGraw-Hill.

28. Saaty, Thomas L. (1990). How to make a decision: The analytic hierarchy process. European Journal of Operational Research, 48, 9-26.

29. Saaty, Thomas L. (1996). Decision Making with Dependence and Feedback: The Analytic Network Process. Pittsburgh, Pennsylvania: RWS Publications.

30. Saaty, Thomas L. (2001). Decision Making with Dependence and Feedback: The Analytic Network Process (Second ed.). Pittsburgh, USA: RWS Publications.

31. Saaty, Thomas L. (2004a). Decision making - the Analytic Hierarchy and Network Processes (AHP/ANP). Journal of Systems Science and Systems Engineering, 13(1), 1-35. doi: 10.1007/s11518-006-0151-5

32. Saaty, Thomas L. (2004b). Fundamentals of the analytic network process - Dependence and feedback in decision-making with a single network. Journal of Systems Science and Systems Engineering, 13(2), 129-157. doi: http://dx.doi.org/10.1007\%2Fs11518-006-0158-y

33. Saaty, Thomas L. (2006). Decision making with the analytic network process economic, political, social and technological applications with benefits, opportunities, costs and risks. New York: Springer.

34. Saaty, Thomas L., \& Vargas, Luis G. (2012). Models, Methods, Concepts \& Applications of the Analytic Hierarchy Process (2nd ed.): Springer US. 
35. Sarkis, Joseph ; Sundarraj, R.P. . (2005). Evaluation of Enterprise Information Technologies: A Decision Model for High-Level Consideration of Strategic and Operational Issues. IEEE Transactions on Systems, Man., and Cybernetics, Part C: Applications and Reviews, 1-14.

36. Sevkli, Mehmet, Oztekin, Asil, Uysal, Ozgur, Torlak, Gökhan, Turkyilmaz, Ali, \& Delen, Dursun. (2012). Development of a fuzzy ANP based SWOT analysis for the airline industry in Turkey. Expert Systems with Applications, 39(1), 14-24. doi: http://dx.doi.org/10.1016/i.eswa.2011.06.047

37. Taslicali, Ali Kamil, \& Ercan, Sami. (2006). THE ANALYTIC HIERARCHY \& THE ANALYTIC NETWORK PROCESSES IN MULTICRITERIA DECISION MAKING: A COMPARATIVE STUDY. Journal of Aeronautics \& Space Technologies / Havacilik ve Uzay Teknolojileri Dergisi, 2(4), 55-65.

38. Thompson, K. N. (1990). Vendor Profile Analysis. Journal of Purchasing and Materials Management, 1(26), 8.

39. Timmerman, E. (1986). An approach to vendor performance evaluation. Journal of Purchasing and Supply Management, 1, 27-32.

40. Tran, Liem T., Knight, C. Gregory, O'Neill, Robert V., \& Smith, Elizabeth R. (2004). Integrated Environmental Assessment of the Mid-Atlantic Region with Analytical Network Process. Environmental Monitoring and Assessment, 94(1-3), 263-277. doi: http://dx.doi.org/10.1023/B:EMAS.0000016893.77348.67

41. Tsai, Wen-Chin. (1999). A Procedure for the Supplier Evaluation Problem Under Risk using Fuzzy Sets. Alabama: ProQuest Dissertations \&Theses (PQDT).

42. Vaidya, Omkarprasad S., \& Kumar, Sushil. (2006). Analytic hierarchy process: An overview of applications. European Journal of Operational Research, 169(1), 1-29. doi: http://dx.doi.org/10.1016/j.ejor.2004.04.028

43. Viglas, Konstantinos, Fitsilis, Panos, \& Kameas, Achilles. (2011). An Integrated Approach for Selecting Information Systems: A Case Study. Technology and Investment, 2(2), 142-153.

44. Voulgaridou, Dimitra, Kirytopoulos, Konstantinos, \& Leopoulos, Vrassidas. (2009). An analytic network process approach for sales forecasting. Operational Research, 9(1), 35-53. doi: http://dx.doi.org/10.1007/s12351-008-0026-2

45. Weber, C. A., \& Current, J. R. (1991). Vendor Selection Criteria and Methods. European Journal of Operational Research, 50(1), 2-18.

46. Yang, Y. H., Hui, Y. V., Leung, L. C., \& Chen, G. (2010). An analytic network process approach to the selection of logistics service providers for air cargo. The Journal of the Operational Research Society, 61(9), 1365-1376. doi: http://dx.doi.org/10.1057/jors.2009.111

47. Yazdani-Chamzini, Abdolreza, \& Yakhchali, Siamak Haji. (2012). Tunnel Boring Machine (TBM) selection using fuzzy multicriteria decision making methods. Tunnelling and Underground Space Technology, 30(0), 194-204. doi: http://dx.doi.org/10.1016/j.tust.2012.02.021

48. Yong, Zhao, \& Chunyan, Shao. (2010). The Application of the Analytic Network Process in Evaluating Assets Management of the Institution of Higher Education. International Journal of Business and Management, 5(11), 236-243.

49. Zenz, G. (1981). Purchasing and the management of Materials: Wiley, New York.

50. Zhang, Z., \& Lei, J. (2004). Evolution of Supplier Selection Criteria and Methods. Paper presented at the The Second Globelics Conference Innovation Systems and Development: Emerging Opportunities and Challenges, Beijing, China. 


\section{Appendices}

\section{Appendix 1: The questionnaires and results of the Delphi main criteria selection.}

The email sent to the experts to ask them for the participation in the first Delphi survey to define the main criteria.

Thank you for participating in this Delphi survey on the criteria selection for the tender evaluation process in the company. This questionnaire round is the first of up to three rounds of the survey. Please try to provide as many answers as you can. You will have the opportunity to revise your answers with subsequent rounds of the survey. In these surveys, you will be asked to develop the main criteria important to the tender evaluation in general and also those that are important to the VMS (Voice Message System) tender that is going to be conducted in near future. You may provide as many criteria as you think is necessary to be considered in the evaluation process. Where appropriate, a space is also provided for you to comment on the underlying reasons for your responses.

Once responses were received from all panelists, the findings will be collated and summarized and the $2^{\text {nd }}$ questionnaire will be formulated. You should receive this in the next few days. I would like to assure you that your participation in the survey and your individual responses will be strictly confidential and will not be divulged to any outside party, including other panelists.

The questionnaire form is shared with you on Google Drive under the name: "Delphi_Main”. You can access the file by visiting: http://drive.google.com and log in using your Google account username and password. You may fill it out online and the answers will be available to me immediately. Please reply to this email once you finished this round.

Kind regards 
Questionnaire and Answers sample for the $1^{\text {st }}$ iteration of Delphi criteria selection to define the main criteria.

\begin{tabular}{|l|l|}
\hline Q) & $\begin{array}{l}\text { What are the main criteria for the tender evaluation if you need to outsource a } \\
\text { service for the company? }\end{array}$ \\
\hline & Please specify at least 10 criteria \\
\hline & ANSWER: \\
\hline 1 & Price \\
\hline 2 & General requirements \\
\hline 3 & User interfaces \\
\hline 4 & Project specifications \\
\hline 5 & Privacy management \\
\hline 6 & Technical specifications \\
\hline 7 & Technical support \\
\hline 8 & Previous experience \\
\hline 9 & Extra features \\
\hline 10 & Training \\
\hline 11 & Billing features \\
\hline 12 & \\
\hline 13 & \\
\hline 14 & \\
\hline 15 & \\
\hline
\end{tabular}


List of the criteria after the $1^{\text {st }}$ round with frequency that was provided to the experts for the $2^{\text {nd }}$ round.

\begin{tabular}{|c|c|c|}
\hline & Criteria & Frequency \\
\hline 1 & Price & 6 \\
\hline 2 & Technical specifications & 6 \\
\hline 3 & Project specifications & 5 \\
\hline 4 & Previous experience & 5 \\
\hline 5 & Privacy management & 5 \\
\hline 6 & General requirements & 3 \\
\hline 7 & Customer interfaces & 3 \\
\hline 8 & Delivery time & 2 \\
\hline 9 & Billing & 2 \\
\hline 10 & Extra features & 2 \\
\hline 11 & Documentation and CDR details & 2 \\
\hline 12 & Company profile & 2 \\
\hline 13 & Technical support & 2 \\
\hline 14 & Integration & 2 \\
\hline 15 & Training & 2 \\
\hline 16 & Project management of the tenderer & 2 \\
\hline 17 & Implementation capabilities & 1 \\
\hline 18 & Multi language support & 1 \\
\hline 19 & Software and hardware requirements & 1 \\
\hline 20 & Monopoly of the product & 1 \\
\hline 21 & Dimensioning & 1 \\
\hline 22 & Previous contracts with the tenderer & 1 \\
\hline 23 & Maintenance cost & 1 \\
\hline 24 & Customer care & 1 \\
\hline 25 & Physical location & 1 \\
\hline
\end{tabular}

The total number of the criteria collected from the panel of experts was 25 . This list was sent to all experts along with their own answers to let them compare and revise if needed. 
List of the criteria after the 2 nd round with frequency that was provided to the experts for the 3rd round and the comments.

\begin{tabular}{|c|c|c|c|}
\hline Criteria & $\begin{array}{c}\text { 1st } \\
\text { Frequency }\end{array}$ & $\begin{array}{l}\text { 2nd } \\
\text { Frequency }\end{array}$ & Comments \\
\hline Price & 6 & 6 & \\
\hline Technical specifications & 6 & 6 & \\
\hline Project specifications & 5 & 6 & \\
\hline Privacy management & 5 & 6 & \\
\hline General requirements & 3 & 5 & \\
\hline Customer interfaces & 3 & 4 & \\
\hline Previous experience & 2 & 1 & \\
\hline Delivery time & 2 & 0 & \\
\hline Billing & 2 & 4 & \\
\hline Extra features & 2 & 4 & \\
\hline Documentation and CDR details & 2 & 0 & \\
\hline Company profile & 2 & 0 & \\
\hline Technical support & 2 & 0 & \\
\hline Integration & 2 & 0 & \\
\hline Training & 2 & 1 & \\
\hline $\begin{array}{l}\text { Project management of the } \\
\text { tenderer }\end{array}$ & 2 & 0 & \\
\hline Implementation capabilities & 1 & 0 & \\
\hline Multi language support & 1 & 0 & \\
\hline $\begin{array}{l}\text { Software and hardware } \\
\text { requirements }\end{array}$ & 1 & 0 & \\
\hline Monopoly of the product & 1 & 0 & $\begin{array}{l}\text { In case of monopoly there is no } \\
\text { need for a tender !! }\end{array}$ \\
\hline Dimensioning & 1 & 0 & It's technical specs \\
\hline $\begin{array}{l}\text { Previous contracts with the } \\
\text { tenderer }\end{array}$ & 1 & 1 & \\
\hline Maintenance cost & 1 & 0 & Can be a part of price \\
\hline Customer care & 1 & 0 & \\
\hline Physical location & 1 & 0 & \\
\hline
\end{tabular}

After the second round, the 25 criteria were reduced to 11 criteria 
List of the criteria after the 3rd round with frequency of the 3rd round and the comments.

\begin{tabular}{|l|c|r|r|l|}
\hline \multicolumn{1}{|c|}{ Criteria } & $\begin{array}{c}\text { 1st } \\
\text { Frequency }\end{array}$ & $\begin{array}{c}\text { 2nd } \\
\text { Frequency }\end{array}$ & $\begin{array}{c}\text { 3rd } \\
\text { Frequency }\end{array}$ & Comments \\
\hline Price & 6 & 6 & 6 & \\
\hline Technical specifications & 6 & 6 & 6 & \\
\hline Project specifications & 5 & 6 & 6 & \\
\hline Privacy management & 5 & 6 & 6 & \\
\hline General requirements & 3 & 5 & 6 & \\
\hline Customer Interfaces & 3 & 4 & 5 & \\
\hline & & 1 & 1 & Can be sub-criteria of \\
Previous experience & 2 & 4 & 5 & \\
\hline Billing & 2 & 4 & 5 & \\
\hline Extra features & 2 & 1 & 0 & \\
\hline Training & 2 & 1 & 0 & \\
\hline Previous contracts with the & & & & \\
tenderer & & & &
\end{tabular}

List of the final criteria after the 3rd round which was sent to the experts for final verification.

\begin{tabular}{|l|}
\hline \multicolumn{1}{|c|}{ Criteria } \\
\hline Price \\
\hline Technical specifications \\
\hline Project specifications \\
\hline Privacy management \\
\hline General requirements \\
\hline Customer interfaces \\
\hline Billing \\
\hline Extra features \\
\hline
\end{tabular}

The third round was conducted for the tender evaluation process and the criteria which had a frequency of less than 2 were removed and the results were sent to the experts(6) for the verification. This resulted in the criteria being reduced from 11 to 8 items. 


\section{Appendix 2: The questionnaires and results of the Delphi sub-criteria selection.}

Questionnaire and Answers sample for the $1^{\text {st }}$ iteration of Delphi sub-criteria selection.

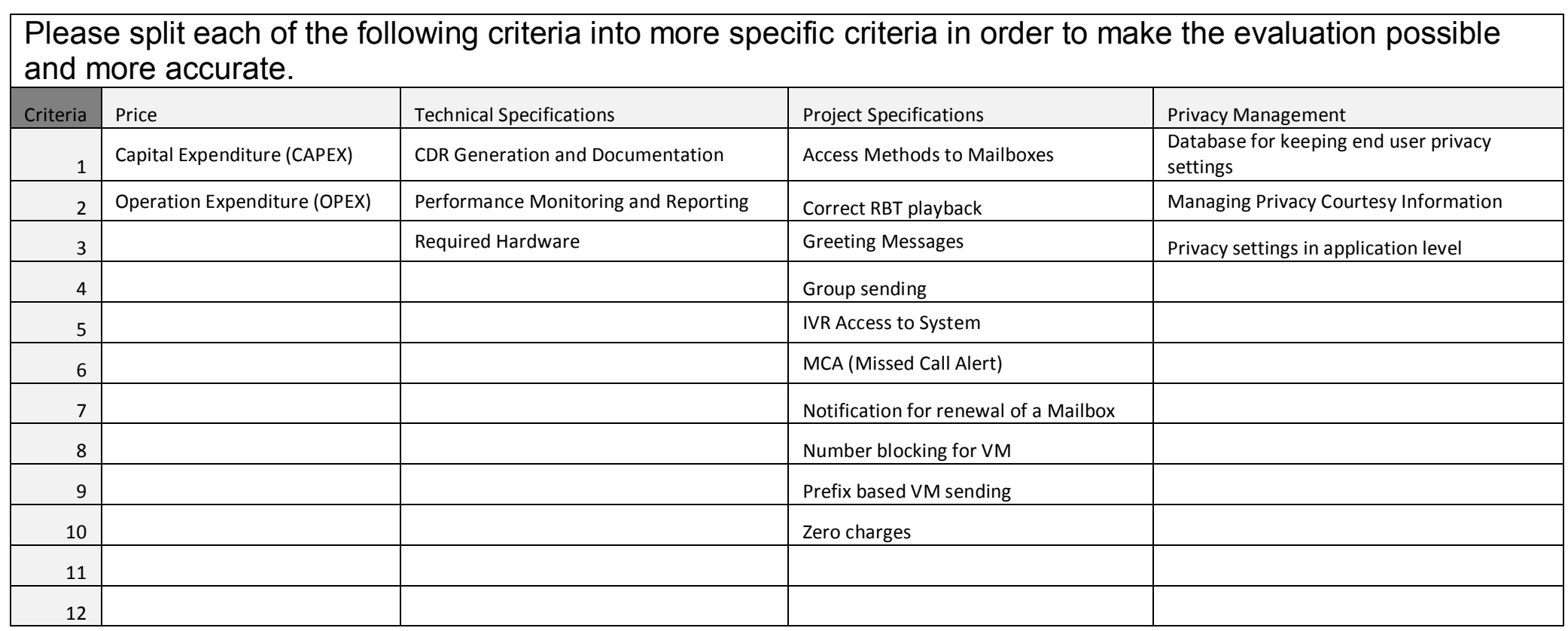


Questionnaire and Answers sample for the $1^{\text {st }}$ iteration of Delphi sub-criteria selection (cont.).

\begin{tabular}{|r|l|l|l|l|}
\hline \multicolumn{1}{|c|}{ Criteria } & General Requirements & Customer Interfaces & Billing & Extra features \\
\hline 1 & After Launch Support & Administrative/Operation Interface & Delivery based charging & Licensing \\
\hline 2 & $\begin{array}{l}\text { Available and assigned manpower for business } \\
\text { requirements }\end{array}$ & Different Calendars Support & Postpaid Charging \\
\hline 3 & Available and assigned manpower for Technical Support & Feel and Look & Prepaid Charging \\
\hline 4 & $\begin{array}{l}\text { Capture and Analysis of business requirement (time \& } \\
\text { quality) }\end{array}$ & User Interface & Zero Charges \\
\hline 5 & Company Profile & & & \\
\hline 6 & Evidences of Previous Experiences & & & \\
\hline 7 & Flexibility & & & \\
\hline 8 & Flexibility and Agileness in Customization & & & \\
\hline 9 & Implementation Support (on-site) & & & \\
\hline 10 & Implementation Time/ Minimum Time to Market & & & \\
\hline 11 & Project Management Capabilities & & & \\
\hline 12 & Quality for Developments & & & \\
\hline
\end{tabular}


List of the sub-criteria after the $1^{\text {st }}$ round with frequency that was provided to the experts for the $2^{\text {nd }}$ round.

\begin{tabular}{|c|c|c|c|c|c|c|c|c|c|c|c|c|}
\hline Criteria & Price & Freq. & Comments & Technical Specifications & Freq. & Comments & Project Specifications & Freq. & Comments & Privacy Management & Freq. & Comments \\
\hline 1 & $\begin{array}{l}\text { Capital Expenditure } \\
\text { (CAPEX) }\end{array}$ & 6 & & Required Hardware & 6 & & Delivery and Notification Options & 5 & & $\begin{array}{l}\text { Enforcing End Users to Accept Terms } \\
\text { and Conditions }\end{array}$ & 4 & \\
\hline 2 & $\begin{array}{l}\text { Operation Expenditure } \\
\text { (OPEX) }\end{array}$ & 6 & & $\begin{array}{l}\text { Alarm/Performance Monitoring and } \\
\text { Reporting }\end{array}$ & 5 & & Sending Voice Message Features & 5 & & Managing Privacy Courtesy Information & 4 & \\
\hline 3 & & & & Required Software & 5 & & Greeting Messages & 4 & & $\begin{array}{l}\text { Database for keeping end user privacy } \\
\text { settings }\end{array}$ & 2 & \\
\hline 4 & & & & CDR Generation and Documentation & 4 & & IVR Access to System & 4 & & Privacy settings in application level & 1 & \\
\hline 5 & & & & Integration Capabilities & 4 & & Voice Mailbox Types & 4 & & & & \\
\hline 6 & & & & Provisioning Features & 2 & & Access Methods to Mailboxes & 3 & & & & \\
\hline 7 & & & & Training & 2 & & Notifications & 3 & & & & \\
\hline 8 & & & & & & & API for external applications & 2 & & & & \\
\hline 9 & & & & & & & Full voice-mailbox notification & 2 & & & & \\
\hline 10 & & & & & & & $\begin{array}{l}\text { Integration with current } \\
\text { Voicemail platform }\end{array}$ & 2 & & & & \\
\hline 11 & & & & & & & $\begin{array}{l}\text { Integration with MCA \& } \\
\text { Voicemail platforms }\end{array}$ & 2 & & & & \\
\hline 12 & & & & & & & MCA (Missed Call Alert) & 2 & & & & \\
\hline 13 & & & & & & & Number Blocking & 2 & & & & \\
\hline 14 & & & & & & & Number blocking for VM & 2 & & & & \\
\hline 15 & & & & & & & Correct RBT playback & 1 & & & & \\
\hline 16 & & & & & & & Group sending & 1 & & & & \\
\hline 17 & & & & & & & Limited duration for messages & 1 & & & & \\
\hline 18 & & & & & & & $\begin{array}{l}\text { Notification for renewal of a } \\
\text { Mailbox }\end{array}$ & 1 & & & & \\
\hline 19 & & & & & & & Prefix based VM sending & 1 & & & & \\
\hline 20 & & & & & & & Temporary Voice Mailbox & 1 & & & & \\
\hline 21 & & & & & & & Zero charges & 1 & & & & \\
\hline
\end{tabular}

The first round of data collection was like a brainstorming and all the possible criteria were collected and listed with their frequencies for the $2^{\text {nd }}$ round. The total number of 92 criteria were defined in this round. 
List of the sub-criteria after the $1^{\text {st }}$ round with frequency that was provided to the experts for the $2^{\text {nd }}$ round (cont.).

\begin{tabular}{|c|c|c|c|c|c|c|c|c|c|c|c|c|}
\hline Criteria & $\begin{array}{l}\text { General } \\
\text { Requirements }\end{array}$ & Freq. & Comments & $\begin{array}{l}\text { Customer } \\
\text { Interfaces }\end{array}$ & Freq. & Comments & Billing & Freq. & Comments & $\begin{array}{l}\text { Extra } \\
\text { features }\end{array}$ & Freq. & Comments \\
\hline 1 & After Launch Support & 6 & & Different Calendars Support & 5 & & General Notice & 4 & & Licensing & 5 & \\
\hline 2 & Company Profile & 6 & & Multi Language Support & 5 & & Postpaid Charging & 4 & & Sizing & 5 & \\
\hline 3 & Evidences of Previous Experiences & 6 & & Feel and Look & 4 & & Prepaid Charging & 4 & & & & \\
\hline 4 & Implementation Support (on-site) & 6 & & User Interface & 4 & & Billing database & 1 & & & & \\
\hline 5 & $\begin{array}{l}\text { Implementation Time/ Minimum Time } \\
\text { to Market }\end{array}$ & 6 & & $\begin{array}{l}\text { Administrative/Operation } \\
\text { Interface }\end{array}$ & 3 & & Charging & 1 & & & & \\
\hline 6 & Project Management Capabilities & 6 & & GUI & 2 & & & & & & & \\
\hline 7 & Flexibility & 3 & & Unicode support & 1 & & & & & & & \\
\hline 8 & On-site Developments & 3 & & & & & & & & & & \\
\hline 9 & Agileness in customization & 2 & & & & & & & & & & \\
\hline 10 & $\begin{array}{l}\text { Available and assigned manpower for } \\
\text { business requirements }\end{array}$ & 1 & & & & & & & & & & \\
\hline 11 & $\begin{array}{l}\text { Available and assigned manpower for } \\
\text { Technical Support }\end{array}$ & 1 & & & & & & & & & & \\
\hline 12 & $\begin{array}{l}\text { Capture and Analysis of business } \\
\text { requirement (time \& quality) }\end{array}$ & 1 & & & & & & & & & & \\
\hline 13 & $\begin{array}{l}\text { Flexibility and Agileness in } \\
\text { Customization }\end{array}$ & 1 & & & & & & & & & & \\
\hline 14 & Quality for Developments & 1 & & & & & & & & & & \\
\hline 15 & Quality for Developments & 1 & & & & & & & & & & \\
\hline 16 & & & & & & & & & & & & \\
\hline 17 & & & & & & & & & & & & \\
\hline 18 & & & & & & & & & & & & \\
\hline 19 & & & & & & & & & & & & \\
\hline 20 & & & & & & & & & & & & \\
\hline 21 & & & & & & & & & & & & \\
\hline
\end{tabular}


List of the sub-criteria after the $2^{\text {nd }}$ round with frequency that was provided to the experts for the $3^{\text {rd }}$ round.

\begin{tabular}{|c|c|c|c|c|c|c|c|c|c|c|c|c|c|c|c|c|}
\hline Criteria & Price & $\begin{array}{l}1 \text { st } \\
\text { Freq. }\end{array}$ & $\begin{array}{l}\text { 2nd } \\
\text { Freq. }\end{array}$ & Comments & Technical Specifications & $\begin{array}{l}1 s t \\
\text { Freq. }\end{array}$ & $\begin{array}{l}\text { 2nd } \\
\text { Freq. }\end{array}$ & Comments & Project Specifications & $\begin{array}{l}1 s t \\
\text { Freq. }\end{array}$ & $\begin{array}{l}\text { 2nd } \\
\text { Freq. }\end{array}$ & Comments & Privacy Management & $\begin{array}{l}1 s t \\
\text { Freq. }\end{array}$ & $\begin{array}{l}\text { 2nd } \\
\text { Freq. }\end{array}$ & Comments \\
\hline 1 & $\begin{array}{l}\text { Capital Expenditure } \\
\text { (CAPEX) }\end{array}$ & 6 & 6 & & $\begin{array}{l}\text { Alarm/Performance } \\
\text { Monitoring and }\end{array}$ & 5 & 6 & & Access Methods to Maillboxes & 3 & 4 & & $\begin{array}{l}\text { Database for keeping end user privacy } \\
\text { settings }\end{array}$ & 2 & 1 & \\
\hline 2 & $\begin{array}{l}\text { Operation Expenditure } \\
\text { (OPEX) }\end{array}$ & 6 & 6 & & $\begin{array}{l}\text { CDR Generation and } \\
\text { Documentation }\end{array}$ & 4 & 6 & & API for external applications & 2 & 1 & It is integration & $\begin{array}{l}\text { Enforcing End Users to Accept Terms } \\
\text { and Conditions }\end{array}$ & 4 & 6 & \\
\hline 3 & & & & & Integration Capabilities & 4 & 6 & & Correct RBT playback & 1 & 0 & & Managing Privacy Courtesy Information & 4 & 6 & \\
\hline 4 & & & & & Provisioning Features & 2 & 4 & & $\begin{array}{l}\text { Delivery and Notification } \\
\text { Options }\end{array}$ & 5 & 6 & & Privacy settings in application level & 1 & 0 & \\
\hline 5 & & & & & Required Hardware & 6 & 6 & & Full voice-mailbox notification & 2 & 1 & Notification & & & & \\
\hline 6 & & & & & Required Software & 5 & 6 & & Greeting Messages & 4 & 6 & & & & & \\
\hline 7 & & & & & Training & 2 & 3 & & Group sending & 1 & 0 & & & & & \\
\hline 8 & & & & & & & & & $\begin{array}{l}\text { Integration with current } \\
\text { Voicemail platform }\end{array}$ & 2 & 0 & It is integration & & & & \\
\hline 9 & & & & & & & & & $\begin{array}{l}\text { Integration with MCA \& } \\
\text { Voicemail platforms }\end{array}$ & 2 & 0 & It is integration & & & & \\
\hline 10 & & & & & & & & & IVR Access to System & 4 & 5 & & & & & \\
\hline 11 & & & & & & & & & Limited duration for messages & 1 & 0 & & & & & \\
\hline 12 & & & & & & & & & MCA (Missed Call Alert) & 2 & 0 & is available in the network & & & & \\
\hline 13 & & & & & & & & & $\begin{array}{l}\text { Notification for renewal of a } \\
\text { Maillbox }\end{array}$ & 1 & 0 & & & & & \\
\hline 14 & & & & & & & & & Notifications & 3 & 6 & & & & & \\
\hline 15 & & & & & & & & & Number Blocking & 2 & 5 & & & & & \\
\hline 16 & & & & & & & & & Number blocking for VM & 2 & 0 & & & & & \\
\hline 17 & & & & & & & & & Prefix based VM sending & 1 & 1 & & & & & \\
\hline 18 & & & & & & & & & Sending Voice Message Features & 5 & 5 & & & & & \\
\hline 19 & & & & & & & & & Temporary Voice Mailbox & 1 & 0 & & & & & \\
\hline 20 & & & & & & & & & Voice Mailbox Types & 4 & 4 & & & & & \\
\hline 21 & & & & & & & & & Zero charges & 1 & 0 & & & & & \\
\hline
\end{tabular}

After the $2^{\text {nd }}$ round, some criteria were changed and some comments were added by the experts in order to justify their idea or change the others' idea for the $3^{\text {rd }}$ round. The criteria were reduced to 63 at this round. 
List of the sub-criteria after the $2^{\text {nd }}$ round with frequency that was provided to the experts for the $3^{\text {rd }}$ round (cont.).

\begin{tabular}{|c|c|c|c|c|c|c|c|c|c|c|c|c|c|c|c|c|}
\hline Criteria & General Requirements & $\begin{array}{l}1 \text { st } \\
\text { Freq. }\end{array}$ & $\begin{array}{l}\text { 2nd } \\
\text { Freq. }\end{array}$ & Comments & Customer Interfaces & $\begin{array}{l}1 \text { st } \\
\text { Freq. }\end{array}$ & $\begin{array}{l}\text { 2nd } \\
\text { Freq. }\end{array}$ & Comments & Billing & $\begin{array}{l}\text { 1st } \\
\text { Freq. }\end{array}$ & $\begin{array}{l}\text { 2nd } \\
\text { Freq. }\end{array}$ & Comments & Extra features & $\begin{array}{l}1 s t \\
\text { Freq. }\end{array}$ & $\begin{array}{l}\text { 2nd } \\
\text { Freq. }\end{array}$ & Comments \\
\hline 1 & After Launch Support & 6 & 6 & & Administrative/Operation Interface & 3 & 6 & & Billing database & 1 & 1 & $\begin{array}{l}\text { this is integrated } \\
\text { in Prepaid and }\end{array}$ & Licensing & 5 & 6 & \\
\hline 2 & Agileness in customization & 2 & 0 & & Different Calendars Support & 5 & 6 & & Charging & 1 & 0 & & Sizing & 5 & 6 & \\
\hline 3 & $\begin{array}{l}\text { Available and assigned manpower for business } \\
\text { requirements }\end{array}$ & 1 & 0 & & Feel and Look & 4 & 4 & & General Notice & 4 & 6 & & & & & \\
\hline 4 & $\begin{array}{l}\text { Available and assigned manpower for Technical } \\
\text { Support }\end{array}$ & 1 & 0 & & GUI & 2 & 1 & $\begin{array}{l}\text { User } \\
\text { interface }\end{array}$ & Postpaid Charging & 4 & 6 & & & & & \\
\hline 5 & $\begin{array}{l}\text { Capture and Analysis of business requirement } \\
\text { (time \& quality) }\end{array}$ & 1 & 0 & & Multi Language Support & 5 & 6 & & Prepaid Charging & 4 & 4 & & & & & \\
\hline 6 & Company Profile & 6 & 6 & & Unicode support & 1 & 0 & & & & & & & & & \\
\hline 7 & Evidences of Previous Experiences & 6 & 6 & & User Interface & 4 & 6 & & & & & & & & & \\
\hline 8 & Flexibility & 3 & 0 & & & & & & & & & & & & & \\
\hline 9 & Flexibility and Agileness in Customization & 1 & 6 & & & & & & & & & & & & & \\
\hline 10 & Implementation Support (on-site) & 6 & 6 & & & & & & & & & & & & & \\
\hline 11 & Implementation Time/Minimum Time to Market & 6 & 6 & & & & & & & & & & & & & \\
\hline 12 & On-site Developments & 3 & 3 & & & & & & & & & & & & & \\
\hline 13 & Project Management Capabilities & 6 & 6 & & & & & & & & & & & & & \\
\hline 14 & Quality for Developments & 1 & 0 & & & & & & & & & & & & & \\
\hline 15 & & & & & & & & & & & & & & & & \\
\hline 16 & & & & & & & & & & & & & & & & \\
\hline 17 & & & & & & & & & & & & & & & & \\
\hline 18 & & & & & & & & & & & & & & & & \\
\hline 19 & & & & & & & & & & & & & & & & \\
\hline 20 & & & & & & & & & & & & & & & & \\
\hline 21 & & & & & & & & & & & & & & & & \\
\hline
\end{tabular}


List of the sub-criteria after the $3^{\text {rd }}$ round with frequency:

\begin{tabular}{|c|c|c|c|c|c|c|c|c|c|c|c|c|c|c|c|c|}
\hline Criteria & Price & $\begin{array}{l}1 \text { st } \\
\text { Freq. }\end{array}$ & $\begin{array}{l}\text { 2nd } \\
\text { Freq. }\end{array}$ & $\begin{array}{l}\text { 3rd } \\
\text { Freq. }\end{array}$ & Technical Specifications & $\begin{array}{l}1 \text { st } \\
\text { Freq. }\end{array}$ & $\begin{array}{l}\text { 2nd } \\
\text { Freq. }\end{array}$ & $\begin{array}{l}\text { 3rd } \\
\text { Freq. }\end{array}$ & Project Specifications & $\begin{array}{l}1 \text { st } \\
\text { Freq. }\end{array}$ & $\begin{array}{l}\text { 2nd } \\
\text { Freq. }\end{array}$ & $\begin{array}{l}3 \text { rd } \\
\text { Freq. }\end{array}$ & Privacy Management & $\begin{array}{l}1 \text { st } \\
\text { Freq. }\end{array}$ & $\begin{array}{l}\text { 2nd } \\
\text { Freq. }\end{array}$ & 3rd Freq. \\
\hline 1 & $\begin{array}{l}\text { Capital Expenditure } \\
\text { (CAPEX) }\end{array}$ & 6 & 6 & 6 & $\begin{array}{l}\text { Alarm/Performance } \\
\text { Monitoring and Reporting }\end{array}$ & 5 & 6 & 6 & $\begin{array}{l}\text { Access Methods to } \\
\text { Mailboxes }\end{array}$ & 3 & 4 & 4 & $\begin{array}{l}\text { Database for keeping } \\
\text { end user privacy } \\
\text { settings }\end{array}$ & 2 & 1 & 0 \\
\hline 2 & $\begin{array}{l}\text { Operation } \\
\text { Expenditure (OPEX) }\end{array}$ & 6 & 6 & 6 & $\begin{array}{l}\text { CDR Generation and } \\
\text { Documentation }\end{array}$ & 4 & 6 & 6 & $\begin{array}{l}\text { API for external } \\
\text { applications }\end{array}$ & 2 & 1 & 1 & $\begin{array}{l}\text { Enforcing End Users to } \\
\text { Accept Terms and } \\
\text { Conditions }\end{array}$ & 4 & 6 & 6 \\
\hline 3 & & & & & Integration Capabilities & 4 & 6 & 6 & Correct RBT playback & 1 & 0 & 0 & $\begin{array}{l}\text { Managing Privacy } \\
\text { Courtesy Information }\end{array}$ & 4 & 6 & 6 \\
\hline 4 & & & & & Provisioning Features & 2 & 4 & 4 & $\begin{array}{l}\text { Delivery and } \\
\text { Notification Options }\end{array}$ & 5 & 6 & 6 & $\begin{array}{l}\text { Privacy settings in } \\
\text { application level }\end{array}$ & 1 & 0 & 0 \\
\hline 5 & & & & & Required Hardware & 6 & 6 & 6 & $\begin{array}{l}\text { Full voice-mailbox } \\
\text { notification }\end{array}$ & 2 & 1 & 0 & & & & \\
\hline 6 & & & & & Required Software & 5 & 6 & 6 & Greeting Messages & 4 & 6 & 6 & & & & \\
\hline 7 & & & & & Training & 2 & 3 & 4 & Group sending & 1 & 0 & 0 & & & & \\
\hline 8 & & & & & & & & & $\begin{array}{l}\text { Integration with current } \\
\text { Voicemail platform }\end{array}$ & 2 & 0 & 0 & & & & \\
\hline 9 & & & & & & & & & $\begin{array}{l}\text { Integration with MCA \& } \\
\text { Voicemail platforms }\end{array}$ & 2 & 0 & 0 & & & & \\
\hline 10 & & & & & & & & & IVR Access to System & 4 & 5 & 5 & & & & \\
\hline 11 & & & & & & & & & $\begin{array}{l}\text { Limited duration for } \\
\text { messages }\end{array}$ & 1 & 0 & 0 & & & & \\
\hline 12 & & & & & & & & & MCA (Missed Call Alert) & 2 & 0 & 0 & & & & \\
\hline 13 & & & & & & & & & $\begin{array}{l}\text { Notification for renewal } \\
\text { of a Mailbox }\end{array}$ & 1 & 0 & 0 & & & & \\
\hline 14 & & & & & & & & & Notifications & 3 & 6 & 6 & & & & \\
\hline 15 & & & & & & & & & Number Blocking & 2 & 5 & 5 & & & & \\
\hline 16 & & & & & & & & & $\begin{array}{l}\text { Number blocking for } \\
\text { VM }\end{array}$ & 2 & 0 & 0 & & & & \\
\hline 17 & & & & & & & & & $\begin{array}{l}\text { Prefix based VM } \\
\text { sending } \\
\end{array}$ & 1 & 1 & 1 & & & & \\
\hline 18 & & & & & & & & & $\begin{array}{l}\text { Sending Voice Message } \\
\text { Features }\end{array}$ & 5 & 5 & 6 & & & & \\
\hline 19 & & & & & & & & & $\begin{array}{l}\text { Temporary Voice } \\
\text { Mailbox }\end{array}$ & 1 & 0 & 0 & & & & \\
\hline 20 & & & & & & & & & Voice Mailbox Types & 4 & 4 & 6 & & & & \\
\hline 21 & & & & & & & & & Zero charges & 1 & 0 & 0 & & & & \\
\hline
\end{tabular}

After the $3^{\text {rd }}$ round, the criteria with the frequency of less than 2 were removed resulting in having 37 sub-criteria and the results were sent to the experts for the final verification. 
List of the sub-criteria after the $3^{\text {rd }}$ round with frequency (cont.).

\begin{tabular}{|c|c|c|c|c|c|c|c|c|c|c|c|c|c|c|c|c|}
\hline Criteria & General Requirements & $\begin{array}{l}1 s t \\
\text { Freq. }\end{array}$ & $\begin{array}{l}\text { 2nd } \\
\text { Freq. }\end{array}$ & $\begin{array}{l}3 \text { rd } \\
\text { Freq. }\end{array}$ & Customer Interfaces & $\begin{array}{l}1 \text { st } \\
\text { Freq. }\end{array}$ & $\begin{array}{l}\text { 2nd } \\
\text { Freq. }\end{array}$ & $\begin{array}{l}3 \text { rd } \\
\text { Freq. }\end{array}$ & Billing & $\begin{array}{l}1 \text { st } \\
\text { Freq. }\end{array}$ & $\begin{array}{l}\text { 2nd } \\
\text { Freq. }\end{array}$ & $\begin{array}{l}\text { 3rd } \\
\text { Freq. }\end{array}$ & Extra features & $\begin{array}{l}1 \text { st } \\
\text { Freq. }\end{array}$ & $\begin{array}{l}\text { 2nd } \\
\text { Freq. }\end{array}$ & 3rd Freq. \\
\hline 1 & After Launch Support & 6 & 6 & 6 & $\begin{array}{l}\text { Administrative/Operation } \\
\text { Interface }\end{array}$ & 3 & 6 & 6 & Billing database & 1 & 1 & 0 & Licensing & 5 & 6 & 6 \\
\hline 2 & Agileness in customization & 2 & 0 & 0 & $\begin{array}{l}\text { Different Calendars } \\
\text { Support }\end{array}$ & 5 & 6 & 6 & Charging & 1 & 0 & 0 & Sizing & 5 & 6 & 6 \\
\hline 3 & $\begin{array}{l}\text { Available and assigned } \\
\text { manpower for business } \\
\text { requirements }\end{array}$ & 1 & 0 & 0 & Feel and Look & 4 & 4 & 5 & General Notice & 4 & 6 & 6 & & & & \\
\hline 4 & $\begin{array}{l}\text { Available and assigned } \\
\text { manpower for Technical } \\
\text { Support }\end{array}$ & 1 & 0 & 0 & GUI & 2 & 1 & 0 & Postpaid Charging & 4 & 6 & 6 & & & & \\
\hline 5 & $\begin{array}{l}\text { Capture and Analysis of } \\
\text { business requirement (time \& } \\
\text { quality) }\end{array}$ & 1 & 0 & 0 & Multi Language Support & 5 & 6 & 6 & Prepaid Charging & 4 & 4 & 6 & & & & \\
\hline 6 & Company Profile & 6 & 6 & 6 & Unicode support & 1 & 0 & 0 & & & & & & & & \\
\hline 7 & $\begin{array}{l}\text { Evidences of Previous } \\
\text { Experiences }\end{array}$ & 6 & 6 & 6 & User Interface & 4 & 6 & 6 & & & & & & & & \\
\hline 8 & Flexibility & 3 & 0 & 0 & & & & & & & & & & & & \\
\hline 9 & $\begin{array}{l}\text { Flexibility and Agileness in } \\
\text { Customization }\end{array}$ & 1 & 6 & 6 & & & & & & & & & & & & \\
\hline 10 & $\begin{array}{l}\text { Implementation Support (on- } \\
\text { site) }\end{array}$ & 6 & 6 & 6 & & & & & & & & & & & & \\
\hline 11 & $\begin{array}{l}\text { Implementation } \\
\text { Time/Minimum Time to } \\
\text { Market }\end{array}$ & 6 & 6 & 6 & & & & & & & & & & & & \\
\hline 12 & On-site Developments & 3 & 3 & 5 & & & & & & & & & & & & \\
\hline 13 & $\begin{array}{l}\text { Project Management } \\
\text { Capabilities }\end{array}$ & 6 & 6 & 6 & & & & & & & & & & & & \\
\hline 14 & Quality for Developments & 1 & 0 & 0 & & & & & & & & & & & & \\
\hline 15 & & & & & & & & & & & & & & & & \\
\hline 16 & & & & & & & & & & & & & & & & \\
\hline 17 & & & & & & & & & & & & & & & & \\
\hline 18 & & & & & & & & & & & & & & & & \\
\hline 19 & & & & & & & & & & & & & & & & \\
\hline 20 & & & & & & & & & & & & & & & & \\
\hline 21 & & & & & & & & & & & & & & & & \\
\hline
\end{tabular}




\section{List of the final selected sub-criteria with frequency.}

\begin{tabular}{|c|c|c|c|}
\hline Price & 1st Freq. & 2nd Freq. & 3rd Freq. \\
\hline Capital Expenditure (CAPEX) & 6 & 6 & 6 \\
\hline Operation Expenditure (OPEX) & 6 & 6 & 6 \\
\hline Technical Specifications & 1st Freq. & 2nd Freq. & 3rd Freq. \\
\hline Alarm/Performance Monitoring and Reporting & 5 & 6 & 6 \\
\hline CDR Generation and Documentation & 4 & 6 & 6 \\
\hline Integration Capabilities & 4 & 6 & 6 \\
\hline Provisioning Features & 2 & 4 & 4 \\
\hline Required Hardware & 6 & 6 & 6 \\
\hline Required Software & 5 & 6 & 6 \\
\hline Training & 2 & 3 & 4 \\
\hline Project Specifications & 1st Freq. & 2nd Freq. & 3rd Freq. \\
\hline Access Methods to Mailboxes & 3 & 4 & 4 \\
\hline Delivery and Notification Options & 5 & 6 & 6 \\
\hline Greeting Messages & 4 & 6 & 6 \\
\hline IVR Access to System & 4 & 5 & 5 \\
\hline Notifications & 3 & 6 & 6 \\
\hline Number Blocking & 2 & 5 & 5 \\
\hline Sending Voice Message Features & 5 & 5 & 6 \\
\hline Voice Mailbox Types & 4 & 4 & 6 \\
\hline Privacy Management & 1st Freq. & 2nd Freq. & 3rd Freq. \\
\hline Enforcing End Users to Accept Terms and Conditions & 4 & 6 & 6 \\
\hline Managing Privacy Courtesy Information & 4 & 6 & 6 \\
\hline General Requirements & 1st Freq. & 2nd Freq. & 3rd Freq. \\
\hline After Launch Support & 6 & 6 & 6 \\
\hline Company Profile & 6 & 6 & 6 \\
\hline Evidences of Previous Experiences & 6 & 6 & 6 \\
\hline Flexibility and Agileness in Customization & 1 & 6 & 6 \\
\hline Implementation Support (on-site) & 6 & 6 & 6 \\
\hline Implementation Time/Minimum Time to Market & 6 & 6 & 6 \\
\hline On-site Developments & 3 & 3 & 5 \\
\hline Project Management Capabilities & 6 & 6 & 6 \\
\hline
\end{tabular}


List of the final selected sub-criteria with frequency (cont.).

\begin{tabular}{|c|c|c|c|}
\hline Customer Interfaces & 1st Freq. & 2nd Freq. & 3rd Freq. \\
\hline Administrative/Operation Interface & 3 & 6 & 6 \\
\hline Different Calendars Support & 5 & 6 & 6 \\
\hline Feel and Look & 4 & 4 & 5 \\
\hline Multi Language Support & 5 & 6 & 6 \\
\hline User Interface & 4 & 6 & 6 \\
\hline Billing & 1st Freq. & 2nd Freq. & 3rd Freq. \\
\hline General Notice & 4 & 6 & 6 \\
\hline Postpaid Charging & 4 & 6 & 6 \\
\hline Prepaid Charging & 4 & 4 & 6 \\
\hline Extra features & 1st Freq. & 2nd Freq. & 3rd Freq. \\
\hline Licensing & 5 & 6 & 6 \\
\hline Sizing & 5 & 6 & 6 \\
\hline
\end{tabular}

The total number of 37 sub-criteria were defined under the main criteria after 3 iterations of Delphi method. 


\section{Appendix 3: The questionnaires and results of the Delphi criteria classification in $B, O, C, R$ merits.}

\section{Criteria classification under $B, O, C, R$ with Delphi, $1^{\text {st }}$ round questionnaire:}

Q: Please classify the listed criteria under one of the Benefits, Opportunities, Costs or Risks merits based on their relevance to them. Please select just one merit that you think is more appropriate by putting an $\mathrm{X}$ under that merit.

\begin{tabular}{|c|c|c|c|c|c|}
\hline & \multirow{2}{*}{ Criteria } & \multicolumn{4}{|c|}{ 1st Round } \\
\hline & & Benefit & Opportunity & Cost & Risk \\
\hline 1 & Access Methods to Mailboxes & $\mathrm{x}$ & & & \\
\hline 2 & Administrative/Operation Interface & $x$ & & & \\
\hline 3 & After Launch Support & $\mathrm{x}$ & & & \\
\hline 4 & $\begin{array}{l}\text { Alarm/Performance Monitoring and } \\
\text { Reporting }\end{array}$ & & & & $x$ \\
\hline 5 & Capital Expenditure (CAPEX) & & & $\mathrm{x}$ & \\
\hline 6 & CDR Generation and Documentation & $\mathrm{x}$ & & & \\
\hline 7 & Company Profile & & & & $\mathrm{x}$ \\
\hline 8 & Delivery and Notification Options & & $\mathrm{x}$ & & \\
\hline 9 & Different Calendars Support & $\mathrm{x}$ & & & \\
\hline 10 & $\begin{array}{l}\text { Enforcing End Users to Accept Terms } \\
\text { and Conditions }\end{array}$ & $\mathrm{x}$ & & & \\
\hline 11 & Evidences of Previous Experiences & & & $x$ & \\
\hline 12 & Feel and Look & $\mathrm{x}$ & & & \\
\hline 13 & $\begin{array}{l}\text { Flexibility and Agileness in } \\
\text { Customization }\end{array}$ & & $\mathrm{x}$ & & \\
\hline 14 & General Notice & $x$ & & & \\
\hline 15 & Greeting Messages & $\mathrm{x}$ & & & \\
\hline 16 & Implementation Support (on-site) & $x$ & & & \\
\hline 17 & $\begin{array}{l}\text { Implementation Time/ Minimum Time } \\
\text { to Market }\end{array}$ & $\mathrm{x}$ & & & \\
\hline 18 & Integration Capabilities & $x$ & & & \\
\hline 19 & IVR Access to System & & $\mathrm{x}$ & & \\
\hline 20 & Licensing & $x$ & & & \\
\hline 21 & Managing Privacy Courtesy Information & & & & $\mathrm{x}$ \\
\hline 22 & Multi Language Support & & $x$ & & \\
\hline 23 & Notifications & $\mathrm{x}$ & & & \\
\hline 24 & Number Blocking & $x$ & & & \\
\hline 25 & On-site Developments & & $\mathrm{x}$ & & \\
\hline 26 & Operation Expenditure (OPEX) & & & $x$ & \\
\hline 27 & Postpaid Charging & $\mathrm{x}$ & & & \\
\hline 28 & Prepaid Charging & $x$ & & & \\
\hline 29 & Project Management Capabilities & & & & $\mathrm{x}$ \\
\hline 30 & Provisioning Features & $\mathrm{x}$ & & & \\
\hline 31 & Required Hardware & & & $\mathrm{x}$ & \\
\hline 32 & Required Software & & & $x$ & \\
\hline 33 & Sending Voice Message Features & & $\mathrm{x}$ & & \\
\hline 34 & Sizing & & $\mathrm{x}$ & & \\
\hline 35 & Training & & $\mathrm{x}$ & & \\
\hline 36 & User Interface & $x$ & & & \\
\hline 37 & Voice Mailbox Types & $\mathrm{x}$ & & & \\
\hline
\end{tabular}


Criteria classification results after $3^{\text {rd }}$ Delphi iteration with frequencies.

\begin{tabular}{|c|c|c|c|c|c|c|c|c|c|c|c|c|c|}
\hline & \multirow{2}{*}{ Criteria } & \multicolumn{4}{|c|}{ 1st Round } & \multicolumn{4}{|c|}{ 2nd Round } & \multicolumn{4}{|c|}{ 3rd Round } \\
\hline & & C & 0 & C & $\mathbf{R}$ & B & 0 & C & $\mathbf{R}$ & B & 0 & $\mathbf{C}$ & $\mathbf{R}$ \\
\hline 1 & Access Methods to Mailboxes & 5 & 1 & & & 6 & & & & 6 & & & \\
\hline 2 & $\begin{array}{l}\text { Administrative/Operation } \\
\text { Interface }\end{array}$ & 5 & 1 & & & 6 & & & & 6 & & & \\
\hline 3 & After Launch Support & 4 & 2 & & & 6 & & & & 6 & & & \\
\hline 4 & $\begin{array}{l}\text { Alarm/Performance } \\
\text { Monitoring and Reporting }\end{array}$ & & 2 & & 4 & & 2 & & 4 & & 2 & & 4 \\
\hline 5 & Capital Expenditure (CAPEX) & & & 6 & & & & 6 & & & & 6 & \\
\hline 6 & $\begin{array}{l}\text { CDR Generation and } \\
\text { Documentation }\end{array}$ & 5 & 1 & & & 5 & 1 & & & 4 & 2 & & \\
\hline 7 & Company Profile & & 2 & & 4 & & & 1 & 5 & & & 1 & 5 \\
\hline 8 & $\begin{array}{l}\text { Delivery and Notification } \\
\text { Options }\end{array}$ & 2 & 4 & & & 5 & 1 & & & 5 & 1 & & \\
\hline 9 & Different Calendars Support & 6 & & & & 6 & & & & 6 & & & \\
\hline 10 & $\begin{array}{l}\text { Enforcing End Users to Accept } \\
\text { Terms and Conditions }\end{array}$ & 4 & 1 & & 1 & 5 & 1 & & & 4 & 2 & & \\
\hline 11 & $\begin{array}{l}\text { Evidences of Previous } \\
\text { Experiences }\end{array}$ & & & 1 & 5 & & & 1 & 5 & & & & 6 \\
\hline 12 & Feel and Look & 5 & 1 & & & 5 & 1 & & & 6 & & & \\
\hline 13 & $\begin{array}{l}\text { Flexibility and Agileness in } \\
\text { Customization }\end{array}$ & 2 & 4 & & & 2 & 4 & & & 2 & 4 & & \\
\hline 14 & General Notice & 5 & 1 & & & 5 & 1 & & & 5 & 1 & & \\
\hline 15 & Greeting Messages & 6 & & & & 6 & & & & 6 & & & \\
\hline 16 & $\begin{array}{l}\text { Implementation Support (on- } \\
\text { site) }\end{array}$ & 5 & 1 & & & 5 & 1 & & & 6 & & & \\
\hline 17 & $\begin{array}{l}\text { Implementation Time/ } \\
\text { Minimum Time to Market }\end{array}$ & 4 & 2 & & & 5 & 1 & & & 6 & & & \\
\hline 18 & Integration Capabilities & 4 & 2 & & & 4 & 2 & & & 4 & 2 & & \\
\hline 19 & IVR Access to System & 4 & 2 & & & 5 & 1 & & & 5 & 1 & & \\
\hline 20 & Licensing & 5 & 1 & & & 6 & & & & 6 & & & \\
\hline 21 & $\begin{array}{l}\text { Managing Privacy Courtesy } \\
\text { Information }\end{array}$ & & 1 & & 5 & 1 & & & 5 & 1 & & & 5 \\
\hline 22 & Multi Language Support & 2 & 4 & & & 2 & 4 & & & 2 & 4 & & \\
\hline 23 & Notifications & 5 & 1 & & & 5 & 1 & & & 6 & & & \\
\hline 24 & Number Blocking & 4 & 2 & & & 4 & 2 & & & 4 & 2 & & \\
\hline 25 & On-site Developments & 2 & 4 & & & 2 & 4 & & & 2 & 4 & & \\
\hline 26 & Operation Expenditure (OPEX) & & & 6 & & & & 6 & & & & 6 & \\
\hline 27 & Postpaid Charging & 6 & & & & 6 & & & & 6 & & & \\
\hline 28 & Prepaid Charging & 6 & & & & 6 & & & & 6 & & & \\
\hline 29 & $\begin{array}{l}\text { Project Management } \\
\text { Capabilities }\end{array}$ & & 1 & & 5 & & & & 6 & & & & 6 \\
\hline 30 & Provisioning Features & 5 & 1 & & & 5 & 1 & & & 5 & 1 & & \\
\hline 31 & Required Hardware & & & 6 & & & & 6 & & & & 6 & \\
\hline 32 & Required Software & & & 6 & & & & 6 & & & & 6 & \\
\hline 33 & $\begin{array}{l}\text { Sending Voice Message } \\
\text { Features }\end{array}$ & 2 & 4 & & & 4 & 2 & & & 4 & 2 & & \\
\hline 34 & Sizing & 3 & 3 & & & 2 & 4 & & & 2 & 4 & & \\
\hline 35 & Training & 2 & 4 & & & 5 & 1 & & & 5 & 1 & & \\
\hline 36 & User Interface & 5 & 1 & & & 6 & & & & 6 & & & \\
\hline 37 & Voice Mailbox Types & 5 & 1 & & & 5 & 1 & & & 6 & & & \\
\hline
\end{tabular}


Criteria classification results after $3^{\text {rd }}$ Delphi iteration with percentages of belongings to merits.

\begin{tabular}{|c|c|c|c|c|c|c|c|c|c|}
\hline & \multirow{2}{*}{ Criteria } & \multicolumn{4}{|c|}{ 3rd Round } & \multicolumn{4}{|c|}{ Percentage } \\
\hline & & B & 0 & $\mathbf{C}$ & $\mathbf{R}$ & B & 0 & C & $\mathbf{R}$ \\
\hline 1 & Access Methods to Mailboxes & 6 & & & & $100 \%$ & & & \\
\hline 2 & Administrative/Operation Interface & 6 & & & & $100 \%$ & & & \\
\hline 3 & After Launch Support & 6 & & & & $100 \%$ & & & \\
\hline 4 & $\begin{array}{l}\text { Alarm/Performance Monitoring and } \\
\text { Reporting }\end{array}$ & & 2 & & 4 & & $33 \%$ & & $67 \%$ \\
\hline 5 & Capital Expenditure (CAPEX) & & & 6 & & & & $100 \%$ & \\
\hline 6 & $\begin{array}{l}\text { CDR Generation and } \\
\text { Documentation }\end{array}$ & 4 & 2 & & & $67 \%$ & $33 \%$ & & \\
\hline 7 & Company Profile & & & 1 & 5 & & & $17 \%$ & $83 \%$ \\
\hline 8 & Delivery and Notification Options & 5 & 1 & & & $83 \%$ & $17 \%$ & & \\
\hline 9 & Different Calendars Support & 6 & & & & $100 \%$ & & & \\
\hline 10 & $\begin{array}{l}\text { Enforcing End Users to Accept } \\
\text { Terms and Conditions }\end{array}$ & 4 & 2 & & & $67 \%$ & $33 \%$ & & \\
\hline 11 & Evidences of Previous Experiences & & & & 6 & & & & $100 \%$ \\
\hline 12 & Feel and Look & 6 & & & & $100 \%$ & & & \\
\hline 13 & $\begin{array}{l}\text { Flexibility and Agileness in } \\
\text { Customization }\end{array}$ & 2 & 4 & & & $33 \%$ & $67 \%$ & & \\
\hline 14 & General Notice & 5 & 1 & & & $83 \%$ & $17 \%$ & & \\
\hline 15 & Greeting Messages & 6 & & & & $100 \%$ & & & \\
\hline 16 & Implementation Support (on-site) & 6 & & & & $100 \%$ & & & \\
\hline 17 & $\begin{array}{l}\text { Implementation Time/ Minimum } \\
\text { Time to Market }\end{array}$ & 6 & & & & $100 \%$ & & & \\
\hline 18 & Integration Capabilities & 4 & 2 & & & $67 \%$ & $33 \%$ & & \\
\hline 19 & IVR Access to System & 5 & 1 & & & $83 \%$ & $17 \%$ & & \\
\hline 20 & Licensing & 6 & & & & $100 \%$ & & & \\
\hline 21 & $\begin{array}{l}\text { Managing Privacy Courtesy } \\
\text { Information }\end{array}$ & 1 & & & 5 & $17 \%$ & & & $83 \%$ \\
\hline 22 & Multi Language Support & 2 & 4 & & & $33 \%$ & $67 \%$ & & \\
\hline 23 & Notifications & 6 & & & & $100 \%$ & & & \\
\hline 24 & Number Blocking & 4 & 2 & & & $67 \%$ & $33 \%$ & & \\
\hline 25 & On-site Developments & 2 & 4 & & & $33 \%$ & $67 \%$ & & \\
\hline 26 & Operation Expenditure (OPEX) & & & 6 & & & & $100 \%$ & \\
\hline 27 & Postpaid Charging & 6 & & & & $100 \%$ & & & \\
\hline 28 & Prepaid Charging & 6 & & & & $100 \%$ & & & \\
\hline 29 & Project Management Capabilities & & & & 6 & & & & $100 \%$ \\
\hline 30 & Provisioning Features & 5 & 1 & & & $83 \%$ & $17 \%$ & & \\
\hline 31 & Required Hardware & & & 6 & & & & $100 \%$ & \\
\hline 32 & Required Software & & & 6 & & & & $100 \%$ & \\
\hline 33 & Sending Voice Message Features & 4 & 2 & & & $67 \%$ & $33 \%$ & & \\
\hline 34 & Sizing & 2 & 4 & & & $33 \%$ & $67 \%$ & & \\
\hline 35 & Training & 5 & 1 & & & $83 \%$ & $17 \%$ & & \\
\hline 36 & User Interface & 6 & & & & $100 \%$ & & & \\
\hline 37 & Voice Mailbox Types & 6 & & & & $100 \%$ & & & \\
\hline
\end{tabular}

The criteria were classified such that they belong to the merit that they have the maximum percentage of belonging to them after the $3^{\text {rd }}$ iteration 
Final criteria classification results.

\begin{tabular}{|c|c|c|}
\hline & Criteria & Merits \\
\hline 1 & Access Methods to Mailboxes & Benefits \\
\hline 2 & Administrative/Operation Interface & Benefits \\
\hline 3 & After Launch Support & Benefits \\
\hline 4 & $\begin{array}{l}\text { CDR Generation and } \\
\text { Documentation }\end{array}$ & Benefits \\
\hline 5 & Delivery and Notification Options & Benefits \\
\hline 6 & Different Calendars Support & Benefits \\
\hline 7 & $\begin{array}{l}\text { Enforcing End Users to Accept } \\
\text { Terms and Conditions }\end{array}$ & Benefits \\
\hline 8 & Feel and Look & Benefits \\
\hline 9 & General Notice & Benefits \\
\hline 10 & Greeting Messages & Benefits \\
\hline 11 & Implementation Support (on-site) & Benefits \\
\hline 12 & $\begin{array}{l}\text { Implementation Time/ Minimum } \\
\text { Time to Market }\end{array}$ & Benefits \\
\hline 13 & Integration Capabilities & Benefits \\
\hline 14 & IVR Access to System & Benefits \\
\hline 15 & Licensing & Benefits \\
\hline 16 & Notifications & Benefits \\
\hline 17 & Number Blocking & Benefits \\
\hline 18 & Postpaid Charging & Benefits \\
\hline 19 & Prepaid Charging & Benefits \\
\hline 20 & Provisioning Features & Benefits \\
\hline 21 & Sending Voice Message Features & Benefits \\
\hline 22 & Training & Benefits \\
\hline 23 & User Interface & Benefits \\
\hline 24 & Voice Mailbox Types & Benefits \\
\hline 25 & $\begin{array}{l}\text { Flexibility and Agileness in } \\
\text { Customization }\end{array}$ & Opportunities \\
\hline 26 & Multi Language Support & Opportunities \\
\hline 27 & On-site Developments & Opportunities \\
\hline 28 & Sizing & Opportunities \\
\hline 29 & Capital Expenditure (CAPEX) & Costs \\
\hline 30 & Operation Expenditure (OPEX) & Costs \\
\hline 31 & Required Hardware & Costs \\
\hline 32 & Required Software & Costs \\
\hline 33 & $\begin{array}{l}\text { Alarm/Performance Monitoring and } \\
\text { Reporting }\end{array}$ & RISKS \\
\hline 34 & Company Profile & RISKS \\
\hline 35 & Evidences of Previous Experiences & RISKS \\
\hline 36 & $\begin{array}{l}\text { Managing Privacy Courtesy } \\
\text { Information }\end{array}$ & RISKS \\
\hline 37 & Project Management Capabilities & RISKS \\
\hline
\end{tabular}

The final classification of the criteria were sent to the experts for final verification. 


\section{Appendix 4: Examples of pairwise comparisons, converting to matrices}

and calculated priorities and consistency ratios.

Pair-wise Comparison of Customer Satisfaction Benefits with respect to "Company A" in Benefits Sub-network.

\begin{tabular}{|l|l|l|l|l|l|l|l|l|l|l|l|l|l|l|l|l|l|l|}
\hline $\begin{array}{l}\text { Access Methods to } \\
\text { Mailboxes }\end{array}$ & 9 & 8 & 7 & 6 & 5 & 4 & 3 & 2 & 1 & 2 & 3 & 4 & 5 & 6 & 7 & 8 & 9 & Notifications \\
\hline $\begin{array}{l}\text { Access Methods to } \\
\text { Mailboxes }\end{array}$ & 9 & 8 & 7 & 6 & 5 & 4 & 3 & 2 & 1 & 2 & 3 & 4 & 5 & 6 & 7 & 8 & 9 & $\begin{array}{l}\text { Number } \\
\text { Blocking }\end{array}$ \\
\hline $\begin{array}{l}\text { Access Methods to } \\
\text { Mailboxes }\end{array}$ & 9 & 8 & 7 & 6 & 5 & 4 & 3 & 2 & 1 & 2 & 3 & 4 & 5 & 6 & 7 & 8 & 9 & $\begin{array}{l}\text { User } \\
\text { Interface }\end{array}$ \\
\hline $\begin{array}{l}\text { Access Methods to } \\
\text { Mailboxes }\end{array}$ & 9 & 8 & 7 & 6 & 5 & 4 & 3 & 2 & 1 & 2 & 3 & 4 & 5 & 6 & 7 & 8 & 9 & $\begin{array}{l}\text { General } \\
\text { Notice }\end{array}$ \\
\hline Notifications & 9 & 8 & 7 & 6 & 5 & 4 & 3 & 2 & 1 & 2 & 3 & 4 & 5 & 6 & 7 & 8 & 9 & $\begin{array}{l}\text { Number } \\
\text { Blocking }\end{array}$ \\
\hline Notifications & 9 & 8 & 7 & 6 & 5 & 4 & 3 & 2 & 1 & 2 & 3 & 4 & 5 & 6 & 7 & 8 & 9 & $\begin{array}{l}\text { User } \\
\text { Interface }\end{array}$ \\
\hline Notifications & 9 & 8 & 7 & 6 & 5 & 4 & 3 & 2 & 1 & 2 & 3 & 4 & 5 & 6 & 7 & 8 & 9 & $\begin{array}{l}\text { General } \\
\text { Notice }\end{array}$ \\
\hline Number Blocking & 9 & 8 & 7 & 6 & 5 & 4 & 3 & 2 & 1 & 2 & 3 & 4 & 5 & 6 & 7 & 8 & 9 & $\begin{array}{l}\text { User } \\
\text { Interface }\end{array}$ \\
\hline Number Blocking & 9 & 8 & 7 & 6 & 5 & 4 & 3 & 2 & 1 & 2 & 3 & 4 & 5 & 6 & 7 & 8 & 9 & $\begin{array}{l}\text { General } \\
\text { Notice }\end{array}$ \\
\hline User Interface & 9 & 8 & 7 & 6 & 5 & 4 & 3 & 2 & 1 & 2 & 3 & 4 & 5 & 6 & 7 & 8 & 9 & $\begin{array}{l}\text { General } \\
\text { Notice }\end{array}$ \\
\hline
\end{tabular}

Comparison Matrix for Customer Satisfaction Benefits with respect to "Company A" in Benefits Sub-network.

\begin{tabular}{|l|r|r|r|r|c|}
\hline & $\begin{array}{l}\text { Access } \\
\text { methods to } \\
\text { Mailboxes }\end{array}$ & Notifications & $\begin{array}{l}\text { Number } \\
\text { Blocking }\end{array}$ & $\begin{array}{l}\text { User } \\
\text { Interface }\end{array}$ & $\begin{array}{l}\text { General } \\
\text { Notice }\end{array}$ \\
\hline Access methods to Mailboxes & 1.0000 & 1.0000 & 1.0000 & 5.0000 & 0.5000 \\
\hline Notifications & 1.0000 & 1.0000 & 0.5000 & 6.0000 & 1.0000 \\
\hline Number Blocking & 1.0000 & 2.0000 & 1.0000 & 5.0000 & 0.5000 \\
\hline User Interface & 0.2000 & 0.1667 & 0.2000 & 1.0000 & 0.1667 \\
\hline General Notice & 2.0000 & 1.0000 & 2.0000 & 6.0000 & 1.0000 \\
\hline
\end{tabular}

Local Priority of the Customer Satisfaction Benefits with respect to "Company A" in Benefits Sub-network and the correspondent inconsistency ratio.

\begin{tabular}{|l|l|}
\hline Access Methods to Mailboxes & 0.1949 \\
\hline Notifications & 0.2108 \\
\hline Number Blocking & 0.2357 \\
\hline User Interface & 0.0417 \\
\hline General Notice & 0.3168 \\
\hline
\end{tabular}

\begin{tabular}{|c|}
\hline Inconsistency \\
\hline 0.0387 \\
\hline
\end{tabular}


Pair-wise Comparison of Alternatives with respect to "User Interface" in Benefits Sub-network.

\begin{tabular}{|l|l|l|l|l|l|l|l|l|l|l|l|l|l|l|l|l|l|l|}
\hline Company A & 9 & 8 & 7 & 6 & 5 & 4 & 3 & 2 & 1 & 2 & 3 & 4 & 5 & 6 & 7 & 8 & 9 & Company B \\
\hline Company A & 9 & 8 & 7 & 6 & 5 & 4 & 3 & 2 & 1 & 2 & 3 & 4 & 5 & 6 & 7 & 8 & 9 & Company C \\
\hline Company A & 9 & 8 & 7 & 6 & 5 & 4 & 3 & 2 & 1 & 2 & 3 & 4 & 5 & 6 & 7 & 8 & 9 & Company D \\
\hline Company B & 9 & 8 & 7 & 6 & 5 & 4 & 3 & 2 & 1 & 2 & 3 & 4 & 5 & 6 & 7 & 8 & 9 & Company C \\
\hline Company B & 9 & 8 & 7 & 6 & 5 & 4 & 3 & 2 & 1 & 2 & 3 & 4 & 5 & 6 & 7 & 8 & 9 & Company D \\
\hline Company C & 9 & 8 & 7 & 6 & 5 & 4 & 3 & 2 & 1 & 2 & 3 & 4 & 5 & 6 & 7 & 8 & 9 & Company D \\
\hline
\end{tabular}

Comparison Matrix for Alternatives with respect to "User Interface" in Benefits Sub-network.

\begin{tabular}{|l|r|r|r|r|}
\hline & Company A & Company B & Company C & Company D \\
\hline Company A & 1 & 0.5 & 0.5 & 0.5 \\
\hline Company B & 2 & 1 & 1 & 2 \\
\hline Company C & 2 & 1 & 1 & 2 \\
\hline Company D & 2 & 0.5 & 0.5 & 1 \\
\hline
\end{tabular}

Local Priority of the Alternatives with respect to "User Interface" in Benefits Subnetwork and the correspondent inconsistency ratio.

\begin{tabular}{|l|l|}
\hline Company A & 0.1404 \\
\hline Company B & 0.3300 \\
\hline Company C & 0.3300 \\
\hline Company D & 0.1996 \\
\hline
\end{tabular}




\section{Appendix 5: Eigenvectors calculation in MATLAB examples.}

Eigenvector calculation for the comparison matrix of Customer Satisfaction Benefits with respect to "Company A" in Benefits Sub-network in MATLAB.

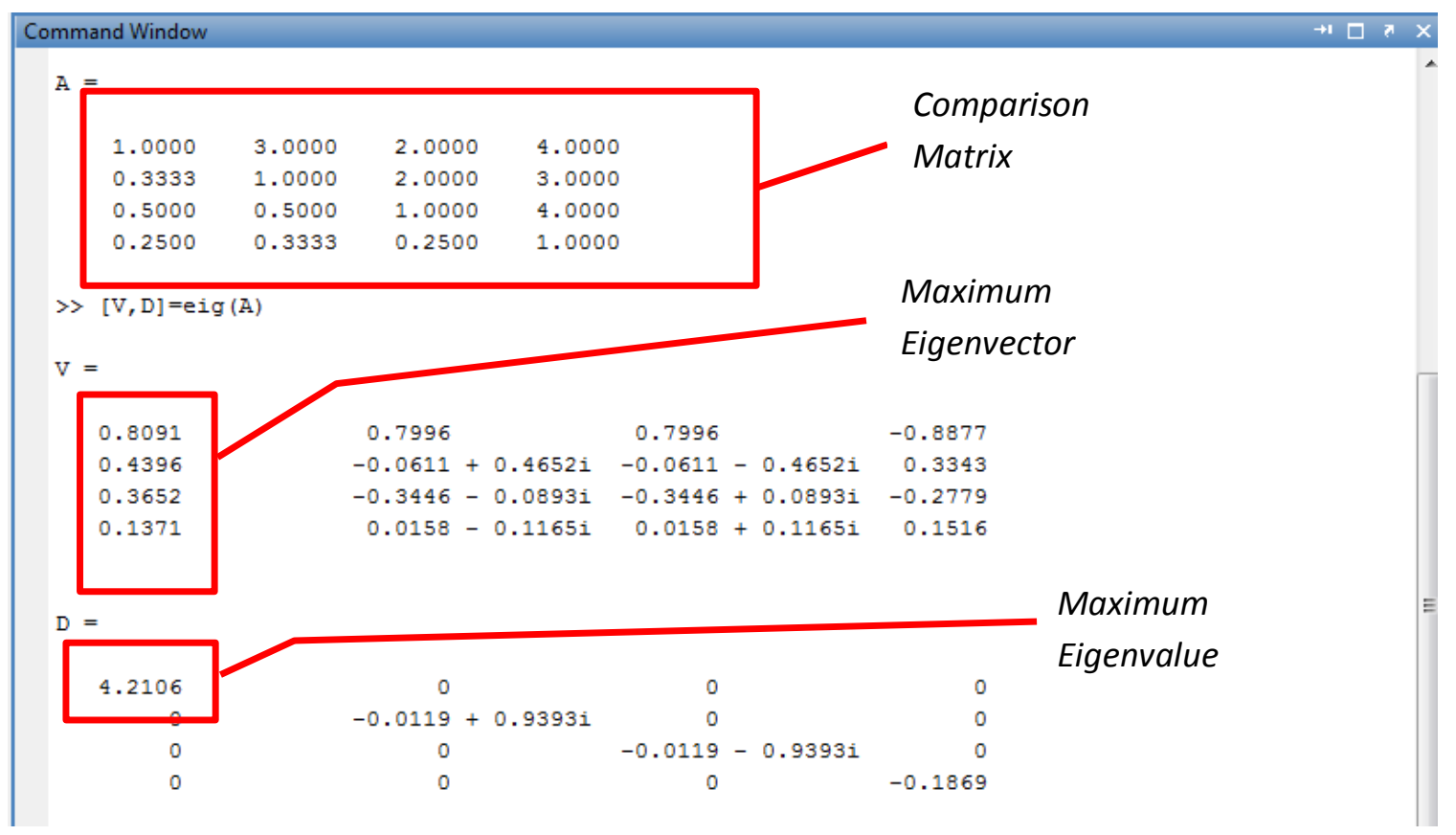


Eigenvector calculation for the comparison matrix of Customer Satisfaction Benefits with respect to "Company A" in Benefits Sub-network in MATLAB (cont.).

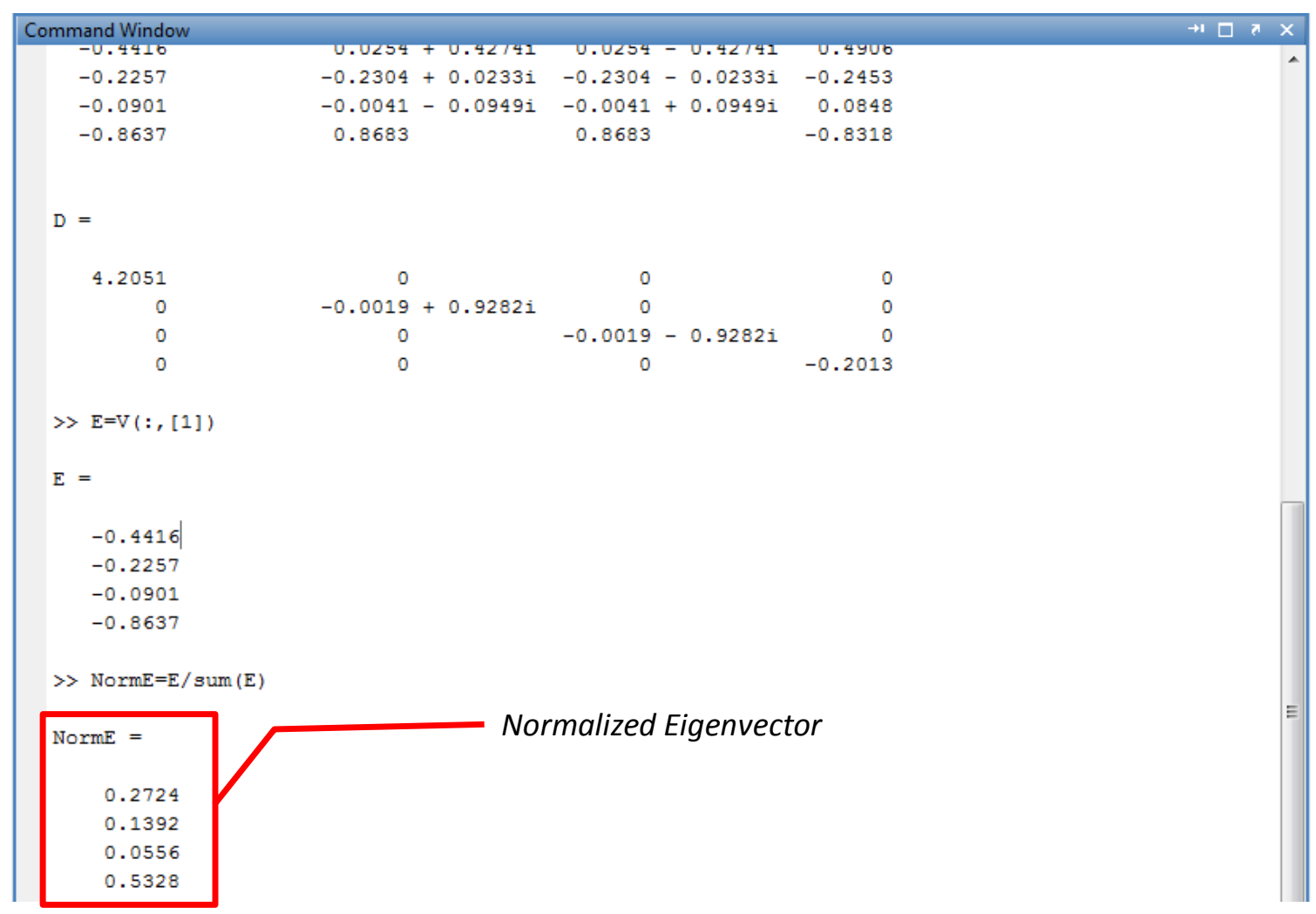




\section{Appendix 6: Inconsistent comparison and the revision of it.}

The inconsistent Pair-wise Comparison of technical benefits sub-network with respect to Company $A$ that was sent to the raters to evaluate it again.

\begin{tabular}{|l|l|l|l|l|l|l|l|l|l|l|l|l|l|l|l|l|l|l|}
\hline $\begin{array}{l}\text { Implementation Support } \\
\text { (on-site) }\end{array}$ & 9 & 8 & 7 & 6 & 5 & 4 & 3 & 2 & 1 & 2 & 3 & 4 & 5 & 6 & 7 & 8 & 9 & $\begin{array}{l}\text { After Launch } \\
\text { Support }\end{array}$ \\
\hline $\begin{array}{l}\text { Implementation Support } \\
\text { (on-site) }\end{array}$ & 9 & 8 & 7 & 6 & 5 & 4 & 3 & 2 & 1 & 2 & 3 & 4 & 5 & 6 & 7 & 8 & 9 & $\begin{array}{l}\text { Integration } \\
\text { Capabilities }\end{array}$ \\
\hline $\begin{array}{l}\text { Implementation Support } \\
\text { (on-site) }\end{array}$ & 9 & 8 & 7 & 6 & 5 & 4 & 3 & 2 & 1 & 2 & 3 & 4 & 5 & 6 & 7 & 8 & 9 & $\begin{array}{l}\text { Provisioning } \\
\text { Features }\end{array}$ \\
\hline $\begin{array}{l}\text { Implementation Support } \\
\text { (on-site) }\end{array}$ & 9 & 8 & 7 & 6 & 5 & 4 & 3 & 2 & 1 & 2 & 3 & 4 & 5 & 6 & 7 & 8 & 9 & Training \\
\hline After Launch Support & 9 & 8 & 7 & 6 & 5 & 4 & 3 & 2 & 1 & 2 & 3 & 4 & 5 & 6 & 7 & 8 & 9 & $\begin{array}{l}\text { Integration } \\
\text { Capabilities }\end{array}$ \\
\hline After Launch Support & 9 & 8 & 7 & 6 & 5 & 4 & 3 & 2 & 1 & 2 & 3 & 4 & 5 & 6 & 7 & 8 & 9 & $\begin{array}{l}\text { Provisioning } \\
\text { Features }\end{array}$ \\
\hline After Launch Support & 9 & 8 & 7 & 6 & 5 & 4 & 3 & 2 & 1 & 2 & 3 & 4 & 5 & 6 & 7 & 8 & 9 & Training \\
\hline Integration Capabilities & 9 & 8 & 7 & 6 & 5 & 4 & 3 & 2 & 1 & 2 & 3 & 4 & 5 & 6 & 7 & 8 & 9 & Features \\
\hline Integration Capabilities & 9 & 8 & 7 & 6 & 5 & 4 & 3 & 2 & 1 & 2 & 3 & 4 & 5 & 6 & 7 & 8 & 9 & Training \\
\hline Provisioning Features & 9 & 8 & 7 & 6 & 5 & 4 & 3 & 2 & 1 & 2 & 3 & 4 & 5 & 6 & 7 & 8 & 9 & Training \\
\hline
\end{tabular}

Local Priority of the technical benefits sub-network with respect to Company $A$ and the correspondent inconsistency ratio.

\begin{tabular}{|l|l|}
\hline $\begin{array}{l}\text { Implementation } \\
\text { Support (on-site) }\end{array}$ & 0.2263 \\
\hline $\begin{array}{l}\text { After Launch } \\
\text { Support }\end{array}$ & 0.0665 \\
\hline $\begin{array}{l}\text { Integration } \\
\text { Capabilities }\end{array}$ & 0.2423 \\
\hline $\begin{array}{l}\text { Provisioning } \\
\text { Features }\end{array}$ & 0.2423 \\
\hline Training & 0.2423 \\
\hline
\end{tabular}

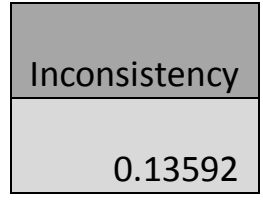


The consistent Pair-wise Comparison of technical benefits sub-network with respect to Company $A$ that were revised.

\begin{tabular}{|c|c|c|c|c|c|c|c|c|c|c|c|c|c|c|c|c|c|c|}
\hline $\begin{array}{l}\text { Implementation } \\
\text { Support (on-site) }\end{array}$ & 9 & 8 & 7 & 6 & 5 & 4 & 3 & 2 & 1 & 2 & 3 & 4 & 5 & 6 & 7 & 8 & 9 & $\begin{array}{l}\text { After Launch } \\
\text { Support }\end{array}$ \\
\hline $\begin{array}{l}\text { Implementation } \\
\text { Support (on-site) }\end{array}$ & 9 & 8 & 7 & 6 & 5 & 4 & 3 & 2 & 1 & 2 & 3 & 4 & 5 & 6 & 7 & 8 & 9 & $\begin{array}{l}\text { Integration } \\
\text { Capabilities }\end{array}$ \\
\hline $\begin{array}{l}\text { Implementation } \\
\text { Support (on-site) }\end{array}$ & 9 & 8 & 7 & 6 & 5 & 4 & 3 & 2 & 1 & 2 & 3 & 4 & 5 & 6 & 7 & 8 & 9 & $\begin{array}{l}\text { Provisioning } \\
\text { Features }\end{array}$ \\
\hline $\begin{array}{l}\text { Implementation } \\
\text { Support (on-site) }\end{array}$ & 9 & 8 & 7 & 6 & 5 & 4 & 3 & 2 & 1 & 2 & 3 & 4 & 5 & 6 & 7 & 8 & 9 & Training \\
\hline $\begin{array}{l}\text { After Launch } \\
\text { Support }\end{array}$ & 9 & 8 & 7 & 6 & 5 & 4 & 3 & 2 & 1 & 2 & 3 & 4 & 5 & 6 & 7 & 8 & 9 & $\begin{array}{l}\text { Integration } \\
\text { Capabilities }\end{array}$ \\
\hline $\begin{array}{l}\text { After Launch } \\
\text { Support }\end{array}$ & 9 & 8 & 7 & 6 & 5 & 4 & 3 & 2 & 1 & 2 & 3 & 4 & 5 & 6 & 7 & 8 & 9 & $\begin{array}{l}\text { Provisioning } \\
\text { Features }\end{array}$ \\
\hline $\begin{array}{l}\text { After Launch } \\
\text { Support }\end{array}$ & 9 & 8 & 7 & 6 & 5 & 4 & 3 & 2 & 1 & 2 & 3 & 4 & 5 & 6 & 7 & 8 & 9 & Training \\
\hline $\begin{array}{l}\text { Integration } \\
\text { Capabilities }\end{array}$ & 9 & 8 & 7 & 6 & 5 & 4 & 3 & 2 & 1 & 2 & 3 & 4 & 5 & 6 & 7 & 8 & 9 & $\begin{array}{l}\text { Provisioning } \\
\text { Features }\end{array}$ \\
\hline $\begin{array}{l}\text { Integration } \\
\text { Capabilities }\end{array}$ & 9 & 8 & 7 & 6 & 5 & 4 & 3 & 2 & 1 & 2 & 3 & 4 & 5 & 6 & 7 & 8 & 9 & Training \\
\hline $\begin{array}{l}\text { Provisioning } \\
\text { Features }\end{array}$ & 9 & 8 & 7 & 6 & 5 & 4 & 3 & 2 & 1 & 2 & 3 & 4 & 5 & 6 & 7 & 8 & 9 & Training \\
\hline
\end{tabular}

Local Priority of the technical benefits sub-network with respect to Company $A$ and the correspondent inconsistency ratio after the revision.

\begin{tabular}{|l|l|}
\hline $\begin{array}{l}\text { Implementation } \\
\text { Support (on-site) }\end{array}$ & 0.1565 \\
\hline $\begin{array}{l}\text { After Launch } \\
\text { Support }\end{array}$ & 0.0615 \\
\hline $\begin{array}{l}\text { Integration } \\
\text { Capabilities }\end{array}$ & 0.2628 \\
\hline $\begin{array}{l}\text { Provisioning } \\
\text { Features }\end{array}$ & 0.2628 \\
\hline Training & 0.2563 \\
\hline
\end{tabular}

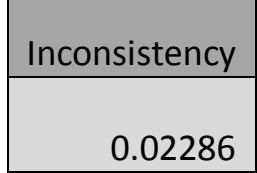

